University of Tennessee Health Science Center UTHSC Digital Commons

\title{
Time-Related Centile Ranges for Quality of Life Outcomes in Renal Transplantation
}

\author{
Katy Garth \\ University of Tennessee Health Science Center
}

Follow this and additional works at: https://dc.uthsc.edu/dissertations

Part of the Diseases Commons, and the Nursing Commons

\section{Recommended Citation}

Garth, Katy , "Time-Related Centile Ranges for Quality of Life Outcomes in Renal Transplantation" (2008). Theses and Dissertations (ETD). Paper 90. http://dx.doi.org/10.21007/etd.cghs.2008.0107. 


\title{
Time-Related Centile Ranges for Quality of Life Outcomes in Renal Transplantation
}

\author{
Abstract \\ The purpose of this study was to create time-related centile ranges that could be \\ used as benchmarks for evaluating and monitoring quality of life (QoL) following kidney transplantation. \\ QoL is commonly viewed as an important indicator of successful outcomes in chronic disease including \\ kidney transplantation. Despite extensive research documenting the value of QoL, routine measurement \\ of QoL outcomes in clinical practice as a means of patient evaluation to augment clinical care has not \\ been widely accepted. Lack of benchmarks for interpreting QoL scores may contribute to the reluctance \\ to incorporate QoL measures into clinical care. The research question and study aim were: Do QoL \\ outcomes differ for patients by gender and race at four separate time intervals following renal \\ transplantation? Based on this analysis which demographic groups or combination of groups would be \\ required to accurately represent $\mathrm{Q}$ LL outcomes through time-related centile ranges? \\ A convenience sample was drawn from the surveys housed by the national Patient \\ Outcomes Registry for Transplant Effects on Life (PORTEL). To be included in the \\ study, surveys must have been completed by Caucasian or African American recipients of one kidney \\ transplantation who were between 18 and 65 years of age and who were greater than 14 days post- \\ transplant. SF-12 and Memphis Survey scores were extracted as the QoL measures for creation of time- \\ related centile ranges. Data were analyzed using nonparametric statistical methods. Time-related centile \\ ranges were constructed depicting the 5th through the 95th percentile scores on the QoL outcome \\ measures.
}

The analysis included 943 surveys bracketed into four time groups, less than 4 months, 4 to 19 months, 19-36 months and greater that 36 months from transplantation. Kruskal-Wallis analyses demonstrated a strong degree of homogeneity among racial and gender groups with only 2 of 16 QoL outcome measures differing significantly; SF-12 PCS scores at 19-36 months and Memphis Frequency scores at less than 4 months. Variation in means across the groups was small and the centile ranges were large leading to the conclusion that negligible clinical differences exist for these QoL outcomes by racial and gender subgroups in this sample. Therefore, one time-related centile range was constructed for each QoL outcome measure for this cohort of kidney transplant recipients which will be graphically presented.

These time-related centile ranges have immediate clinical utility as a tool for educating patients regarding QoL expectations and for monitoring post transplant QoL outcomes. They can also provide a means for transplant recipients to compare their QoL to a reference range that is derived from a like population and serve as a catalyst for discussion regarding interventions to enhance QoL for kidney transplant recipients.

\section{Document Type}

Dissertation

\section{Degree Name}

Doctor of Philosophy (PhD)

\section{Program}

Nursing 


\section{Research Advisor}

Donna Hathaway, Ph.D.

\section{Keywords}

Renal transplant, Quality of life, centile ranges, benchmarks

\section{Subject Categories}

Diseases | Medicine and Health Sciences | Nursing 
TIME-RELATED CENTILE RANGES FOR QUALITY OF LIFE OUTCOMES IN RENAL TRANSPLANTATION

\author{
A Dissertation \\ Presented for \\ The Graduate Studies Council \\ The University of Tennessee \\ Health Science Center \\ In Partial Fulfillment \\ Of the Requirements for the Degree \\ Doctor of Philosophy \\ From The University of Tennessee
}

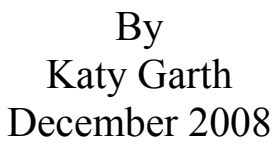


Copyright (C) 2008 by Katy Garth

All rights reserved 


\section{ACKNOWLEDGEMENTS}

I would like to acknowledge the help and support provided by a number of individuals and groups in the completion of this dissertation. First I would like to thank my committee for sharing their expertise and for their encouragement. I would like to acknowledge the contributions of Quorum Consulting in providing the data used in this study, in particular Kuo Tong, Founder and CEO and Andrew Layton, Director, Healthcare Data and Applications for assistance with study design and data management. I want to thank Leslie Evans for her contributing her expertise in graphic arts that led to the design of the time-related centile ranges developed in this dissertation. Finally, I want to thank my family for their ongoing support in all of my academic efforts. 


\begin{abstract}
The purpose of this study was to create time-related centile ranges that could be used as benchmarks for evaluating and monitoring quality of life (QoL) following kidney transplantation. QoL is commonly viewed as an important indicator of successful outcomes in chronic disease including kidney transplantation. Despite extensive research documenting the value of QoL, routine measurement of QoL outcomes in clinical practice as a means of patient evaluation to augment clinical care has not been widely accepted. Lack of benchmarks for interpreting QoL scores may contribute to the reluctance to incorporate QoL measures into clinical care. The research question and study aim were: Do QoL outcomes differ for patients by gender and race at four separate time intervals following renal transplantation? Based on this analysis which demographic groups or combination of groups would be required to accurately represent QoL outcomes through time-related centile ranges?
\end{abstract}

A convenience sample was drawn from the surveys housed by the national Patient Outcomes Registry for Transplant Effects on Life (PORTEL). To be included in the study, surveys must have been completed by Caucasian or African American recipients of one kidney transplantation who were between 18 and 65 years of age and who were greater than 14 days post-transplant. SF-12 and Memphis Survey scores were extracted as the QoL measures for creation of time-related centile ranges. Data were analyzed using nonparametric statistical methods. Time-related centile ranges were constructed depicting the $5^{\text {th }}$ through the $95^{\text {th }}$ percentile scores on the QoL outcome measures.

The analysis included 943 surveys bracketed into four time groups, less than 4 months, 4 to 19 months, 19-36 months and greater that 36 months from transplantation. Kruskal-Wallis analyses demonstrated a strong degree of homogeneity among racial and gender groups with only 2 of 16 QoL outcome measures differing significantly; SF-12 PCS scores at 19-36 months and Memphis Frequency scores at less than 4 months. Variation in means across the groups was small and the centile ranges were large leading to the conclusion that negligible clinical differences exist for these QoL outcomes by racial and gender subgroups in this sample. Therefore, one time-related centile range was constructed for each QoL outcome measure for this cohort of kidney transplant recipients which will be graphically presented.

These time-related centile ranges have immediate clinical utility as a tool for educating patients regarding QoL expectations and for monitoring post transplant QoL outcomes. They can also provide a means for transplant recipients to compare their QoL to a reference range that is derived from a like population and serve as a catalyst for discussion regarding interventions to enhance QoL for kidney transplant recipients. 


\section{TABLE OF CONTENTS}

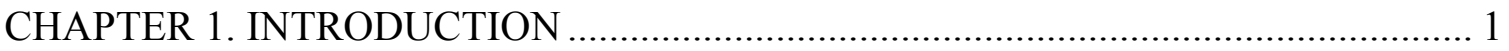

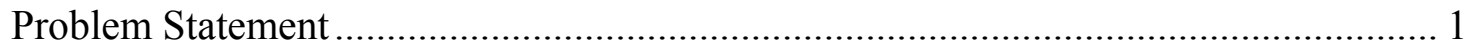

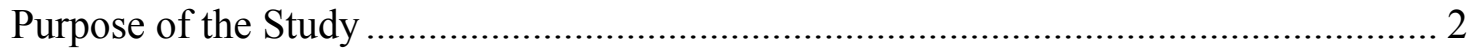

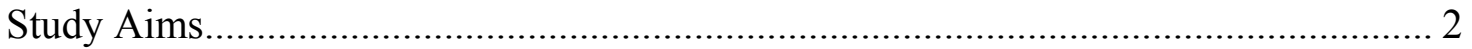

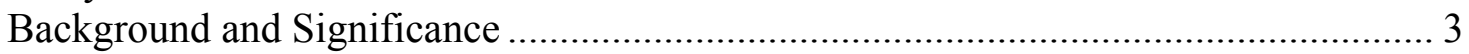

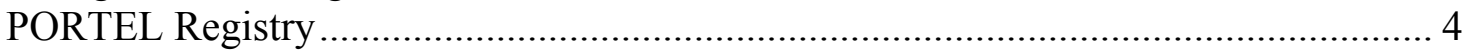

The PORTEL Registry Four-Cornered Framework …….............................................. 4

Time-Related Centile Ranges …………………............................................... 5

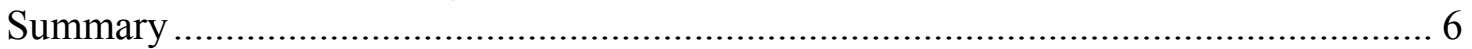

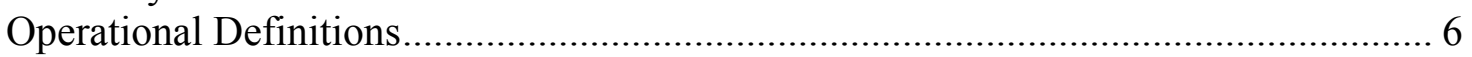

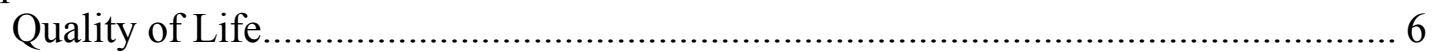

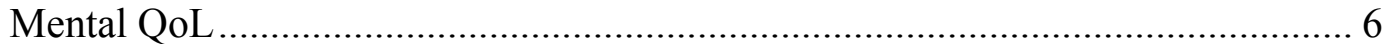

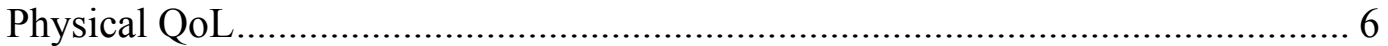

Immunosuppressant Side Effects........................................................................ 8

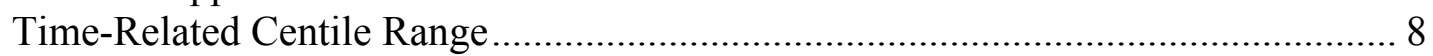

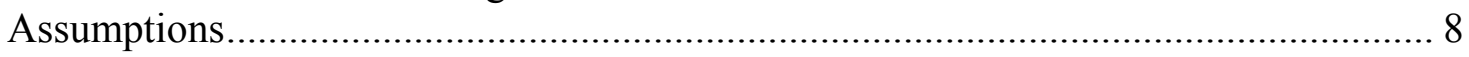

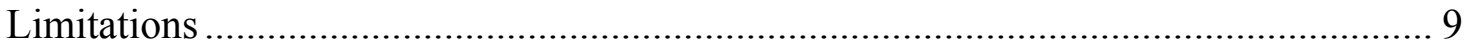

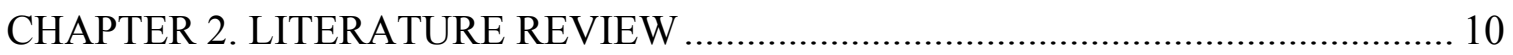

The Changing Face of Chronic Illness........................................................................ 10

Quality of Life: The Key Outcome in Chronic Disease ................................................ 11

Trajectories in Chronic Illness and Kidney Transplantation ........................................ 12

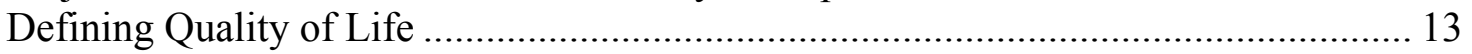

Quality of Life in Kidney Transplantation.................................................................. 14

Predictors of Quality of Life in Kidney Transplantation ............................................. 14

Quality of Life Measurement as a Tool in the Clinical Setting .................................... 15

Centile Ranges to Interpret Quality of Life .............................................................. 17

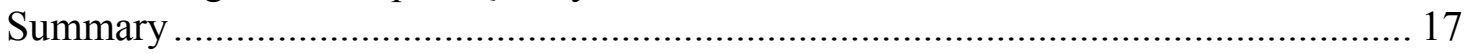

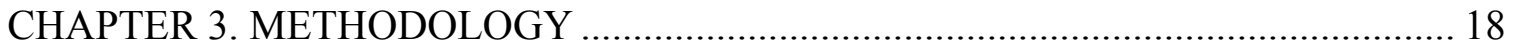

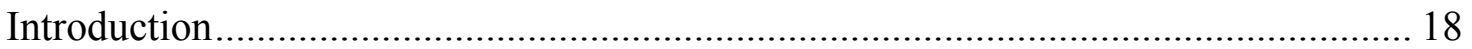

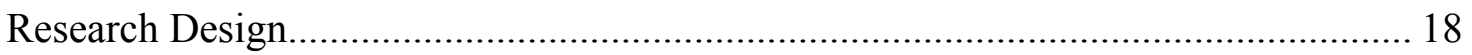

Research Question and Study Aim ........................................................................ 18

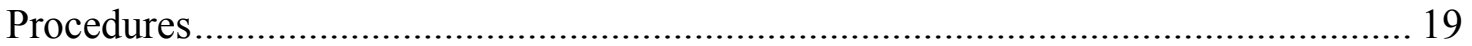

Quality of Life Instruments Included in the PORTEL Registry Survey....................... 20

12-Item Short-Form Health Survey ................................................................... 20

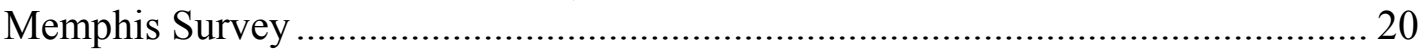

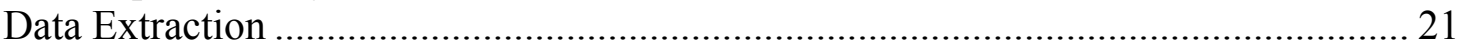

Sample

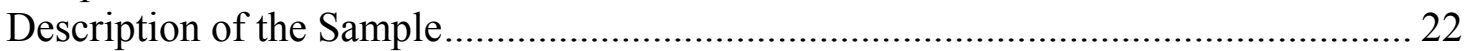




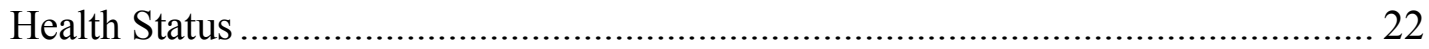

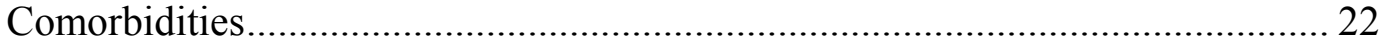

Rejection, Infection, Hospital Admissions, and Hospital Days............................ 24

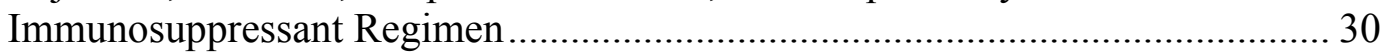

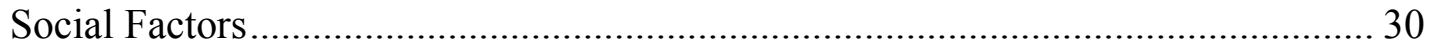

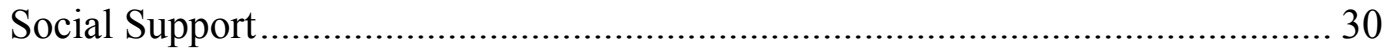

Health Care Coverage ....................................................................................... 30

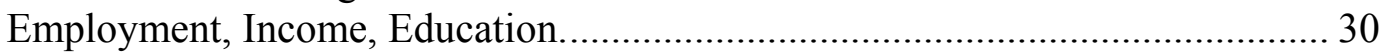

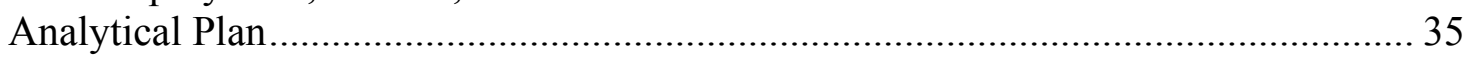

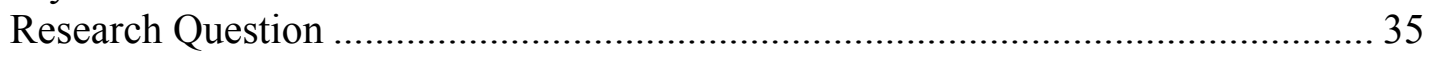

Study Aim: Construction of Centile Ranges............................................................ 35

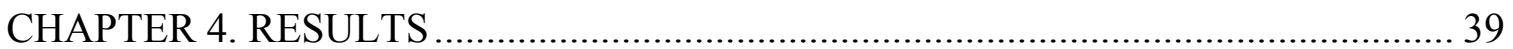

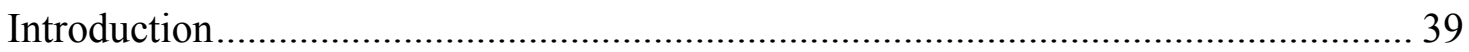

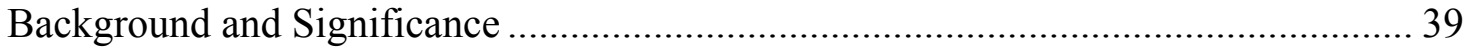

Time-Related Centile Ranges .......................................................................... 40

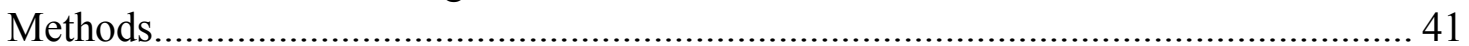

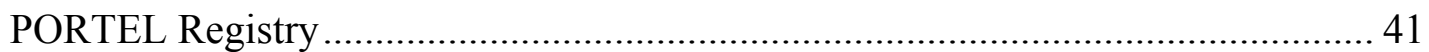

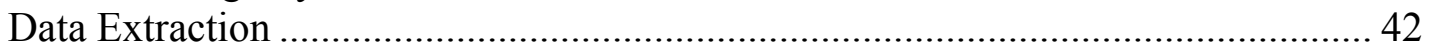

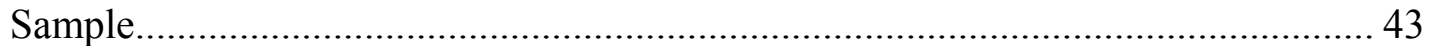

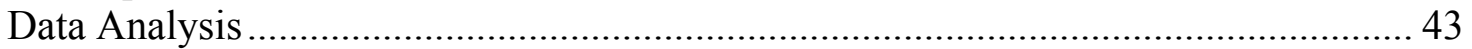

Differences in SF-12 Scores by Racial and Gender Groups.................................... 43

Differences in Memphis Survey Scores by Racial and Gender Groups ................... 45

Construction of Time-Related Centile Ranges ………................................................ 45

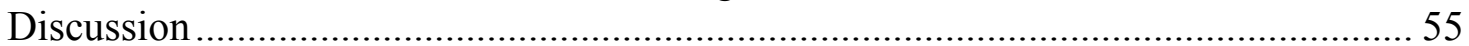

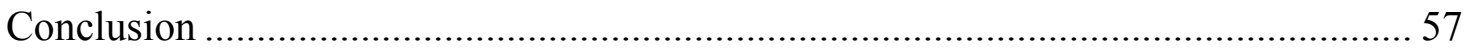

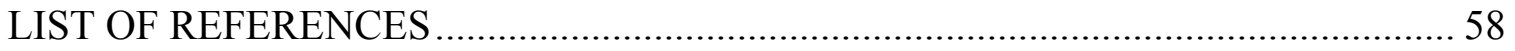

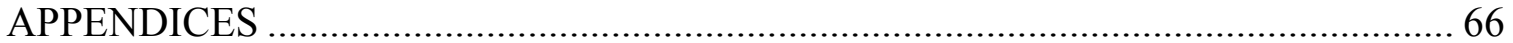

Appendix A: Descriptive Statistics for Quality of Life Outcome Measures by

Racial and Gender Groups for Time Intervals Following Transplantation ................... 67

Appendix B: Memphis Survey Subscales.................................................................... 76

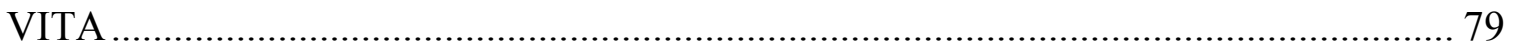




\section{LIST OF TABLES}

Table 3.1. Comparison of Sample Demographic Distribution with

UNOS Data.................................................... 23

Table 3.2. Comorbidity by Time Bracket Since Transplantation...................25

Table 3.3. Frequency of Rejection Episodes by Time Since Transplantation.......26

Table 3.4. Number of Reported Infections by Time Since Transplantation.........27

Table 3.5. Frequency of Hospital Admissions by Time Since Transplantation...... 28

Table 3.6. Number of Hospital Days by Time Since Transplantation................29

Table 3.7. Immunosuppressant Agent by Time Since Transplantation............... 31

Table 3.8. Living Situation by Time Bracket Since Transplantation................32

Table 3.9. Available Assistance by Time Since Transplantation.................... 33

Table 3.10. Health Care Coverage by Time Since Transplantation...................34

Table 3.11. Employment Status by Time Since Transplantation....................36

Table 3.12. Annual Income by Time Since Transplantation........................ 37

Table 3.13. Education by Time Since Transplantation.............................38

Table 4.1. Kruskal-Wallis Ranks and Test Statistics for Differences in MCS Scores between Demographic Groups at $<4$ Months, 4-18 Months, 19-36 Months and $>36$ Months Post-Transplantation.

Table 4.2. Kruskal-Wallis Ranks and Test Statistics for Differences in PCS Scores between Demographic Groups at $<4$ Months, 4-18 Months, 19-36 Months and $>36$ Months Post-Transplantation.

Table 4.3. Kruskal-Wallis Ranks and Test Statistics for Differences in Memphis Survey Frequency Scores between Demographic Groups at $<4$ Months, 4-18 Months, 19-36 Months and >36 Months Post-Transplantation.

Table 4.4. Kruskal-Wallis Ranks and Test Statistics for Differences in Memphis Survey Severity Scores between Demographic Groups at $<4$ Months, 4-18 Months, 19-36 Months and >36 Months Post-Transplantation......50 
Table A.1. Descriptive Statistics for the MCS Scores by Racial and Gender Groups for Time Intervals Following Transplantation...................68

Table A.2. Descriptive Statistics for the PCS Scores by Racial and Gender Groups for Time Intervals Following Transplantation...................70

Table A.3. Descriptive Statistics for the Memphis Survey Frequency Scores by Racial and Gender Groups for Time Intervals Following Transplantation................................................. 72

Table A.4. Descriptive Statistics for the Memphis Survey Severity Scores by Racial and Gender Groups for Time Intervals Following Transplantation

Table B.1. Descriptive Statistics for the Memphis Survey Frequency Subscale Scores.......................................................... 77

Table B.2. Descriptive Statistics for the Memphis Survey Severity Subscale

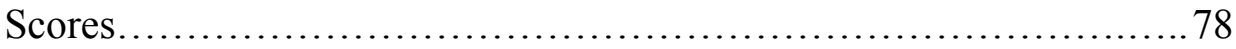




\section{LIST OF FIGURES}

Figure 1.1. Conceptual Model of QoL Domains as Defined by the PORTEL Framework with the Integration of QoL Outcome Measurement and Time-Related Centile Ranges.

Figure 4.1. Mean MCS Scores for Demographic Groups by Time Since

Transplantation.

Figure 4.2. Mean PCS Scores for Demographic Groups by Time Since

Transplantation

Figure 4.3. Mean Memphis Survey Frequency Scores for Demographic

Groups by Time Since Transplantation.

Figure 4.4. Mean Memphis Survey Severity Scores for Demographic

Groups by Time Since Transplantation.

Figure 4.5. Time-Related Centile Range for Kidney Transplantation

Recipients: SF-12 Health Survey.

Figure 4.6. Time-Related Centile Range for Kidney Transplantation Recipients:

Memphis Survey .................................................. 54

Figure A.1. $50^{\text {th }}$ Percentile, MCS Scores for Demographic Groups by

Time Since Transplantation.

Figure A.2. $50^{\text {th }}$ Percentile, PCS Scores for Demographic Groups by Time

Since Transplantation.

Figure A.3. $\quad 50^{\text {th }}$ Percentile, Memphis Survey Frequency Scores for

Demographic Groups by Time Since Transplantation.

Figure A.4. $50^{\text {th }}$ Percentile, Memphis Survey Severity Scores for

Demographic Groups by Time Since Transplantation .75 


\section{CHAPTER 1. INTRODUCTION}

Extraordinary advancements in science achieved in the $20^{\text {th }}$ century have changed the view of and expectations for health, disease, and treatment of disease. New treatments and technology allow individuals to survive for many years with conditions that previously would have been fatal such as end-stage renal disease (ESRD). Renal replacement therapy (RRT), peritoneal dialysis or hemodialysis; and transplantation have led to long term survival for individuals with ESRD. Kidney transplantation has not only prolonged life, but in addition it has been shown to improve quality of life (QoL) for many individuals as well (Dew et al., 1997; Ogutmen et al., 2006; Overbeck et al., 2005). However, while transplantation and the immunosuppressant therapy that is required to prevent rejection make survival possible with a better QoL, patients continue to have health related issues following transplantation. Ongoing treatments, including intensive medication regimens, often lead to compromises in health or functional ability that can impact QoL (Winsett et al., 2004). With improved patient and graft survival, attention to, and evaluation of, QoL in transplant recipients is an important part of ongoing care, as well as the assessment of graft and patient survival.

\section{Problem Statement}

As individuals contemplate whether they should undergo a treatment such as organ transplantation in order to improve their health care outcomes, they seek information regarding the typical recovery pattern displayed by individuals who are like them. Health care providers also look at patterns of response in groups of patients to recommend treatment plans based on the risks and benefits of the treatments in question. The knowledge gained through examining patterns of recovery can assist the patient in determining whether their progress or their health status is typical for an individual in a similar situation at a particular point in time. This type of information is often a key factor in making initial treatment decisions as well as in the planning of care to facilitate recovery. QoL has become an important outcome used by patients and health care providers alike for evaluating the effectiveness of treatment regimens for chronic disease (Carr, Gibson, \& Robinson, 2001; Sullivan, 2003). Understanding QoL outcomes may be particularly important for the individual contemplating kidney transplantation since in many cases alternative therapy (i.e. hemodialysis or peritoneal dialysis) is available. The choice to undergo transplantation is seen as a means to improve QoL as opposed to the only treatment means available for survival. Although kidney transplantation has been shown in multiple studies to improve QoL (Cameron, Whiteside, Katz, \& Devins, 2000; Dew et al., 1997), individuals who have undergone kidney transplantation want to know how their post-transplantation quality of life compares to others at the same point in their recovery; yet this information is not available. 


\section{Purpose of the Study}

The overwhelming number of articles published each year that focus on QoL is testimony to the growing interest in the QoL associated with the treatment of chronic disease. In spite of the tremendous interest in QoL in the field of kidney transplantation and the numerous reports documenting improvement in QoL following transplantation, construction of a trajectory that maps the typical progression in QoL after transplantation has not been reported. Therefore, the purpose of this study will be to construct timerelated centile ranges that depict the progressive changes in QoL that occur following kidney transplantation.

\section{Study Aims}

This descriptive study established time-related centile reference ranges to report QoL outcomes in such a way that clinicians and patients can evaluate the QoL of individuals and compare it with others who have similar demographic characteristics. The time-related centile ranges were constructed from data collected through the Patient Outcomes Registry for Transplant Effects on Life (PORTEL), which conducted surveys of transplant recipients from 2000-2005. The QoL outcome measures drawn from the PORTEL Survey for creation of time-related centile ranges included the physical and mental component summary scores from the 12-Item Short Form Health Survey (SF-12) and the frequency and severity scores from the Memphis Survey, a measure of immunosuppressant related side effects. The study progressed in two stages guided by the research question and a study aim. Stage 1 was directed by the research question and identified how the study population should be grouped to address the study aim during stage 2 of the study which involved generation of the centile ranges. The research question (1) and study aim (2) are as follows:

1. Do QoL outcomes differ within groups of patients categorized by gender and race? If so then:

a) Do the QoL outcome measures for patients grouped by gender and race differ at four specific time intervals following transplantation?

b) Which of the variables or combination of variables (gender and race) identify cohorts of patients most appropriate for creation of timerelated centile ranges used to illustrate QoL outcomes?

2. Individual time-related centile ranges were established for scores on the SF-12 and the Memphis Survey for each patient group identified in stage 1. The QoL measures included separate scores for the:

a) SF-12:

i. Physical Component Summary (PCS)

ii. Mental Component Summary (MCS)

b) Memphis Survey scores:

i. Frequency score how often side effects occur)

ii. Severity score (level of distress caused by the side effects) 


\section{Background and Significance}

The health related literature is replete with references to QoL. Though the concept is has been defined in many ways the definitions are often ambiguous (Meeberg, 1993). According to Hathaway, et al. (2003a), QoL is "broadly accepted to be a multidimensional construct that represents an individual's perception of his or her health, happiness, and general well-being at any given period of time" (p. 1). Other authors have differentiated the general term QoL from the concept of health related QoL including the physical, psychological, and social domains of health in the definition (Pinson et al., 2000; Testa \& Simonson, 1996). QoL has also been defined in such a way that it reflects the individual's functional ability, their perception of their health and well being, and their emotional health (Cetingok, Winsett, \& Hathaway, 2004). Many factors beyond disease influence QoL including overall health and social status (Cetingok et al., 2004).

There has been a shift in the emphasis of the health care industry from focusing primarily on curing disease to focusing on controlling disease while enhancing QoL and utilizing QoL as a measure of success in the treatment of disease (Yildirim, 2006). In the past, the goal of health care as an industry was on treatment to cure disease, or palliative care when curative treatment was not an option. Advances in therapeutics have led to changes in the delivery of health care, and diseases that would have once been fatal, are now regarded as chronic conditions with patients leading long and productive lives. As a result of this transition, the goal of treatment for patients with chronic illness is increasingly aimed at controlling disease and maintaining QoL.

Side effects associated with treatment for both acute and chronic disease present challenges for health care providers as well as the patient. As opposed to palliating symptoms of disease, interventions often involve palliation of the side effects of the treatment regimen (Holley, 2007). Assessment of the QoL that a patient experiences on a day to day basis, as they live with their disease and the treatment of their disease, can guide health care providers in recognizing patient's needs and formulating a plan of care to meet those needs. The use of QoL outcome measurements in nontransplantation clinical settings have been shown to enhance communication between the patient and the health care provider about QoL issues such as social functioning or symptoms that might be otherwise left unaddressed (Detmar, Muller, Schornagel, Wever, \& Aaronson, 2002).

An individual's expectation of their QoL at a given time in life or in relation to a given illness can influence the perception of their QoL (Carr et al., 2001). It is in this context that patients who are contemplating transplantation; or who are post transplantation seek information regarding the QoL they can anticipate or how their actual QoL compares with that of other transplant recipients. Studies have examined both short- and long-term QoL post transplantation, and several instruments have been developed and validated to measure QoL. However, routine use of QoL outcome measurement in the clinical setting has not been widely implemented (Higginson \& Carr, 2001). There are no established norms for QoL post kidney transplantation that can be used for providing education or for evaluating recovery. Benchmarks that reflect the QoL of kidney transplant recipients could provide an additional tool in the clinical 
armamentarium to augment post transplantation care. These benchmarks would provide normative data for use in educating patients regarding QoL post transplantation and help reconcile their post-transplantation QoL with those reported by other transplant recipients.

This study creates time-related centile ranges from QoL data collected through the Patient Outcomes Registry for Transplant Effects on Life (PORTEL) that could be used in the clinical setting as benchmarks for evaluation of QoL outcomes of individual patients. These ranges provide clinical tools for education, evaluation, and identification of individuals at risk for poor QoL and enabling pre-emptive interventions to improve their QoL outcomes.

\section{PORTEL Registry}

The Patient Outcomes Registry for Transplant Effects on Life (PORTEL) is a national data registry that was established by Fujisawa Pharmaceuticals in 2000 to document various aspects of the QoL of solid organ transplant recipients. The goals of the PORTEL registry included the collection of longitudinal data following solid organ transplantation, documenting of the side effects of immunosuppressive therapy, and identifying predictors of QoL post transplantation with the intent of using the data to establish norms for QoL following transplantation (Hathaway, Winsett, Prendergast, \& Subaiya, 2003). The PORTEL survey instrument was based on a QoL framework composed of 5 interrelated domains that included QoL, health and social factors and, major health and major life events (Hathaway, et al., 2003b) that influence both the physical and psychosocial aspects of QoL. This framework provides direction for the examination of QoL and exploration of the concept in this population.

\section{The PORTEL Registry Four-Cornered Framework}

The QoL that an individual experiences is related to health and social factors, as well as major health and life events. "Factors" (health and social) are conceptualized to reflect those circumstances or conditions that, though they may fluctuate to some degree over time, remain relatively stable. As these factors reach an optimal state and stabilize, post transplantation QoL is enhanced. "Events" (health and life) are conceptualized to reflect more acute and transient circumstances or conditions that may negatively impact QoL. These "events" and "factors" interact with one another to moderate each of their relative influences on QoL, which in turn influences adaptation to and coping with the health and social factors and major life and major health events that are a part of the transplant recipient's life (Hathaway et al., 2003b).

Health factors include comorbidities that were present prior to transplantation, or developed subsequent to transplantation, requiring ongoing therapy; or that occured following transplantation as a result of side effects from immunosuppressant therapy (Hathaway, et al., 2003b). Social factors include situations and events that define an 
individual's social environment including the financial resources available to the individual, their health care coverage and the social support available to the transplant recipient (Hathaway et al., 2003b). Health and social factors influence QoL, as well as each other, and the health and life events that the individual encounters.

While health factors and social factors may determine an individual's day to day routine, the ability to cope with them is effected by the major health and life events that occur episodically throughout life. Major health events, according to Hathaway, et al. (2003b), may be related to a major change in the individual's health, such as a rejection episode. A major health event could also be a fracture secondary to osteoporosis related to immunosuppressant therapy or a cardiac event. Major health events could be life threatening, a threat to the function of the graft, or a threat to the individual's ability to function or live independently.

Major life events, as with major health events, are those events which also occur periodically, disrupting the established routine of the individual or the family (Hathaway, et al., 2003b). A major life event as defined in the PORTEL framework may be a divorce, death in the family, or loss of a job. Major life and health events influence the perception of QoL and health and social factors.

\section{Time-Related Centile Ranges}

Reference ranges, often referred to as normal ranges, have long been used in health care to evaluate the health status of individual patients, on some specific parameter, by comparing a variable to a standard for that variable established from a healthy population. The range of normal for a given variable is typically defined as the range of values for that variable in the population of interest that fall between the $2.5^{\text {th }}$ and the $97.5^{\text {th }}$ percentile (Griffiths, Iles, Koduah, \& Nix, 2004). A basic assumption must be that the population from which the reference range is derived is representative of "typical" individuals and therefore the values for that variable in that population are considered to be the normal range. The variables that are reported in a reference range are often affected by other characteristics of the representative population (Wright \& Royston, 1997). When this is the case, a single reference range is inadequate. Time is an example of such a covariate that can affect the outcome of interest (Cole \& Green, 1992). The age of the individual at the time of measurement or the amount of time that has elapsed since an event has occurred can have a significant influence on the mean and standard deviation of a given measurement, therefore reference intervals are commonly established with age or time as a covariate (Royston \& Wright, 1998). A common example of a reference range established to follow change in a variable over time is the series of ranges that have been established to monitor the rate of human growth. Growth charts are routinely used by health care providers to evaluate the growth of children over time. These charts are used to identify those children who are not growing at the anticipated rate or who have not achieved the desired height or weight for their age. The time-related centile ranges for QoL outcomes of kidney transplant recipients proposed in 
this study could be used in a similar manner to follow QoL outcomes over time as well asevaluating QoL at a particular point in time.

\section{Summary}

The PORTEL Four-corner framework provided the conceptual underpinnings for this investigation. It provided direction for the consideration of QoL outcomes, the factors and events that influence these outcomes, and potential avenues for interventions to enhance QoL when it is less than what is perceived to be "normal." The PORTEL framework was merged with the analytical perspective of time-related centile ranges to provide a mechanism by which to establish a normal range for QoL outcomes measurements for transplant recipients, enabling patients and providers to make informed decisions regarding treatment, including initiation of new disease management therapy or health promotion to improve QoL (Figure 1.1). QoL can change over time as the factors and events that influence it change, therefore, continued follow up with periodic evaluation is important for long term well being.

\section{Operational Definitions}

\section{Quality of Life}

Defining QoL requires integration of objective and subjective domains (Testa \& Simonson, 1996) that include objective measurements of the individual's physical health, their perception of their health, and their overall sense of well being. Health and life events or factors effect the individual's perception of their QoL as well as their ability to function. For purposes of this study, QoL is considered to be a multidimensional concept reflected by the following domains and measures.

Mental QoL. Mental QoL refers to the individual's perception of their well-being and ability to function in their social roles as measured by the MCS Score of the SF-12. The SF-12 includes questions concerning vitality, social functioning, role-emotional functioning, and mental health (Ware, Kosinski, \& Keller, 1996).

Physical QoL. Physical quality of life includes the individual's objective health indicators as well as their perception of their physical health. The PCS score on the SF12, was used as the measure of physical QoL, and incorporates physical functioning, role functioning, pain, and general health (Ware et al., 1996). 


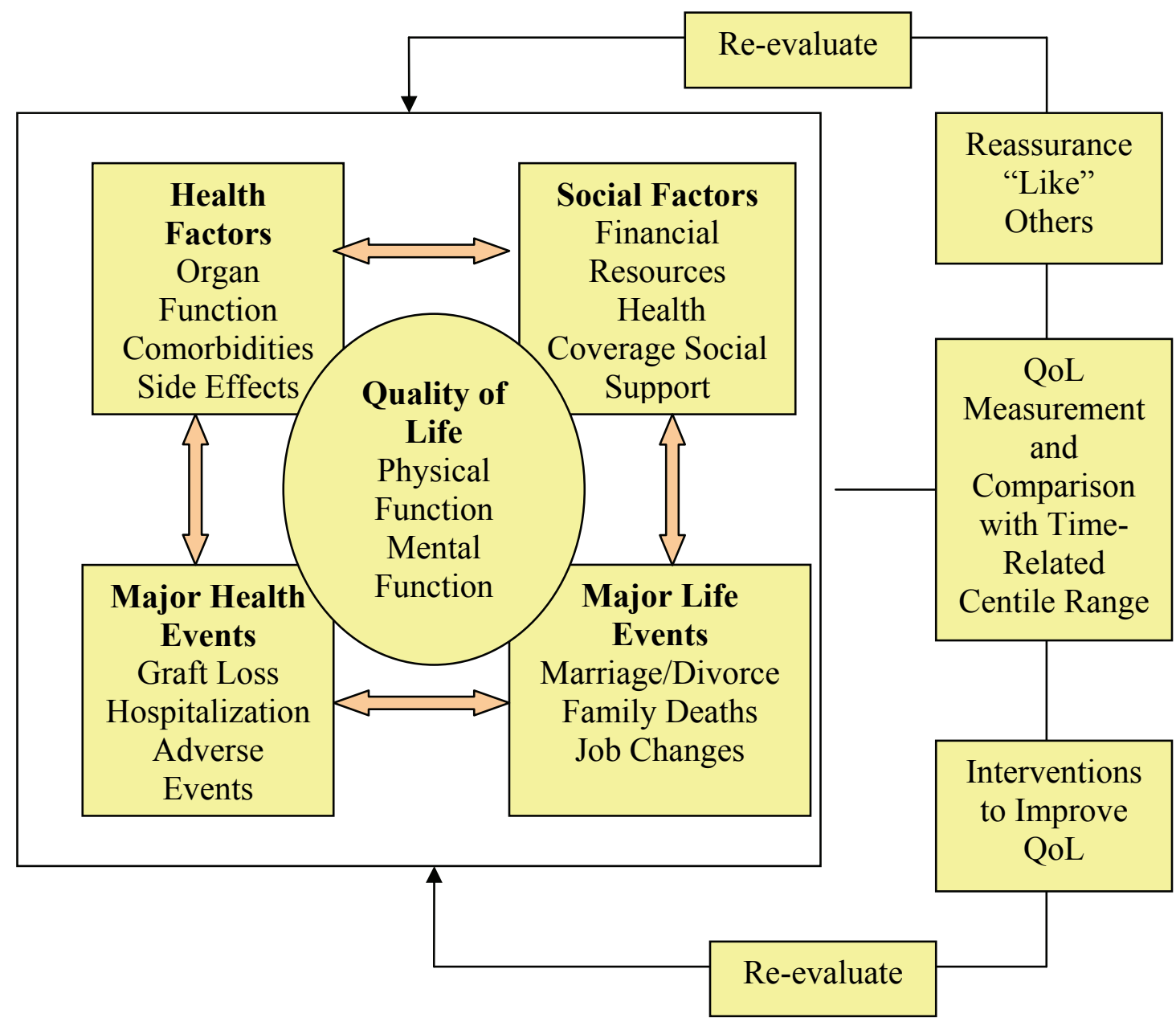

Figure 1.1. Conceptual Model of QoL Domains as Defined by the PORTEL Framework with the Integration of QoL Outcome Measurement and Time-Related Centile Ranges. Adapted with permission. Hathaway, D., Barr, M. L., Ghobrial, R. M., Rodrigue, J., Bogner, S., Prendergast, M. M., et al. (2003b). The PORTEL registry: Overview and selected findings. Progress in Transplantation, Supplement, 3-13. 


\section{Immunosuppressant Side Effects}

The multiple side effects that can result from immunosuppressive therapy have a marked impact on QoL and are defined by, and measured, using the Memphis Survey. This is a disease specific tool designed to assess the impact of side effects on QoL based on their frequency and severity; specifically related to emotional burden, life/role responsibilities, mobility, gastrointestinal distress, and miscellaneous side effects including gingival hypertrophy, increased hunger, somnolence, weight gain, increased hair growth, infections, trembling hands, high blood pressure, easy bruising, decreased libido and sexual performance (Winsett et al., 2004).

\section{Time-Related Centile Range}

Time-related centile ranges plot a value for a variable against a covariate such as time. The ranges established provide an estimation of the value of a variable that the majority of a population exhibit at a given time and is considered to be a norm for the population. Time-related centile ranges have been used for evaluation of a patient's current status or to monitor changes in the variable over time. In this study the covariate of interest was the time that has elapsed since kidney transplantation and the variable of interest was QoL as measured by the SF-12 and the Memphis Survey. Values from these instruments were used to create time-related centile ranges that provided benchmarks for QoL following kidney transplantation.

\section{Assumptions}

The framework of this study was grounded on the following assumptions:

1. Improvement in QoL is desired by individuals.

2. Expected QoL outcomes play a key role in decisions regarding whether to undergo kidney transplantation or continue with alternative methods of kidney replacement therapy.

3. Patients and providers use normal values to benchmark patient progress.

4. QoL is multi-dimensional composed of physical and mental functions that influence and are influenced by health and social factors and major life and health events.

5. QoL is dynamic and can be influenced positively and negatively by external conditions and circumstances, some of which are modifiable or can be accommodated.

6. The survey was self-administered and returned to the registry via mail or internet, therefore an assumption related to the nature of the study was that the survey was completed by the individual and not a family member or friend. 


\section{Limitations}

The following limitations were considered during the conduct of, and in interpreting the outcomes of, this study:

1. QoL is an individually perceived phenomenon and may or may not reflect the actual health and well being of the individual. However, by definition QoL is the individual's self perception, therefore, regardless of how one compares their status with a "normal" benchmark, it is the patient's perception of their QoL that determines successful outcomes.

2. The patient's desire to be "normal" as they have previously defined it may not be a realistic, or achievable, goal given the complexity of personal, social, \& health factors and events that surround kidney transplantation. Regardless, time-related centile ranges provide valuable comparison data. This vast array of potential combinations of personal, social and health factors and events precludes establishing centile ranges for all the conceivable combinations, therefore application and use must be done with caution. 


\section{CHAPTER 2. LITERATURE REVIEW}

QoL has been well established as an important concept in society as well as for health care. Pais-Riberio (2004) stated that measurement of QoL dates to President Eisenhower's Commission on National Goals published in 1960. There have been literally hundreds of articles from all over the world published on QoL in kidney transplantation alone. It is well accepted that kidney transplantation has led to improved QoL as compared to hemodialysis or peritoneal dialysis (Dew, et al., 1997), however little has been done that translates that knowledge for use in direct patient care. Tools providing benchmarks for comparison of the QoL outcomes of an individual patient to a large population of kidney transplant recipients would augment the interpretation of QoL measures in the clinical setting and enhance patient assessment. The purpose this manuscript is to discuss the elements that lead toward the next step in addressing QoL of kidney transplant recipients, that is bringing the measurement of QoL to the practice arena.

Chronic disease, including renal disease, presents special challenges for patients in attaining their desired QoL and for health care providers as they attempt to measure and monitor their patients' QoL. Yet the desire to address these challenges grows as patients and providers seek interventions to improve QoL and methods by which they can document the success of these interventions. Much has been learned from numerous clinical trials about how to measure QoL at various stages of disease and from different patient populations. However, little has been done that addresses how QoL assessments could be used to evaluate the individual patient's progress, to identify patients who could benefit from interventions designed to improve QoL, to help patients evaluate their own QoL in relationship to others with similar characteristics, or to inform patients and providers about reasonable QOL expectations on an individual basis. Using QoL measures to inform patient care brings $\mathrm{QoL}$ assessment from the research arena to the bedside. This paper will discuss the changes in chronic illness, particularly renal disease, that have made attention to the assessment of QoL a primary focus for patient care, present an overview of findings from extant research, and make recommendations for the practical application of transplantation-related QOL knowledge that has accumulated over the last several decades.

\section{The Changing Face of Chronic Illness}

The incidence of chronic disease has increased over the course of the last century. The primary cause of death at the beginning of the last century was infectious disease but by the beginning of the $21^{\text {st }}$ century the leading cause of death had changed and chronic diseases such as heart disease, stroke, and cancer had become the most common causes of death (Healthy people, 2001). Newer and more effective treatment modalities for both acute and chronic illnesses have led to long term survival for many individuals with conditions that would have previously been fatal, contributing to the increase in the number of individuals who are living with chronic conditions (Ironside et al., 2003). With 
this increase in the prevalence of chronic and often disabling conditions, the focus of health care has expanded to encompass not only quantity but quality of life with attention to rehabilitation and health promotion for individuals with disabling disease as a primary goal (Brandt \& Pope, 1997).

Chronic conditions, by definition, are of long duration if not life-long (Bury, 1991). The goal of treatment is not to achieve cure of disease, but rather control of the progression and symptoms of disease. Improved coping and enhancement or maintenance of function becomes the goals in planning and implementing care (Cluff, 1981). With this shift from cure of disease to disease control as the focus of therapy, QoL becomes a common factor that brings together a variety of issues that influence an individual's wellbeing and can be used to determine the effectiveness of therapy (Musschenga, 1997). Thus, QoL and the impact of disease and treatment on QoL, have been recognized as priorities in planning and implementing health care (Moons, 2004).

\section{Quality of Life: The Key Outcome in Chronic Disease}

Incorporation of patient centered QoL outcomes as desirable indicators of the efficacy of health care is causing a paradigmatic shift, where the focus of care and care planning is the patient not the disease (Carr \& Higginson, 2001). This paradigm shift can have particular significance for the patient who is dealing with a long-term chronic condition, and the chosen or required treatment, as well as the disease itself, can impact QoL. Moreover, because the patient is dealing with a long-term condition their relationship with the health care community will be ongoing. The diagnosis of a chronic condition can have a dramatic impact on an individual's life and role function. The manner in which they adapt to and cope with chronic illness will influence the way in which an individual lives their life and hence perceives the quality of the life they are living (Corbin \& Strauss, 1992)

The attributes that define QoL for a person or family are varied, steeped in their values and cultural traditions. The individual's perception of QoL is determined by the interaction of their expectation of what QoL should be and their experience related to wellness, illness, and functional ability (Carr, Gibson, \& Robinson, 2001). Two patients in similar settings with similar conditions may perceive their QoL differently depending on their life experiences and expectations regarding QoL, illness, and the interaction of the two. Studies have attempted to describe patients' perceptions of their diseases and implications for QoL and have demonstrated that attitudes toward chronic illness and the perceptions of chronic illness have changed over time. Thorne and Patterson (1998), in a meta-study examining the roles of clients with chronic disease through two decades of qualitative research found that the perceptions of patients had evolved from a predominantly negative theme of suffering and loss during the 1980's to a more positive perception with themes such as reshaping or reconstituting self, finding meaning, and regaining control. They postulate that this transition in perception may in part contribute to a shift in the viewpoints of health care providers and patients from one of the client as patient to the client as partner. Assuming a partnership role in planning care, 
reconstituting, reshaping, and regaining control implies an active role taken by patients in disease and lifestyle management, and includes seeking information and self evaluation as integral to that role. QoL outcome measures used in the clinical setting as assessment tools for patients and providers can be a beneficial adjunct as patients evaluate their QoL and how it compares with others.

\section{Trajectories in Chronic Illness and Kidney Transplantation}

Corbin and Strauss (1992) in their nursing model for chronic illness conceptualize the course of chronic illness as a multiphase trajectory that changes over time. The trajectory of chronic illness, and the associated QoL changes that may follow when one is diagnosed with a chronic illness, reflect not only the physiologic qualities of the illness but all aspects of the patient's life and that of their family (Corbin \& Strauss, 1992). The experience of chronic illness requires a shift in expectation from the anticipated preillness life trajectory to one of life with a chronic illness that incorporates the changes that occur as a result of the chronic illness or accompanying disability. Within this shift is the added reality that a chronic illness is not a static but a dynamic state, influenced by multiple aspects of life and changing with time and disease progression (Joachim \& Acorn, 2000). The ultimate goal in addressing the changing trajectory of a chronic illness is improving or maintaining the QoL of the patient and family. Chronic illness trajectories are individual; however, certain aspects of the trajectory can be anticipated and guidance can be provided that influences the trajectory at particular points in time (Corbin \& Strauss, 1992). Ponton et al., (2001) identified variation in QoL outcome measurements after kidney transplantation over time. QoL in the immediate post transplantation period was rated as high, with a decrease in perceived QoL during the 7 to 36 month period after transplantation; followed by improvement as the time from transplantation subsequently increased. The variation in QoL may be related to social or health factors that intervene over time, including adjustment to the reality that post transplantation, patients continue to have health issues consisting of medication side effects, complications, and psychosocial issues (Ponton et al., 2001). Assessment of QoL in chronic illness and the changes in QoL that occur is an ongoing process that requires continued attention and follow-up in order to identify points at which intervention to improve QoL might be beneficial.

The desire to be normal or to achieve normalcy in life in the face of chronic disease is associated with QoL by patients in studies focusing on coping and adaptation in chronic illness (Bradford, 1991; McGrath, Paton, \& Huff, 2005; Obrecht, Gallo, \& Knafl, 1992; Snethen, Broome, Bartels, \& Warady, 2001). Chronic illness, including kidney transplantation may require that an individual redefine what they consider to be normal in terms of their QoL as they adapt to their individual chronic illness trajectory. Failure to make such a redefinition can lead to feelings of ongoing frustration and failure (Baines, Joseph, \& Jindal, 2002). Redefining normal requires that the individual reevaluate their potential, and develop an understanding of the limitations that may become challenges in adapting to life following kidney transplantation. Benchmarks that establish references for QoL following kidney transplantation may help transplant recipients in the transition 
to a new normal by reframing their pre-illness expectations for QoL with a more realistic view of their capabilities. Comparison of QoL with that of other transplant recipients to determine whether their QoL is comparable to, better than, or worse than the QoL that other transplant recipients are experiencing would provide a reference point for evaluating their current status. Support groups provide a similar function and have been shown to relieve some of the anxiety associated with chronic illness when individuals find that their feelings and experiences are not unique to themselves but are shared by others and are a product of their situation (Mechanic, 1977). Seeking information, whether it is from health care providers or others who have had the same or similar experiences, aides in coping with and in adaptation to chronic disease (Craig \& Edwards, 1983).

\section{Defining Quality of Life}

Although, the importance of QoL for individuals in evaluating health care outcomes is well established, a widely accepted definition of QoL has been elusive making agreement as to how it should be measured difficult (Haas, 1999; Meeberg, 1993). QoL is generally viewed as a multidimensional term representing both subjective and objective domains (Testa \& Simonson, 1996). The general concept of QoL has been differentiated from that of health related QoL with physical, psychological, and social domains of health included in the definition (Pinson et al., 2000). QoL has also been defined in such a way that it reflects the individual's functional ability, health and well being, and psycho-emotional health (Cetingok, Winsett, \& Hathaway, 2004). Many factors beyond the impact of disease influence QoL including overall health status and social status (Cetingok et al., 2004).

The developers of the Patient Outcomes Registry for Transplant Effects on Life (PORTEL) have developed a framework for describing QoL following solid organ transplantation which includes 5 separate but interrelated domains (Hathaway et al., 2003b). The domains include health and social factors, major life and health events, and QoL. Health factors are those health related issues that the transplant recipient deals with on a daily basis, such as the quality of organ function, co-morbidity that can lead to disability including diabetes or osteoporosis, side effects of immunosuppressant agents, or health behaviors that can promote or impair health. Social factors are the daily issues that shape social functioning, such as, economic support, health care coverage, or available social support. Major life and major health events are episodic in nature, but can have a significant effect on QoL and daily functioning. Major life events could include loss of a job, death of a family member, a marriage or divorce in the family. Major health events could include graft loss, a serious infection or other adverse event, or hospitalization. The fifth domain in this model is QoL. While QoL can be viewed as a separate entity, it is influenced by, and influences the other four domains (Hathaway et al., 2003b). Figure 1.1 depicts a model adapted from the PORTEL QoL framework that incorporates the use of outcomes based on the original framework as benchmarks for comparison of the patient's QoL with that of others from a similar comparison group. Comparing one's QoL with a similar group can be reassuring as transplant recipients 
recognize that their QoL is similar to, or exceeds, standard benchmarks. Use of benchmarks can also identify individuals who, with intervention, could experience enhanced QoL. The dynamic nature of QoL can also be captured when QoL is reevaluated over time to monitor a patient's progress. With improved patient and graft survival following kidney transplantation, long term follow-up will require continued reassessment of QoL outcomes as aging influences health and social factors, and life and health events occur.

\section{Quality of Life in Kidney Transplantation}

Many studies have demonstrated that kidney transplantation improves QoL compared to hemodialysis or peritoneal dialysis (Fujisawa et al., 2000; Lazzaretti, Carvalho, Mulinari, \& Rasia, 2004; Molzahn, 1991; Niu \& Li, 2005; Ogutmen et al., 2006; Ostrowski, Wesolowski, Makar, \& Bohatyrewicz, 2000; Overbeck et al., 2005). Liem, Bosch, Arends, Heijunbrok-Kal \& Hunink (2007) in a meta-analyses of 52 studies that used the SF-36 to compare the QoL of transplantation, hemodialysis, and peritoneal dialysis patients, found that following kidney transplantation, patients had better QoL than patients receiving hemodialysis or peritoneal dialysis as renal replacement therapy. While the majority of studies reported that kidney transplantation improved QoL, there have also been studies which found no differences in QoL scores between transplantation, hemodialysis, and peritoneal dialysis patients (Sayin, Mutluay, \& Sindel, 2007).

When QoL post transplantation is compared to that of the general population the results have been mixed. QoL after kidney transplantation has been reported as similar to the QoL of the general population on subjective indicators including role performance, social functioning, role limitations due to emotional function, and mental health (Evans et al., 1985; Neipp et al., 2006; Rebollo et al., 2000). In other studies, QoL following kidney transplantation was improved over other means of kidney replacement therapy but it did not equal that of the general population (Dew et al., 1997; Overbeck et al., 2005). Older transplant recipients, over 55 years of age, have scored higher on general health perception than younger recipients, possibly because older patients are better able to cope with changes and limitations that occur with age (Noohi, Karami, Lorgard-Dezfuli-Nejad, Najafi, \& Saadat, 2007). With this variation in mind, benchmarks specific to QoL post kidney transplantation would provide more accurate and realistic comparisons for patients and health care providers to use in assessing QoL than benchmarks from general population data.

\section{Predictors of Quality of Life in Kidney Transplantation}

While the majority of studies have found that the QoL of transplant recipients overall is superior to the QoL of patients receiving other types of renal replacement therapy, there are subgroups of transplant recipients who have not experienced improvement in QoL following transplantation. In an attempt to identify those individuals 
at risk for poorer QoL several studies have identified various health and social factors that are predictive of QoL post kidney transplantation. Rosenberger et al. (2006) used the term perceived health status (PHS) in lieu of QoL in a study designed to explore the predictors of PHS. They found that the predictors of PHS changed over time, with social support and lower creatinine predictive of higher PHS in younger patients, and fewer hospitalizations and absence of diabetes mellitus predictive of higher PHS in older patients. Lower stress related to adverse effects was shown to predict PHS across all groups. Following transplantation, side effects of immunosuppressant therapy can replace the symptoms associated with chronic renal failure as a source of patient distress that compromises QoL (Habwe, 2006). Khedmat et. al (2007) found poorer QoL to be associated with lower education levels, being single or widowed, and the presence of diabetes or hypertension. Morbidity during the first six months post transplantation (as reflected by the number of days hospitalized), employment, and social support were identified as predictors of decreased QoL by Hathaway, et al. (1998). Employment after transplantation, viewed as a measure of returning to social functioning, has been correlated with better QoL (Matas et al., 2002; Matas et al., 1996). Neipp et al. (2006) also found social factors, including employment and social support to be an important predictor of better QoL for transplant recipients. The inter-relationships among various predictors of post transplantation QoL is supported by findings that demonstrate that the presence of comorbidities, the type of transplantation (cadaveric or living donor), age and time since transplantation are correlated with participation in social activities such as employment, education, and performance of household tasks (van der Mei et al., 2006); both are sets of variables which have been found to be associated with post transplantation QoL as noted above.

QoL in end stage renal disease has been studied for decades. It has been clearly shown that kidney transplantation improves Qol for many patients, but not all, and the desire for better QoL drives the decision for many to undergo kidney transplantation (Shah et al., 2006). It is also apparent that there is variability in QoL outcomes and that QoL appears to have some degree of change over time following transplantation (Ponton et al., 2001). In spite of the intense interest in QoL and in measurement of QoL, it has been primarily a tool used in the research setting and has not been readily translated into the clinical setting for use in patient evaluation (Higginson \& Carr, 2001). The variability in QoL outcomes and the many health and social factors that have been identified as predictors of QoL imply that assessment of the perceived QoL of kidney transplant recipients in the clinical setting would be beneficial in identifying those patients at risk for less than optimal QoL.

\section{Quality of Life Measurement as a Tool in the Clinical Setting}

There is general agreement that discussion of QoL between patients and health care providers is beneficial, however few studies have demonstrated that measuring QoL outcomes change clinical decision making or the patient's clinical outcomes (Espallargues, Valderas, \& Alonso, 2000; Greenhalgh, Long, \& Flynn, 2005, Levine \& Ganz, 2002). Measuring QoL in routine practice has, however, been demonstrated to 
increase communication between patients and providers (Detmar, Muller, Schornagel, Wever, \& Aaronson, 2002) leading to increased discussion of nonspecific symptoms and better QoL and emotional functioning for patients without prolonging the patient encounters (Velikova et al., 2004). Although most studies using QoL instruments to assess patient outcomes did not find a change in the clinical decision making process; increased communication was reported to be benficial in patient care. Higginson \& Carr (2001) cite five potential uses for QoL measures in the clinical setting directly related to clinical care or the evaluation of care; including prioritizing problems, facilitating communication, screening for potential problems, identifying preferences of patients, monitoring changes or responses to treatments, and training new staff. While QoL measures do not substitute for physiologic evaluation of disease; they do capture the personal and social context of the patient and put the patient at the forefront of the encounter.

Detmar, Muller, Schornagel, Wever, and Aaronson (2000) found that patients were willing to discuss QoL with their health care provider. In a sample of patients in oncology practice, it was found that patients were very willing to discuss their physical and emotional function; but while the patient felt comfortable initiating the discussion of physical function, they expected that the provider would initiate any discussion of emotional function including social and family issues. Providers on the other hand, in this case physicians, tended to discuss emotional issues if the topic was initiated by the patient. The authors concluded that this discrepancy as to who should take the lead in discussion of psychosocial issues may decrease the likelihood that the discussion will take place. Systematic clinical assessment of QoL would provide a catalyst for initiation of conversation about social or emotional factors and QoL issues.

In order for QoL measures to become a part of clinical evaluation, barriers to the use of QoL instruments must be addressed. In a study that examined the attitudes toward the use of health outcome questionnaires in clinical practice Meadows, Rogers, and Greene (1998) found that physicians in general practice and nurses expressed a positive attitude about using health outcome measurements but were not sure how they would use the data in patient care. Other identified barriers to the use of QoL outcome measures include time and resource constraints, the perception that available instruments were inadequate to measure outcomes, and the belief that QoL outcome measurements were unnecessary (Morris, Perez, \& McNoe, 1998). Familiarity with QoL questionnaires and their use was associated with a more positive attitude toward incorporating them into clinical practice in a sample of providers in a pediatric clinical practice (Baars, van der Pal, Koopman, \& Wit, 2004). A review of trials that assessed the influence of QoL outcome measures on clinical decision-making noted that education regarding the administration and interpretation of QoL measurement tools, presentation of results in a usable format, and implementation in a manner reflecting the process of clinical decisionmaking would be helpful in overcoming barriers to using QoL measures in the clinical setting (Greenhalgh et al., 2005). Benchmarks for QoL post transplantation based on aggregate data, and presented in an easily interpretable format could provide tools that would make the use of QoL outcome measures a beneficial part of patient assessment. These tools would be used to evaluate the patient's current QoL, alert the patient and 
provider to changes in QoL that have occurred, and identify points in the patient's recovery trajectory where strategies or interventions for improving QoL could be implemented.

\section{Centile Ranges to Interpret Quality of Life}

If QoL outcome measurement is to be useful in the clinical setting, then tools that aid in interpreting the values will be helpful for patients and providers. The establishment of a range of QoL outcome measurement scores that are typical for patients at particular points in time post transplantation would present the data in such a way that it has greater utility in the clinical setting. Reference ranges, often referred to as normal ranges for measurements, have long been used in health care to evaluate the health status of patients. The range of normal for a particular variable is typically defined as the area between the $2.5^{\text {th }}$ and the $97.5^{\text {th }}$ percentiles (Griffiths, Iles, Koduah, \& Nix, 2004). The assumption is made that the reference population in which the variable is measured is a population representative of "normal" or "healthy" individuals, thus the term normal range. The simple reference range is inadequate for evaluation when the variable in question is strongly dependent on a covariate such as time (Cole \& Green, 1992). The tools established to document human growth and the references used to monitor bone density are common examples of reference ranges that have been established to follow change in a variable over time. Development of time-related centile ranges for QoL outcomes based on data collected from kidney transplant recipients that would the QoL experienced by that population of patients would provide an adjunct to the evaluation of the patient's physical and disease specific outcomes in the clinical setting.

\section{Summary}

Improved graft survival and long-term patient survival following kidney transplantation has led to a growing interest in addressing the QoL of patients (De Geest $\&$ Moons, 2000). The wealth of data that is presently available regarding QoL and the instruments that have been developed to measure QoL have not been translated into the clinical setting for routine evaluation of QoL. Establishing benchmarks for the assessment of QoL is an initial step in translating years of research into practice.

Standardized benchmark data would provide a baseline for interpreting individual patient QoL outcomes in such a way that the information could be used to educate patients prior to transplantation, allow transplant recipients to compare their QoL with others at similar points in time post transplantation, and identify patients who could benefit from interventions designed to improve QoL. 


\title{
CHAPTER 3. METHODOLOGY
}

\author{
Introduction
}

This chapter will describe the methodology used to address the research question and study aim outlined in chapter one. It will include a discussion of the research design, the sample and sampling method, and analytical plan.

\section{Research Design}

This descriptive study is a secondary data analysis focused on the development of time-related centile ranges that document QoL outcome measure scores in four different time blocks following kidney transplantation. Time-related centile ranges such as these are used in clinical settings as benchmarks for patients and health care providers to compare the patient's status or progress with others having similar characteristics.

\section{Research Question and Study Aim}

The primary outcome of this study was the creation of time-related centile reference ranges depicting QoL outcomes following kidney transplantation for use in patient evaluation and education. The research question (1) and study aim (2) were as follows:

1. Do QoL outcomes differ within groups of patients categorized by gender and race? If so then:

a) Do the QoL outcome measures for patients grouped by gender and race differ at four specific time intervals following transplantation?

b) Which of the variables or combination of variables (gender and race) identify cohorts of patients most appropriate for creation of timerelated centile ranges used to illustrate QoL outcomes?

2. Individual time-related centile ranges were established for scores on the SF-12 and the Memphis Survey for each patient group identified in stage 1. The QoL measures included separate scores for the:

a) SF-12:

i. Physical Component Summary (PCS)

ii. Mental Component Summary (MCS)

b) Memphis Survey scores:

i. Frequency score how often side effects occur)

ii. Severity score (level of distress caused by the side effects) 


\section{Procedures}

The Patient Outcomes Registry for Transplant Effects of Life (PORTEL) Survey, a national data registry, was established in 2000 by Fujisawa Pharmaceuticals, and later supported by Astellas Pharmaceuticals, in response to increasing concern regarding the QoL of transplant recipients. The registry was designed to collect longitudinal data on QoL outcomes following solid organ transplantation. The PORTEL database houses data collected using a systematic approach to assessment of the QoL experienced by solid organ transplant recipients. The intent in the development of the registry was to provide a resource for data that could serve as a benchmark for evaluating the QoL of solid organ transplant recipients in order to develop strategies to improve QoL (Hathaway et al., 2003b). With this goal in mind, the PORTEL survey design was based on a multidimensional QoL framework that encompassed both objective and subjective indicators of QoL. The PORTEL registry is unique in that it is a stand alone patientdriven and patient-centered registry with data collected for the sole purpose of assessing QoL. It was not a part of a larger clinical study with additional goals that could influence the individual's perception of their QoL.

The participants in the registry represent transplant recipients recruited from multiple institutions and through multiple venues across the United States. Recruitment to the registry was both patient-centric and site-centric. The patient-centric recruitment was achieved through contact with transplant recipients at national transplantation meetings, community events, support groups, and direct mail. Site-centric recruitment occurred through four transplantation centers representing different regions of the United States, Unversity of Southern California, University of Alabama, Birmingham, University of Tennessee Health Science Center, and Unversity of Minnesota. Transplantation centers participating in data collection received IRB approval from their institution prior to enrollment of subjects (Hathaway, et al., 2003b). The PORTEL database represents a more diverse sample of the population of transplant recipients than samples reported in which data are collected from a single institution.

Participants were entered into the registry and data were collected from 20002005. PORTEL registry participants completed surveys at 6 month intervals during the data collection period. Enrollment and participation in the registry was open to any solid organ transplant recipient who had a functioning graft and was greater than 16 years of

age at the time that the survey was completed. All participants enrolled in the registry were solid organ transplant recipients including, heart, lung, kidney, kidney-pancreas, and liver transplant recipients. Participants received an incentive in the form of a $\$ 10$ dollar Target gift certificate each time a survey was completed. Year to year retention in the database was approximately 70 percent.

The design of the PORTEL Registry survey instrument was based on the four cornered QoL framework discussed in chapter one. The instrument was comprised of 100 items organized to capture demographic variables, clinical outcomes, medications, and side effects (Hathaway, Winsett, Prendergast, \& Subaiya, 2003). The content of the 
survey addressed each of the five domains described in the QoL framework for the registry: QoL, health factors, social factors, major health factors, and major life events.

Quality of Life Instruments Included in the PORTEL Registry Survey

\section{2-Item Short-Form Health Survey}

The SF-12 is an instrument that has been used to document QoL in the general population as well as groups of patients with various chronic illnesses. It is comprised of a subset of 12 items from the SF-36 and was developed to provide an alternative to the longer form, be easier to administer and yet provide the same reliability as the longer SF36 (Ware, Kosinski, \& Keller, 1996). The SF-36 has been widely used to evaluate health related quality of life in transplant recipients and is considered the gold standard for measuring QoL (Aasebo, Midtvedt, Hartmann, \& Stavem, 2005; Fiebiger, Mitterbauer, \& Oberbauer, 2004; Griva et al., 2002; Pinson et al., 2000; Rebollo et al., 2000). The SF-12 has been shown to correlate with the SF-36 in assessing QoL trauma patients, individuals with cervical spondylosis, and persons infected with HIV (Delate \& Coons, 2000; Kiely, Brasel, Guse, \& Weigelt, 2006; Singh, Gnanalingham, Casey, \& Crockard, 2006).

The SF-12 is composed of two domains comprising a Mental (MCS) and Physical Component Summary (PCS). Mental and physical factors were found to account for 80 to 85 percent of the variance in the SF-36 (Ware et al., 1996). Psychometric methods were used to reduce the number of health dimensions in the SF-36 to those included in the SF12 and maintain comparable information (Ware et al., 1996). The SF-12 is scored from 0100 with higher scores indicating better QoL.

\section{Memphis Survey}

A disease specific instrument, the Memphis Survey was included in the PORTEL instrument to document side effects of immunosuppressant medications. The survey was developed in 1997 by a group of researchers at University of Tennessee Health Science Center. The development of the Memphis Survey was unrelated to the establishment of the PORTEL registry (Hathaway et al., 2003b). The survey was designed to evaluate the frequency and severity of side-effects of immunosuppressive regimens on QoL in solid organ transplant recipients (Hathaway et al., 2003b). A multi-stage factor analysis was used to identify side effects experienced by patients taking a variety of immunosuppressant agents (Winsett et al., 2004). The subscales of the Memphis survey are emotional burden, life/role responsibilities, mobility, gastrointestinal distress, and miscellaneous side-effects which include items related to enlarged gums, increased hunger, sleeping, weight gain, increased hair growth, infections, trembling hands, high blood pressure, easy bruising, loss of interest in sex, and sexual performance (Winsett et al., 2004). Symptoms were assessed for occurrence and the level of distress incurred by the patient. Symptoms were coded on a 0-4 scale, zero being not at all and 4 being 
always. Cumulative subscale scores for frequency of occurrence and severity of the symptom were reported for each patient ranging from 0-160. The higher number indicating a worse side-effect profile (Hathaway et al., 2003b). Reliability and validity of the Memphis Survey was demonstrated by Winsett, et al. (2004) in a national survey of 505 transplant recipients designed to quantify the consequences of the side effects of immunosuppressant therapy on QoL.

\section{Data Extraction}

Data for this study were extracted from the PORTEL Registry database. Inclusion criteria for the study were recipients of a single kidney transplantation who were between the ages of 18 and 65 at the time the survey was completed and greater than 14 days from the transplant surgery. The total PORTEL database includes 7,327 surveys completed by 1,434 recipients of solid organ transplantation. The initial data extraction identified 3,144 surveys completed by 681 individuals who had undergone single kidney transplantation. Time intervals were established for construction of time-related centile ranges representing four separate time brackets between the transplant surgery and survey completion: less than 4 months from transplantation, 4 months to 18 months, 19 months to 36 months, and greater that 36 months from transplantation. These specific time brackets were selected to allow for even distribution of the surveys and to be consistent with times typically used for clinical assessment of patients and in post-transplantation follow-up studies. Because individuals contributed multiple surveys to the database, care was taken to assure that only one survey from each individual transplant recipient was included in each time bracket. The first survey completed by an individual within each time bracket was selected for inclusion. If a patient contributed additional surveys, the others were excluded. This process eliminated 1,894 surveys leaving 969 for study inclusion in the study.

Only Caucasian and African American participants were selected for inclusion in the study because the number of participants of other ethnic or racial association was inadequate for data analysis. Of the 969 surveys selected, 22 surveys were eliminated because they did not include QoL data and 4 surveys were eliminated because they did not include information about gender. The final sample consisted of 943 surveys completed by 515 recipients of a single kidney transplantation.

Demographic data, clinical information and QoL outcomes were extracted from each survey to describe the sample and address the research question and study aim. Demographic data included age, income, education, working status, social support, living arrangements, immunosuppressant regimens, and insurance coverage. Clinical information included comorbidities, number of infection and rejection episodes, frequency of hospitalization and number of hospital days since transplantation. Data extracted to address the research questions included race, gender, the Memphis Survey Frequency and Severity scores and the SF-12 PCS and MCS scores. 


\section{Sample}

The 943 PORTEL Registry Surveys included in this study were completed by 515 individuals, 246 contributed a survey in only one time bracket, 128 individuals contributed a survey in each of two time brackets, 123 contributed a survey in three time brackets, and 18 transplant recipients contributed a survey in all 4 time brackets. No PORTEL Registry participant was represented in any time bracket more than once. The description of the sample is reported by time intervals since transplantation in order to provide a description of the portion of the sample included in each time bracket.

\section{Description of the Sample}

The 943 surveys were completed by 484 (51.3\%) men and 459 (48.7\%) women. Seven hundred fifty one (79.6\%) were completed by Caucasians and $192(20.4 \%)$ by African Americans. The average age at the time of survey completion was 46 years with a standard deviation of 11.3 years.

The gender and race distribution of the individual transplant recipients included in this study was compared to the data from the United Network for Organ Sharing (UNOS) data. UNOS administers the Organ Procurement and Transplantation Network (OPTN) and is responsible for collecting and managing data about all transplantation events that occur in the United States. The distribution of racial and gender groups in the PORTEL sample differs from that of the UNOS data $\left(\chi^{2}=25.03, \alpha=0.01\right)$. A comparison of the gender and racial distribution of this sample with the UNOS data is presented in Table 3.1. The percentage of Caucasian males and African-American females in the sample from the PORTEL registry were consistent with the population reported by UNOS. However, African American males comprised only $9.5 \%$ of the study sample compared with $16.24 \%$ reported by UNOS. The percentage of Caucasian females in the study sample was higher than that reported in the UNOS database, $35.7 \%$ and $28.52 \%$ respectively.

\section{Health Status}

Health status includes both the health factors and major health events that transplant recipients deal with on a daily basis and episodically which impact QoL (Hathaway et al., 2003b). Comorbidities, rejection episodes, hospital admissions, hospital days and infections that were reported on each survey were included in the study. The PORTEL Survey is a self-report questionnaire; as a result all surveys were not complete.

Comorbidities. Increased long term survival of transplant recipients leads to increased prevalence of secondary complications of transplantation, including osteoporosis (Cohen \& Shane, 2003; Crippin, 2001), diabetes, and hyperlipidemia 
Table 3.1. Comparison of Sample Demographic Distribution with UNOS Data.

\begin{tabular}{lcc}
\hline \multicolumn{1}{c}{ Demographic Group } & PORTEL Sample & UNOS \\
\hline Caucasian Male & $42.3 \%$ & $44.16 \%$ \\
Caucasian Female & $35.7 \%$ & $28.52 \%$ \\
African American Male & $9.5 \%$ & $16.24 \%$ \\
African American Female & $12.4 \%$ & $11.10 \%$ \\
\hline
\end{tabular}

*Based on OPTN data as of May 8, 2008. 
(Reuben, 2001). Comorbidities, either pre-existing or those that develop following transplantation have an impact on the well-being and QoL of transplant recipients. The survey asked participants if they had been treated for diabetes, hypertension, hypercholesterolemia, or osteoporosis since transplantation. Treatment for comorbidities was reported on 761 surveys.Interestingly, 200 surveys reported no comorbidities. Multiple comorbidities were reported on 328 surveys, 200 reported two, 106 reportedthree and 22 reported treatment for four comorbidities. Table 3.2 reports the percent of surveys reporting treatment for hypertension, cholesterol, diabetes, or osteoporosis ineach time bracket. The incidence of diabetes and hypertension are relatively stable across time.

The frequency of treatment for osteoporosis and hypercholesterolemia is lower for individuals in the early months post transplantation and was increased at the points farthest removed from the transplantation. At less than 4 months post transplantation, $4.7 \%$ of surveys reported treatment for osteoporosis and $25.7 \%$ reported treatment for hypercholesterolemia. At greater than 36 months post transplantation, $23 \%$ of surveys reported treatment for osteoporosis and $46.7 \%$ reported treatment for hypercholesterolemia.

Rejection, Infection, Hospital Admissions, and Hospital Days. The incidence of rejection episodes in the sample is low with the majority of surveys reporting no rejection episodes. The peak period for rejection was in the 4-18 month post transplant block with $10.3 \%$ of surveys reporting 1 to 2 rejection episodes representing 26 surveys. Table 3.3 lists the incidence of rejection episodes in each time bracket.

Frequency of infection was reported as the number of infections treated since transplantation. No information was available regarding severity of infection. Most surveys reported that no treatment for infection had been required since transplantation. Of those reporting that they had been treated for an infection, the most common number of infections reported was 1 to 2 . Over time, the number of infections was relatively stable. The actual number of infections reported in each time bracket is reported in Table 3.4 .

The number of hospital admissions and the number of days spent in the hospital is reported in Tables 3.5 and 3.6. The reported frequency of hospital admissions or hospital days in each time bracket represents the cumulative number of hospitalizations or hospital days since transplantation, not the number occurring during the designated time bracket. The majority of surveys reported no hospitalizations since transplantation. A greater percentage of surveys reported no hospital days at greater than 36 months post transplantation $(53.3 \%)$ than at less than 4 months post transplantation $(29.2 \%)$. Few surveys reported 5 or more hospitalizations in any time bracket and few surveys reported more than 21 days in hospital. More hospital days were reported during the less than 4 month post transplantation period than the later time blocks, which would be consistent with surgical recovery. The percentage of survey that did not report health status 
Table 3.2. Comorbidity by Time Bracket Since Transplantation.

\begin{tabular}{lcccc}
\hline & \multicolumn{4}{c}{ Time Since Transplantation } \\
\cline { 2 - 5 } Cormorbidity & $\begin{array}{l}\text { < months } \\
\mathrm{n}=213\end{array}$ & $\begin{array}{c}4-18 \text { months } \\
\mathrm{n}=213\end{array}$ & $\begin{array}{c}19-36 \text { months } \\
\mathrm{n}=199\end{array}$ & $\begin{array}{c}>36 \text { months } \\
\mathrm{n}=134\end{array}$ \\
\hline \multirow{2}{*}{ Diabetes } & 50 & 43 & 47 & 37 \\
& $23.4 \%$ & $20.2 \%$ & $23.6 \%$ & $27.4 \%$ \\
Hypertension & 118 & 106 & 113 & 80 \\
Osteoporosis & $55.1 \%$ & $49.8 \%$ & $56.8 \%$ & $59.3 \%$ \\
Increased & 10 & 30 & 48 & 31 \\
Cholesterol & $4.7 \%$ & $14.1 \%$ & $24.1 \%$ & $23.0 \%$ \\
& & & & 63 \\
\hline
\end{tabular}


Table 3.3. Frequency of Rejection Episodes by Time Since Transplantation.

Time Since Transplantation

\begin{tabular}{|c|c|c|c|c|}
\hline $\begin{array}{l}\text { Rejection } \\
\text { Episodes }\end{array}$ & $\begin{array}{c}<4 \text { months } \\
\mathrm{n}=236\end{array}$ & $\begin{array}{c}4-18 \text { months } \\
n=253\end{array}$ & $\begin{array}{c}19-36 \text { months } \\
n=225\end{array}$ & $\begin{array}{c}>36 \text { months } \\
n=229\end{array}$ \\
\hline 0 & $\begin{array}{c}200 \\
84.7 \%\end{array}$ & $\begin{array}{c}208 \\
82.2 \%\end{array}$ & $\begin{array}{c}203 \\
90.2 \%\end{array}$ & $\begin{array}{c}181 \\
79 \%\end{array}$ \\
\hline $1-2$ & $\begin{array}{c}15 \\
6.4 \%\end{array}$ & $\begin{array}{c}26 \\
10.3 \%\end{array}$ & $\begin{array}{c}12 \\
5.3 \%\end{array}$ & $\begin{array}{c}7 \\
3.1 \%\end{array}$ \\
\hline $3-4$ & $\begin{array}{l}5 \\
2.1 \%\end{array}$ & $\begin{array}{c}2 \\
.8 \%\end{array}$ & $\begin{array}{c}1 \\
.5 \%\end{array}$ & $\begin{array}{l}3 \\
1.3 \%\end{array}$ \\
\hline 5 or more & $\begin{array}{c}4 \\
1.7 \%\end{array}$ & $\begin{array}{c}0 \\
.0 \%\end{array}$ & $\begin{array}{c}0 \\
.0 \%\end{array}$ & $\begin{array}{c}1 \\
.4 \%\end{array}$ \\
\hline Unknown & $\begin{array}{c}12 \\
5.1 \%\end{array}$ & $\begin{array}{c}17 \\
6.7 \%\end{array}$ & $\begin{array}{c}9 \\
4 \%\end{array}$ & $\begin{array}{c}37 \\
16.2 \%\end{array}$ \\
\hline
\end{tabular}


Table 3.4. Number of Reported Infections by Time Since Transplantation.

Time Since Transplantation

\begin{tabular}{|c|c|c|c|c|}
\hline Infections & $\begin{array}{c}<4 \text { months } \\
n=236\end{array}$ & $\begin{array}{c}\text { 4-18 months } \\
n=253\end{array}$ & $\begin{array}{c}19-36 \text { months } \\
n=225\end{array}$ & $\begin{array}{c}>36 \text { months } \\
n=229\end{array}$ \\
\hline 0 & $\begin{array}{c}152 \\
64.4 \%\end{array}$ & $\begin{array}{c}153 \\
60.5 \%\end{array}$ & $\begin{array}{c}152 \\
67.6 \%\end{array}$ & $\begin{array}{c}138 \\
60.3 \%\end{array}$ \\
\hline $1-2$ & $\begin{array}{c}61 \\
25.8 \%\end{array}$ & $\begin{array}{c}67 \\
26.5 \%\end{array}$ & $\begin{array}{c}55 \\
24.4 \%\end{array}$ & $\begin{array}{c}42 \\
18.3 \%\end{array}$ \\
\hline $3-4$ & $\begin{array}{c}4 \\
1.7 \%\end{array}$ & $\begin{array}{c}13 \\
5.1 \%\end{array}$ & $\begin{array}{c}8 \\
3.6 \%\end{array}$ & $\begin{array}{c}13 \\
5.7 \%\end{array}$ \\
\hline 5 or more & $\begin{array}{c}1 \\
0.4 \%\end{array}$ & $\begin{array}{c}0 \\
.0 \%\end{array}$ & $\begin{array}{c}2 \\
0.9 \%\end{array}$ & $\begin{array}{c}3 \\
1.3 \%\end{array}$ \\
\hline Unknown & $\begin{array}{c}18 \\
7.9 \%\end{array}$ & $\begin{array}{c}20 \\
7.9 \%\end{array}$ & $\begin{array}{c}8 \\
3.6 \%\end{array}$ & $\begin{array}{c}33 \\
14.4 \%\end{array}$ \\
\hline
\end{tabular}


Table 3.5. Frequency of Hospital Admissions by Time Since Transplantation.

Time Since Transplantation

\begin{tabular}{lcccc}
\cline { 2 - 4 } $\begin{array}{l}\text { Hospital } \\
\text { Admissions }\end{array}$ & $\begin{array}{c}<\text { months } \\
\mathrm{n}=236\end{array}$ & $\begin{array}{c}4-18 \text { months } \\
\mathrm{n}=253\end{array}$ & $\begin{array}{c}19-36 \text { months } \\
\mathrm{n}=225\end{array}$ & $\begin{array}{c}>36 \text { months } \\
\mathrm{n}=229\end{array}$ \\
\hline \multirow{3}{*}{162} & 163 & 180 & 153 \\
& $68.6 \%$ & $64.4 \%$ & $80 \%$ & $66.8 \%$ \\
$1-2$ & 57 & 61 & 31 & 20 \\
& $24.2 \%$ & $24.1 \%$ & $13.8 \%$ & $8.7 \%$ \\
$3-4$ & 5 & 7 & 2 & 7 \\
& $2.1 \%$ & $2.8 \%$ & $.9 \%$ & $3.1 \%$ \\
5 or more & 1 & 3 & 1 & 1 \\
& $0.4 \%$ & $1.3 \%$ & $0.4 \%$ & $0.4 \%$ \\
Unknown & 11 & 19 & 11 & 48 \\
& $4.7 \%$ & $7.5 \%$ & $4.9 \%$ & $21 \%$
\end{tabular}


Table 3.6. Number of Hospital Days by Time Since Transplantation.

Time Since Transplantation

\begin{tabular}{|c|c|c|c|c|}
\hline Hospital Days & $\begin{array}{c}<4 \text { months } \\
n=236\end{array}$ & $\begin{array}{l}\text { 4-18 months } \\
n=253\end{array}$ & $\begin{array}{c}19-36 \text { months } \\
n=225\end{array}$ & $\begin{array}{c}>36 \text { months } \\
n=229\end{array}$ \\
\hline 0 & $\begin{array}{c}69 \\
29.2 \%\end{array}$ & $\begin{array}{c}127 \\
50.2 \%\end{array}$ & $\begin{array}{c}134 \\
59.6 \%\end{array}$ & $\begin{array}{c}122 \\
53.3 \%\end{array}$ \\
\hline $1-10$ & $\begin{array}{c}116 \\
49.2 \%\end{array}$ & $\begin{array}{c}84 \\
33.2 \%\end{array}$ & $\begin{array}{c}70 \\
31.1 \%\end{array}$ & $\begin{array}{c}52 \\
22.7 \%\end{array}$ \\
\hline $11-20$ & $\begin{array}{c}22 \\
9.3 \%\end{array}$ & $\begin{array}{c}12 \\
4.7 \%\end{array}$ & $\begin{array}{c}5 \\
2.2 \%\end{array}$ & $\begin{array}{c}4 \\
1.7 \%\end{array}$ \\
\hline $21-30$ & $\begin{array}{c}11 \\
4.7 \%\end{array}$ & $\begin{array}{c}6 \\
2.4 \%\end{array}$ & $\begin{array}{c}3 \\
1.3 \%\end{array}$ & $\begin{array}{c}1 \\
0.4 \%\end{array}$ \\
\hline$>31$ & $\begin{array}{c}7 \\
3.0 \%\end{array}$ & $\begin{array}{c}4 \\
1.6 \%\end{array}$ & $\begin{array}{c}1 \\
0.4 \%\end{array}$ & $\begin{array}{c}2 \\
0.9 \%\end{array}$ \\
\hline Unknown & $\begin{array}{c}11 \\
4.7 \%\end{array}$ & $\begin{array}{c}20 \\
7.9 \%\end{array}$ & $\begin{array}{c}12 \\
5.3 \%\end{array}$ & $\begin{array}{c}48 \\
21 \%\end{array}$ \\
\hline
\end{tabular}


indicators was higher in the greater than 36 months post transplantation group than in any other group (21\%).

Immunosuppressant Regimen. The current immunosuppressant regimen was reported on 760 surveys. The drugs included in the immunosuppressant regimens indicated on the surveys are reported in Table 3.7. Prednisone, the calcineurin inhibitors, cyclosporine and tacrolimus, and mycophenolate mofetil (Cellcept), an antiproliferative agent, were the most common agents indicated. The majority of surveys $(62 \%)$ reported a 3 drug regimen.

\section{Social Factors}

Social factors, including the individual's marital status, social support, and working status have been reported to correlate with better QoL in a number of studies (Blake, Codd, Cassidy, \& O'Meara, 2000; Yildirim, 2006). The QoL framework that forms the basis for both the PORTEL registry and this study included social support, health care coverage and financial resources.

Social Support. Social support data collected through the PORTEL survey included the individual's living situation and the assistance that was available to them. Most surveys reported that the transplant recipient lived with their spouse or a significant other, with percentages ranging from $64.4 \%$ to $71.1 \%$. More people reported living alone at greater than 36 months following transplantation (18.3\%) than in the earlier time brackets (Table 3.8).

Social support in the form of available assistance ranged from "no available assistance" to "more people available to help than I can count". Very few surveys reported that the individual had no available assistance. Most survey reported that they had people available to assist them when needed (Table 3.9). Assistance was not defined.

Health Care Coverage. Health care coverage was reported by the majority of participants. Medicare was most frequently reported with 621 surveys indicating Medicare coverage. Medicaid enrollment was reported on only 92 surveys. Private insurance was reported by 578 individuals. Both private and public health care coverage was reported by 321 individuals. Table 3.10 reports health care coverage by time bracket since transplantation.

Employment, Income, Education. Employment has been shown to correlate with better QoL (Neipp et al., 2006). The working status of the individual was reported on only 440 of the 943 surveys. Of that number, 203 (46.1\%) across all time brackets reported that they were working full-time or part time. Examination of all time brackets 
Table 3.7. Immunosuppressant Agent by Time Since Transplantation.

Time Since Transplantation

\begin{tabular}{lcccc}
\cline { 2 - 4 } $\begin{array}{l}\text { Immunosuppressant } \\
\text { Agent }\end{array}$ & $\begin{array}{c}<4 \text { months } \\
\mathrm{n}=214\end{array}$ & $\begin{array}{c}4-18 \text { months } \\
\mathrm{n}=213\end{array}$ & $\begin{array}{c}19-36 \text { months } \\
\mathrm{n}=199\end{array}$ & $\begin{array}{c}>36 \text { months } \\
\mathrm{n}=136\end{array}$ \\
\hline \multirow{3}{*}{ Prednisone } & 155 & 151 & 139 & 115 \\
& $72.4 \%$ & $70.9 \%$ & $69.8 \%$ & $85.2 \%$ \\
Imuran & 2 & 4 & 4 & 14 \\
& $.9 \%$ & $1.9 \%$ & $2.0 \%$ & $10.4 \%$
\end{tabular}

Calcineurin

Inhibitors:

\begin{tabular}{|c|c|c|c|c|}
\hline Prograf & $\begin{array}{c}110 \\
51.4 \%\end{array}$ & $\begin{array}{c}109 \\
51.2 \%\end{array}$ & $\begin{array}{c}101 \\
50.8 \%\end{array}$ & $\begin{array}{c}59 \\
43.7 \%\end{array}$ \\
\hline Neoral & $\begin{array}{c}71 \\
33.2 \%\end{array}$ & $\begin{array}{c}79 \\
37.1 \%\end{array}$ & $\begin{array}{c}55 \\
27.6 \%\end{array}$ & $\begin{array}{c}45 \\
33.6 \%\end{array}$ \\
\hline $\begin{array}{l}\text { Generic } \\
\text { Cyclosporine }\end{array}$ & $\begin{array}{c}6 \\
2.8 \%\end{array}$ & $\begin{array}{c}11 \\
5.2 \%\end{array}$ & $\begin{array}{c}20 \\
10.1 \%\end{array}$ & $\begin{array}{c}17 \\
12.7 \%\end{array}$ \\
\hline $\begin{array}{l}\text { ycophenolate } \\
\text { ofetil (Cellcept) }\end{array}$ & $\begin{array}{c}159 \\
74.3 \%\end{array}$ & $\begin{array}{c}162 \\
76.1 \%\end{array}$ & $\begin{array}{c}135 \\
67.8 \%\end{array}$ & $\begin{array}{c}83 \\
61.9 \%\end{array}$ \\
\hline pamune & $\begin{array}{c}28 \\
13.1 \%\end{array}$ & $\begin{array}{c}34 \\
16.0 \%\end{array}$ & $\begin{array}{c}35 \\
17.6 \%\end{array}$ & $\begin{array}{c}12 \\
9.0 \%\end{array}$ \\
\hline her & $\begin{array}{c}16 \\
7.5 \%\end{array}$ & $\begin{array}{c}13 \\
6.1 \%\end{array}$ & $\begin{array}{c}13 \\
6.5 \%\end{array}$ & $\begin{array}{c}8 \\
6.0 \%\end{array}$ \\
\hline
\end{tabular}


Table 3.8. Living Situation by Time Bracket Since Transplantation.

Time Since Transplantation

\begin{tabular}{lcccc}
\cline { 2 - 4 } Living Situation & $\begin{array}{c}<\text { months } \\
\mathrm{n}=236\end{array}$ & $\begin{array}{c}4-18 \text { months } \\
\mathrm{n}=253\end{array}$ & $\begin{array}{c}19-36 \text { months } \\
\mathrm{n}=225\end{array}$ & $\begin{array}{c}>36 \text { months } \\
\mathrm{n}=229\end{array}$ \\
\hline $\begin{array}{l}\text { Living with spouse } \\
\text { or significant other }\end{array}$ & 152 & 175 & 160 & 149 \\
& $64.4 \%$ & $69.2 \%$ & $71.1 \%$ & $65.1 \%$ \\
Single, living with & 51 & & & \\
family or friends & $21.6 \%$ & $15.4 \%$ & $13.8 \%$ & 31 \\
& & & & $13.5 \%$ \\
Single, living alone & 26 & 31 & 27 & 42 \\
& $11 \%$ & $12.3 \%$ & $12 \%$ & $18.3 \%$ \\
Widowed & 4 & 4 & 5 & 3 \\
& $1.7 \%$ & $1.6 \%$ & $2.2 \%$ & $1.3 \%$ \\
Unknown & 3 & 4 & 2 & 4 \\
& $1.3 \%$ & $1.6 \%$ & $.9 \%$ & $1.8 \%$ \\
\hline
\end{tabular}


Table 3.9. Available Assistance by Time Since Transplantation.

Time Since Transplantation

\begin{tabular}{|c|c|c|c|c|}
\hline $\begin{array}{l}\text { Available } \\
\text { Assistance }\end{array}$ & $\begin{array}{c}<4 \text { months } \\
n=236\end{array}$ & $\begin{array}{l}\begin{array}{l}\text { 4-18 months } \\
n=253\end{array} \\
\end{array}$ & $\begin{array}{c}19-36 \text { months } \\
n=225\end{array}$ & $\begin{array}{c}>36 \text { months } \\
\mathrm{n}=229\end{array}$ \\
\hline $\begin{array}{l}\text { More people } \\
\text { available than I } \\
\text { can count }\end{array}$ & $\begin{array}{c}32 \\
13.6 \%\end{array}$ & $\begin{array}{c}44 \\
17.4 \%\end{array}$ & $\begin{array}{c}49 \\
21.8 \%\end{array}$ & $\begin{array}{c}27 \\
11.9 \%\end{array}$ \\
\hline $\begin{array}{l}\text { Several friends and } \\
\text { family available }\end{array}$ & $\begin{array}{c}116 \\
49.2 \%\end{array}$ & $\begin{array}{c}92 \\
36.4 \%\end{array}$ & $\begin{array}{c}59 \\
26.2 \%\end{array}$ & $\begin{array}{c}85 \\
37.4 \%\end{array}$ \\
\hline $\begin{array}{l}\text { Just a few friends } \\
\text { and family }\end{array}$ & $\begin{array}{c}78 \\
33.1 \%\end{array}$ & $\begin{array}{c}105 \\
41.5 \%\end{array}$ & $\begin{array}{c}100 \\
44.4 \%\end{array}$ & $\begin{array}{c}95 \\
41.5 \%\end{array}$ \\
\hline $\begin{array}{l}\text { No available to } \\
\text { help }\end{array}$ & $\begin{array}{c}5 \\
2.1 \%\end{array}$ & $\begin{array}{c}6 \\
2.4 \%\end{array}$ & $\begin{array}{c}8 \\
3.6 \%\end{array}$ & $\begin{array}{c}15 \\
6.6 \%\end{array}$ \\
\hline Unknown & $\begin{array}{c}5 \\
2.1 \%\end{array}$ & $\begin{array}{c}6 \\
2.4 \%\end{array}$ & $\begin{array}{c}9 \\
4.0 \%\end{array}$ & $\begin{array}{c}7 \\
3.1 \%\end{array}$ \\
\hline
\end{tabular}


Table 3.10. Health Care Coverage by Time Since Transplantation.

\begin{tabular}{lcccc}
\hline & \multicolumn{4}{c}{ Time Since Transplantation } \\
\cline { 2 - 5 } $\begin{array}{l}\text { Health Care } \\
\text { Coverage }\end{array}$ & $\begin{array}{c}\text { < months } \\
\mathrm{n}=236\end{array}$ & $\begin{array}{c}4-18 \text { months } \\
\mathrm{n}=253\end{array}$ & $\begin{array}{c}19-36 \text { months } \\
\mathrm{n}=225\end{array}$ & $\begin{array}{c}>36 \text { months } \\
\mathrm{n}=229\end{array}$ \\
\hline Medicare & 170 & 185 & 165 & 101 \\
& $72 \%$ & $73.1 \%$ & $73.3 \%$ & $44.1 \%$ \\
Medicaid & 50 & 15 & 15 & 12 \\
& $21.2 \%$ & $6 \%$ & $7 \%$ & $5 \%$ \\
Private Insurance & 134 & 147 & 148 & 149 \\
& $56.8 \%$ & $58.1 \%$ & $65.8 \%$ & $65.1 \%$ \\
\hline
\end{tabular}


revealed that $153(34.7 \%)$ surveys reported that the respondent was not working; 139 $(31.6 \%)$ due to their disease and $14(3 \%)$ by choice. The number employed in each time brackets is reported in Table 3.11 .

The annual income and education level of the participants in the sample is reported in Tables 3.12 and 3.13. Reported income ranged from less than $\$ 10,000$ to greater than $\$ 151,000$. The source of income was not indicated. Education ranged from less than eighth grade to post graduate or professional school. The most frequent response in all time brackets was some college or technical school.

\section{Analytical Plan}

The study progressed in two phases guided by the research question and study aim. Phase 1 addressed the research question and identified how the study sample differed on QoL outcomes based on gender and race, at four separate time brackets posttransplantation. Phase 2 of the study focused on the study aim which involved generating time-related centile ranges to be used in clinical practice to monitor and evaluate kidney transplant recipients.

\section{Research Question}

The QoL outcome measures for each racial and gender specific demographic group were compared at each time following transplantation in order to determine if the scores on each QoL outcome by racial and gender specific demographic group were homogenous enough to include all groups in a single centile range. Descriptive statistics for the QoL outcomes SF-12, MCS and PCS scores, and Memphis Survey Frequency and Severity scores of each group were completed including the mean, median, range, standard deviation and tests for normality at each time point post transplantation. The QoL outcome scores for each group at each time bracket were not normally distributed. In addition, the number of scores in the African American population was fewer than that required for the Central Limit Theorem to apply $(n=30)$ for the use of parametric statistics. Therefore, a nonparametric statistical procedure, the Kruskal-Wallis test was used to evaluate differences between gender and racial groups for the QoL outcome scores at each time bracket post transplantation.

\section{Study Aim: Construction of Centile Ranges}

Time-related centile ranges were constructed by using SPSS 15 to identify the 5th, 25th, 50th, 75th, and 95th percentiles for each QoL outcome at each time point. These percentiles were plotted for each QoL outcome at each time bracket following transplantation. 
Table 3.11. Employment Status by Time Since Transplantation.

Time Since Transplantation

\begin{tabular}{|c|c|c|c|c|}
\hline $\begin{array}{l}\text { Employment } \\
\text { Status }\end{array}$ & $\begin{array}{c}<4 \text { months } \\
\mathrm{n}=142 *\end{array}$ & $\begin{array}{l}\text { 4-18 months } \\
\mathrm{n}=125\end{array}$ & $\begin{array}{c}\text { 19-36 months } \\
\mathrm{n}=94\end{array}$ & $\begin{array}{c}>36 \text { months } \\
n=79\end{array}$ \\
\hline Working full time & $\begin{array}{c}30 \\
21.1 \%\end{array}$ & $\begin{array}{c}47 \\
37.6 \%\end{array}$ & $\begin{array}{c}47 \\
50 \%\end{array}$ & $\begin{array}{c}38 \\
48.1 \%\end{array}$ \\
\hline $\begin{array}{l}\text { Working part time } \\
\text { by choice }\end{array}$ & $\begin{array}{l}5 \\
3.5 \%\end{array}$ & $\begin{array}{l}10 \\
8 \%\end{array}$ & $\begin{array}{c}3 \\
3.2 \%\end{array}$ & $\begin{array}{c}3 \\
3.8 \%\end{array}$ \\
\hline $\begin{array}{l}\text { Working part time } \\
\text { due to disease }\end{array}$ & $\begin{array}{c}8 \\
5.6 \%\end{array}$ & $\begin{array}{c}7 \\
5.6 \%\end{array}$ & $\begin{array}{c}1 \\
1.1 \%\end{array}$ & $\begin{array}{c}4 \\
5.1 \%\end{array}$ \\
\hline $\begin{array}{l}\text { Not working by } \\
\text { choice }\end{array}$ & $\begin{array}{c}3 \\
2.1 \%\end{array}$ & $\begin{array}{c}3 \\
2.4 \%\end{array}$ & $\begin{array}{c}4 \\
4.3 \%\end{array}$ & $\begin{array}{c}4 \\
5.1 \%\end{array}$ \\
\hline $\begin{array}{l}\text { Not working due } \\
\text { to disease }\end{array}$ & $\begin{array}{c}68 \\
47.9 \%\end{array}$ & $\begin{array}{c}31 \\
24.8 \%\end{array}$ & $\begin{array}{c}21 \\
22.3 \%\end{array}$ & $\begin{array}{c}19 \\
24.1 \%\end{array}$ \\
\hline $\begin{array}{l}\text { Not working, } \\
\text { unable to find } \\
\text { employment }\end{array}$ & $\begin{array}{c}5 \\
3.5 \%\end{array}$ & $\begin{array}{c}7 \\
5.6 \%\end{array}$ & $\begin{array}{c}5 \\
5.3 \%\end{array}$ & $\begin{array}{l}5 \\
6.3 \%\end{array}$ \\
\hline Retired & $\begin{array}{c}23 \\
16.2 \%\end{array}$ & $\begin{array}{c}20 \\
16 \%\end{array}$ & $\begin{array}{c}13 \\
13.8 \%\end{array}$ & $\begin{array}{c}6 \\
7.6 \%\end{array}$ \\
\hline
\end{tabular}

$* \mathrm{n}=$ number reporting employment status 
Table 3.12. Annual Income by Time Since Transplantation.

Time Since Transplantation

\begin{tabular}{|c|c|c|c|c|}
\hline Annual Income & $\begin{array}{c}<4 \text { months } \\
n=236\end{array}$ & $\begin{array}{c}4-18 \text { months } \\
n=253\end{array}$ & $\begin{array}{c}19-36 \text { months } \\
n=225\end{array}$ & $\begin{array}{c}>36 \text { months } \\
n=229\end{array}$ \\
\hline$<\$ 10,000$ & $\begin{array}{c}37 \\
16.7 \%\end{array}$ & $\begin{array}{c}27 \\
11.5 \%\end{array}$ & $\begin{array}{c}21 \\
10.4 \%\end{array}$ & $\begin{array}{c}23 \\
10.6 \%\end{array}$ \\
\hline$\$ 11,000-\$ 25,000$ & $\begin{array}{c}37 \\
16.7 \%\end{array}$ & $\begin{array}{c}47 \\
20.1 \%\end{array}$ & $\begin{array}{c}34 \\
16.8 \%\end{array}$ & $\begin{array}{c}30 \\
13.8 \%\end{array}$ \\
\hline$\$ 26,000-\$ 50,000$ & $\begin{array}{c}49 \\
22.1 \%\end{array}$ & $\begin{array}{c}67 \\
28.6 \%\end{array}$ & $\begin{array}{c}61 \\
30.2 \%\end{array}$ & $\begin{array}{c}64 \\
29.8 \%\end{array}$ \\
\hline$\$ 51,000-\$ 75,000$ & $\begin{array}{c}34 \\
15.3 \%\end{array}$ & $\begin{array}{c}35 \\
15.0 \%\end{array}$ & $\begin{array}{c}39 \\
19.3 \%\end{array}$ & $\begin{array}{c}41 \\
19.1 \%\end{array}$ \\
\hline$\$ 76,000-\$ 150,000$ & $\begin{array}{c}29 \\
13.1 \%\end{array}$ & $\begin{array}{c}25 \\
10.7 \%\end{array}$ & $\begin{array}{c}17 \\
8.4 \%\end{array}$ & $\begin{array}{c}19 \\
8.8 \%\end{array}$ \\
\hline$>\$ 151,000$ & $\begin{array}{c}5 \\
2.3 \%\end{array}$ & $\begin{array}{c}10 \\
4.3 \%\end{array}$ & $\begin{array}{c}9 \\
4.5 \%\end{array}$ & $\begin{array}{c}10 \\
4.7 \%\end{array}$ \\
\hline Unknown & $\begin{array}{c}45 \\
19.2 \%\end{array}$ & $\begin{array}{c}42 \\
16.6 \%\end{array}$ & $\begin{array}{c}44 \\
19.6 \%\end{array}$ & $\begin{array}{c}42 \\
18.3 \%\end{array}$ \\
\hline
\end{tabular}


Table 3.13. Education by Time Since Transplantation.

Time Since Transplantation

\begin{tabular}{|c|c|c|c|c|}
\hline Education & $\begin{array}{c}<4 \text { months } \\
\mathrm{n}=236\end{array}$ & $\begin{array}{c}4-18 \text { months } \\
n=253\end{array}$ & $\begin{array}{c}19-36 \text { months } \\
\mathrm{n}=225\end{array}$ & $\begin{array}{c}>36 \text { months } \\
n=229\end{array}$ \\
\hline $8^{\text {th }}$ grade or less & $\begin{array}{c}5 \\
2.1 \%\end{array}$ & $\begin{array}{c}2 \\
.8 \%\end{array}$ & $\begin{array}{c}1 \\
.4 \%\end{array}$ & $\begin{array}{c}4 \\
1.8 \%\end{array}$ \\
\hline $9^{\text {th }}-12^{\text {th }}$ grade & $\begin{array}{c}17 \\
7.2 \%\end{array}$ & $\begin{array}{c}9 \\
3.6 \%\end{array}$ & $\begin{array}{c}8 \\
3.6 \%\end{array}$ & $\begin{array}{c}6 \\
2.6 \%\end{array}$ \\
\hline High School & $\begin{array}{c}57 \\
24.2 \%\end{array}$ & $\begin{array}{c}63 \\
24.9 \%\end{array}$ & $\begin{array}{c}49 \\
21.8 \%\end{array}$ & $\begin{array}{c}40 \\
17.5 \%\end{array}$ \\
\hline $\begin{array}{l}\text { Some college or } \\
\text { technical school }\end{array}$ & $\begin{array}{c}90 \\
38.1 \%\end{array}$ & $\begin{array}{c}101 \\
39.9 \%\end{array}$ & $\begin{array}{c}91 \\
40.4 \%\end{array}$ & $\begin{array}{c}92 \\
40.5 \%\end{array}$ \\
\hline $\begin{array}{l}\text { 4-year } \\
\text { Baccalaureate } \\
\text { College }\end{array}$ & $\begin{array}{c}43 \\
18.2 \%\end{array}$ & $\begin{array}{c}51 \\
20.2 \%\end{array}$ & $\begin{array}{c}45 \\
20.0 \%\end{array}$ & $\begin{array}{c}52 \\
22.9 \%\end{array}$ \\
\hline Graduate School & $\begin{array}{c}11 \\
4.7 \%\end{array}$ & $\begin{array}{c}14 \\
5.5 \%\end{array}$ & $\begin{array}{c}18 \\
8.0 \%\end{array}$ & $\begin{array}{c}20 \\
8.8 \%\end{array}$ \\
\hline $\begin{array}{l}\text { Postgraduate/ } \\
\text { Professional } \\
\text { School }\end{array}$ & $\begin{array}{c}9 \\
3.8 \%\end{array}$ & $\begin{array}{c}11 \\
4.3 \%\end{array}$ & $\begin{array}{c}10 \\
4.4 \%\end{array}$ & $\begin{array}{c}14 \\
6.2 \%\end{array}$ \\
\hline Unknown & $\begin{array}{c}4 \\
1.7 \%\end{array}$ & $\begin{array}{c}2 \\
.8 \%\end{array}$ & $\begin{array}{c}3 \\
1.3 \%\end{array}$ & $\begin{array}{c}1 \\
.4 \%\end{array}$ \\
\hline
\end{tabular}




\section{CHAPTER 4. RESULTS}

The results and discussion section of this dissertation have been written in manuscript format. As a result supporting material, including descriptive statistics for the Memphis Survey Subscale Scores, the Memphis Survey Total Scores, and the SF-12 scores which are of interest for the purposes of the dissertation but not necessarily for a manuscript have been placed in Appendices A and B. Background material presented in other chapters has been included in this section to provide the information necessary for a manuscript.

\section{Introduction}

Quality of life (QoL) is commonly viewed as an important indicator of successful chronic illness management (Leplege \& Hunt, 1997), particularly for conditions such as renal failure in which transplantation is the preferred therapy primarily because of the associated improvement in QoL (Feibiger, Mitterbauer, \& Oberbauer, 2004). Despite extensive research, routine assessment of QoL has not been widely translated into clinical practice as a means to augment clinical decision making, identify patients who would benefit from interventions, or to educate patients about anticipated QoL outcomes (Higginson \& Carr, 2001). Kidney transplantation is no exception.

Time-related centile ranges have been developed for many clinical outcomes such as growth and bone density, and provide reference ranges that are used to interpret a patient's health status as compared to a normative population, or to monitor disease. Similar reference ranges for QoL outcome data would provide a context for interpreting QoL data for patients and providers in the transplantation setting. The purpose of this study was therefore to create time-related centile ranges from data collected in a national data registry that depict QoL outcomes in such a way that they that could be used as benchmarks in evaluating the QoL of patients following kidney transplantation in the clinical setting.

\section{Background and Significance}

QoL has been described as the difference between the patient's expectation of a situation and their actual experience (Carr, Gibson, \& Robinson, 2001). The patient's assessment of their QoL following kidney transplantation may be shaped by their pretransplantation expectations of what life after transplantation would be like. Patients contemplating transplantation or being followed post transplantation often seek information related to QoL expectations following transplantation and how their QoL compares with other transplant recipients. Benchmarks that reflect QoL following kidney transplantation would provide an additional tool in the clinical armamentarium to augment post transplantation care by providing a context for interpreting QoL measures. 
There are relatively few examples in which QoL measurement has been used to guide clinical decision making for individual patients (Levine \& Ganz, 2002). While there is general agreement that discussion of QoL is beneficial, few studies have demonstrated that measuring QoL outcomes actually changes clinical decision making or patient outcomes (Espallargues, Valderas, \& Alonso, 2000; Greenhalgh, Long, \& Flynn, 2005). However, even in studies that do not demonstrate changes in clinical or QoL outcomes, measuring QoL in routine practice has been demonstrated to increase communication between patients and providers about QoL indicators (Detmar, Muller, Schornagel, Wever, \& Aaronson, 2002). Measuring QoL in oncology practice, and providing feedback to patients, has led to increased discussion of nonspecific symptoms and better QoL and emotional functioning without prolonging the duration of patient encounters (Velikova et al., 2004). Although most studies using QoL instruments did not demonstrate changes in clinical decision making or QoL outcomes, the process of increasing communication seems to have benefit in patient care. Higginson \& Carr (2001) cite several potential uses for QoL measures in the clinical setting directly related to clinical care including prioritizing problems, facilitating communication, screening for potential problems, identifying preferences of patients and monitoring changes or responses to treatments. While QoL measures do not substitute for physiologic evaluation of disease, they capture the personal and social context of the patient for a more holistic approach to patient assessment.

\section{Time-Related Centile Ranges}

Reference ranges, often referred to as normal ranges, have long been used in health care to evaluate the health status of individual patients on some specific parameter by comparing them to an standard established from a "normal" population (Wright \& Royston, 1997). The range of normal for a given variable is typically defined as the range of values for that variable that fall between the $2.5^{\text {th }}$ and the $97.5^{\text {th }}$ percentile in the population of interest (Griffiths, Iles, Koduah, \& Nix, 2004). The assumption is made that the reference population in which the variable is measured is a healthy population representative of "normal" or "healthy" individuals, thus the term normal range. The variables that are reported in a reference range are often affected by other characteristics of the representative population (Wright \& Royston, 1997). When the variable in question is strongly dependent on a covariate such as time, a simple reference range is inadequate for evaluation (Cole \& Green, 1992). A common example of a reference range established to follow change in a variable over time is the series of ranges that have been established to monitor growth rates in childhood. Growth charts are routinely used by health care providers to evaluate the growth of children over time, to identify those children who are not growing at the anticipated rate, or whose height or weight is outside of the desired range. The time-related centile ranges for QoL outcomes of kidney transplant recipients proposed in this study could be used in a similar manner to follow QoL outcomes over time as well as a evaluating QoL at a particular point in time. 
Methods

PORTEL Registry

Data for the creation of time-related centile ranges in this study was extracted from the Patient Outcomes Registry for Transplant Effects on Life (PORTEL), a national data registry, established in 2000 by Fujisawa Pharmaceuticals, and later supported by Astellas Pharmaceuticals, in response to increasing concern regarding the QoL of transplant recipients. The registry was designed to collect longitudinal data on QoL outcomes following solid organ transplantation and incorporated a systematic approach to the assessment of QoL experienced by solid organ transplant recipients. The intent of the registry was to provide a resource for QoL data that could serve as a benchmark for assessing QoL in solid organ transplantation leading to the development of strategies to improve QoL (Hathaway et al., 2003b). With this goal, the PORTEL survey design was based on a multidimensional QoL framework that included five interrelated domains; health and social factors, major life and health events and QoL. Health factors are those issues that individuals deal with on a daily basis that influence QoL such as the effects of immunosuppressant drugs and co-morbidities that require daily attention and therefore influence QoL. Social factors include situations and events that define an individual's social environment and include the financial resources available to the individual, health care coverage, and the social support that the transplant recipient has (Hathaway et al., 2003b). Major life and health events are more episodic in nature but may be more disruptive to the established routine of the individual or the family (Hathaway et al, 2003b). Major health events include rejection episodes, hospitalizations, or a new diagnosis. A major life event as defined in the PORTEL framework may be a divorce, death in the family, or loss of a job. Health and social factors and major life and health events influence, and are influenced by, the QoL that an individual is experiencing. The PORTEL survey instrument was a 100 item survey developed to assess the five domains included in the PORTEL framework.

The PORTEL registry was a stand alone patient-driven and patient-centered registry with data collected for the sole purpose of assessing QoL. The participants in the registry represent transplant recipients recruited from multiple institutions and through multiple venues across the United States. Recruitment to the registry was both patientcentric and site-centric. Patient-centric recruitment was achieved through contact with transplant recipients at national transplantation meetings, community events, support groups, and direct mail. Site-centric recruitment was accomplished through four transplantation centers representing different regions of the United States; Unversity of Southern California, University of Alabama, Birmingham, University of Tennessee Health Science Center, and University of Minnesota. Transplantation centers participating in data collection received IRB approval from their institution prior to enrollment of subjects (Hathaway, Winsett, Prendergast, \& Subaiya, 2003). The PORTEL database represented a more diverse sample of the population of transplant recipients than a sample drawn from a single institution and, as such, was appropriate for creation of time-related centile ranges for use in a variety of settings. 
It has been recommended that evaluation of QoL should include a generic QoL instrument and a disease specific instrument (Hathaway, Winsett, et al., 2003). The 12Item Short Form-Health Survey (SF-12) was chosen by the designers of the PORTEL survey as the generic instrument and the Memphis Survey as the disease specific instrument. The SF-12 has been used to document QoL in the general population as well as in the evaluation of QoL of patients with a variety of chronic conditions. Comprised of a subset of 12 items derived from the 36-Item Short-Form Health Survey (SF-36), the gold standard for assessment of QoL, the SF-12 was developed to provide an alternative instrument that would be shorter, easier to administer and yet provide the same reliability as the longer SF-36 (Ware, Kosinski, \& Keller, 1996). The SF-12 has been correlated with the SF-36 in assessing QoL of trauma patients, individuals with cervical spondylosis, and persons infected with HIV (Delate \& Coons, 2000; Kiely, Brasel, Guse, \& Weigelt, 2006; Singh, Gnanalingham, Casey, \& Crockard, 2006). The SF-12 is composed of two domains, the Mental Component Summary and Physical Component Summary. Each Summary is scored on a 0-100 scale with higher scores indicating better QoL.

The Memphis Survey was included in the PORTEL survey to document side effects of immunosuppressant medications. The survey was developed in 1997 by a group of researchers at University of Tennessee Health Science Center. The instrument was designed to evaluate the frequency and severity of side-effects of immunosuppressant regimens on QoL in transplant recipients (Hathaway, Winsett, et al., 2003). A multi-stage factor analysis was utilized to identify those side effects experienced by patients on a variety of immunosuppressant regimens (Winsett et al., 2004). The subscales included in the Memphis survey are emotional burden, life/role responsibilities, mobility, gastrointestinal distress, and miscellaneous side-effects which include items related to enlarged gums, increased hunger, sleeping, weight gain, increased hair growth, infections, trembling hands, high blood pressure, easy bruising, loss of interest in sex, and sexual performance (Hathaway, Winsett, et al., 2003).

Symptoms are assessed for frequency of occurrence and the severity of the side effect and coded on a 0-4 scale. Total scores are tabulated from the subscale scores for frequency of occurrence and for severity of the symptom to provide an overall estimate of the side effect profile and degree of distress. Memphis Survey total scores range from 0-160, the higher number indicating a worse side-effect profile (Hathaway, Winsett, et al., 2003). Reliability and validity of the Memphis Survey has been demonstrated by Winsett, et al. (2004) in a national survey of 505 kidney transplant recipients.

\section{Data Extraction}

Data for this study were extracted from the PORTEL Registry database. The total PORTEL database includes 7,327 surveys completed by 1,434 recipients of any solid organ transplantation. Inclusion criteria for the current study were Caucasian and African American PORTEL registry participants between the ages of 18 and 65 who had undergone one kidney transplantation and were greater than 14 days from transplant surgery when the survey was completed. Initial data extraction identified 3,144 surveys 
completed by 681 individuals who had undergone a single kidney transplantation. PORTEL data were collected longitudinally over a five year period, as a result, individual transplant recipients contributed multiple surveys to the registry.

Four separate time brackets between the transplantation surgery and completion of the survey were established for construction of time-related centile ranges: less than 4 months from transplantation, 4 months to 18 months, 19 months to 36 months, and greater that 36 months from transplantation. The identified time brackets allowed for even distribution of the surveys and were consistent with times typically used for clinical follow-up and in post-transplantation studies. Only one survey from each individual was included in each time block for which time-related centile ranges were established. The first survey completed by an individual within each time bracket was selected for inclusion leaving 943 surveys completed by 515 recipients; 246 individuals were represented in only one time bracket, 128 individuals contributed a survey to two time brackets, 123 contributed a survey to three time brackets, and 18 transplant recipients contributed a survey to all 4 time brackets.

\section{Sample}

Of the 943 surveys included in the study, $484(51.3 \%)$ were men and 459 were (48.7\%) women. Seven hundred fifty one $(79.6 \%)$ surveys were completed by Caucasians and 192 (20.4\%) by African Americans. The average age at survey completion was 46 years with a standard deviation of 11.3 years. The gender and racial distribution of the sample in this study was compared to the data from the United Network for Organ Sharing (UNOS) data and is reported in Table 3.1.

\section{Data Analysis}

The Qol outcome scores for each group at each time bracket were not normally distributed. In addition, the number of scores in the African American population was fewer than that required for the Central Limit Theorem to apply $(n=30)$ for the use of parametric statistics. Therefore, a nonparametric statistical procedure, the Kruskal-Wallis test was used to evaluate the differences between gender and racial groups for the QoL outcome scores at each time bracket post transplantation. A p-value of.05 was set for statistical significance.

\section{Differences in SF-12 Scores by Racial and Gender Groups}

No differences were found between MCS mean ranks for the demographic groups at any of the four time brackets (Table 4.1). Similarly, no differences were found between the mean ranked PCS scores at less than 4 months, 4 months to 18 months or greater than 36 months. However, a significant difference between the mean ranked PCS scores was seen at 19 months to 36 months post transplantation $(\mathrm{p}=.047)$, where the mean 
Table 4.1. Kruskal-Wallis Ranks and Test Statistics for Differences in MCS Scores between Demographic Groups at $<4$ Months, 4-18 Months, 19-36 Months and >36 Months Post-Transplantation.

\begin{tabular}{|c|c|c|c|c|c|c|c|c|}
\hline \multirow[b]{2}{*}{$\begin{array}{l}\text { Racial/Gender } \\
\text { Group }\end{array}$} & \multicolumn{2}{|c|}{$<4$ months } & \multicolumn{2}{|c|}{ 4-18 months } & \multicolumn{2}{|c|}{ 19-36 months } & \multicolumn{2}{|c|}{$>36$ months } \\
\hline & $\mathrm{N}$ & $\begin{array}{l}\text { Mean } \\
\text { Rank }\end{array}$ & $\mathrm{N}$ & $\begin{array}{l}\text { Mean } \\
\text { Rank }\end{array}$ & $\mathrm{N}$ & $\begin{array}{l}\text { Mean } \\
\text { Rank }\end{array}$ & $\mathrm{N}$ & $\begin{array}{l}\text { Mean } \\
\text { Rank }\end{array}$ \\
\hline $\begin{array}{l}\text { Caucasian } \\
\text { Male }\end{array}$ & 94 & 108.64 & 94 & 119.21 & 89 & 98.99 & 90 & 102.41 \\
\hline $\begin{array}{l}\text { Caucasian } \\
\text { Female }\end{array}$ & 66 & 106.32 & 86 & 113.19 & 82 & 108.67 & 83 & 99.64 \\
\hline $\begin{array}{l}\text { African } \\
\text { American } \\
\text { Male }\end{array}$ & 21 & 112.19 & 16 & 90.78 & 14 & 109.71 & 12 & 124.29 \\
\hline \multirow{2}{*}{$\begin{array}{l}\text { African } \\
\text { American } \\
\text { Female }\end{array}$} & 30 & 92.68 & 30 & 108.60 & 22 & 103.23 & 18 & 96.00 \\
\hline & \multicolumn{2}{|c|}{$\begin{array}{c}\chi^{2}=1.821 \\
d f=3 \\
p=.610\end{array}$} & \multicolumn{2}{|c|}{$\begin{array}{c}\chi^{2}=2.820 \\
\mathrm{df}=3 \\
p=.420\end{array}$} & \multicolumn{2}{|c|}{$\begin{array}{c}\chi^{2}=1.253 \\
d f=3 \\
p=.740\end{array}$} & \multicolumn{2}{|c|}{$\begin{array}{c}\chi^{2}=2.054 \\
\mathrm{df}=3 \\
\mathrm{p}=.561\end{array}$} \\
\hline
\end{tabular}


rank of African American women (92.68) was lower than that of Caucasian men (108.64), Caucasian women (106.32), or African American men (112.19) (Table 4. 2). Figures 4.1 and 4.2 illustrate the mean MCS and PCS scores by demographic group. There were minimal differences in the actual mean scores between the groups across the time brackets and although the Kruskal-Wallis Test found a statistical difference in PCS scores, the actual scores are closely grouped.

\section{Differences in Memphis Survey Scores by Racial and Gender Groups}

Memphis Survey Frequency mean rank scores were only found to differ at less than 4 months post transplantation $(\mathrm{p}=.021)$ with African American men reporting better QoL (lower scores) as it relates to the frequency of immunosuppressant side effects (Table 4.3). No differences were found between mean ranks of the Memphis Survey Severity scores (Table 4.4). Bar graphs for the means of both Memphis Survey scores also illustrate, that scores are very closely grouped (Figures 4.3 and 4.4).

\section{Construction of Time-Related Centile Ranges}

The Kruskal-Wallis analyses demonstrated a strong degree of homogeneity among racial and gender specific demographic groups with only 2 of 16 QoL outcome measures found to be significantly different. The two scores that differed were from different instruments (PCS from the SF-12 and Memphis Survey Frequency) and were from different time periods (19 months to 36 months for the PCS and less than 4 months for the Memphis Survey Frequency). Moreover, the variation in the means across the groups was small (PCS at 19 months to 36 months means ranged from 38.15 to 45.99 on a 100 point scale; Memphis Frequency at less than 4 months means ranged from 32.98 to 49.63 on an 160 point scale) leading to the conclusion that negligible clinical differences exist for the QoL outcomes for racial and gender subgroups regardless of the finding that two of the scores differed statistically. Therefore, only one time-related centile range was required to adequately represent the QoL outcomes for this cohort of kidney transplant recipients.

The time-related centile ranges for PCS scores, MCS scores, Memphis Survey Frequency Scores, and Memphis Survey Severity Scores are pictured in Figures 4.5 and 4.6. The design for the time-related centile range enables assessment of QoL of an individual at four separate time brackets following transplantation. Subscales of the SF12 and Memphis Survey are depicted on the same page for ease of use and comparison. Better QoL is indicated by higher scores on the SF-12 but by lower scores on the Memphis Survey; therefore the y-axis of the Memphis Survey centile ranges has been inverted for consistency in visualization of the scores. The darker shading on each bar corresponds to improved QoL scores. 
Table 4.2. Kruskal-Wallis Ranks and Test Statistics for Differences in PCS Scores between Demographic Groups at $<4$ Months, 4-18 Months, 19-36 Months and >36 Months Post-Transplantation.

\begin{tabular}{|c|c|c|c|c|c|c|c|c|}
\hline \multirow[b]{2}{*}{$\begin{array}{l}\text { Racial/Gender } \\
\text { Group }\end{array}$} & \multicolumn{2}{|c|}{$<4$ months } & \multicolumn{2}{|c|}{ 4-18 months } & \multicolumn{2}{|c|}{$19-36$ months } & \multicolumn{2}{|c|}{$>36$ months } \\
\hline & $\mathrm{N}$ & $\begin{array}{l}\text { Mean } \\
\text { Rank }\end{array}$ & $\mathrm{N}$ & $\begin{array}{l}\text { Mean } \\
\text { Rank }\end{array}$ & $\mathrm{N}$ & $\begin{array}{l}\text { Mean } \\
\text { Rank }\end{array}$ & $\mathrm{N}$ & $\begin{array}{l}\text { Mean } \\
\text { Rank }\end{array}$ \\
\hline $\begin{array}{l}\text { Caucasian } \\
\text { Male }\end{array}$ & 94 & 104.44 & 94 & 111.99 & 89 & 106.72 & 90 & 102.03 \\
\hline $\begin{array}{l}\text { Caucasian } \\
\text { Female }\end{array}$ & 66 & 104.97 & 86 & 124.48 & 82 & 111.74 & 83 & 105.57 \\
\hline $\begin{array}{l}\text { African } \\
\text { American } \\
\text { Male }\end{array}$ & 21 & 121.67 & 16 & 92.72 & 14 & 87.93 & 12 & 119.96 \\
\hline \multirow[t]{2}{*}{$\begin{array}{l}\text { African } \\
\text { American } \\
\text { Female }\end{array}$} & 30 & 102.18 & 30 & 97.83 & 22 & 74.36 & 18 & 73.42 \\
\hline & \multicolumn{2}{|c|}{$\begin{array}{c}\chi^{2}=1.580 \\
d f=3 \\
p=.664\end{array}$} & \multicolumn{2}{|c|}{$\begin{array}{c}\chi^{2}=5.815 \\
\mathrm{df}=3 \\
\mathrm{p}=.121\end{array}$} & \multicolumn{2}{|c|}{$\begin{array}{c}\chi^{2}=7.948 \\
d f=3 \\
p=.047\end{array}$} & \multicolumn{2}{|c|}{$\begin{array}{c}\chi^{2}=5.689 \\
\mathrm{df}=3 \\
\mathrm{p}=.128\end{array}$} \\
\hline
\end{tabular}




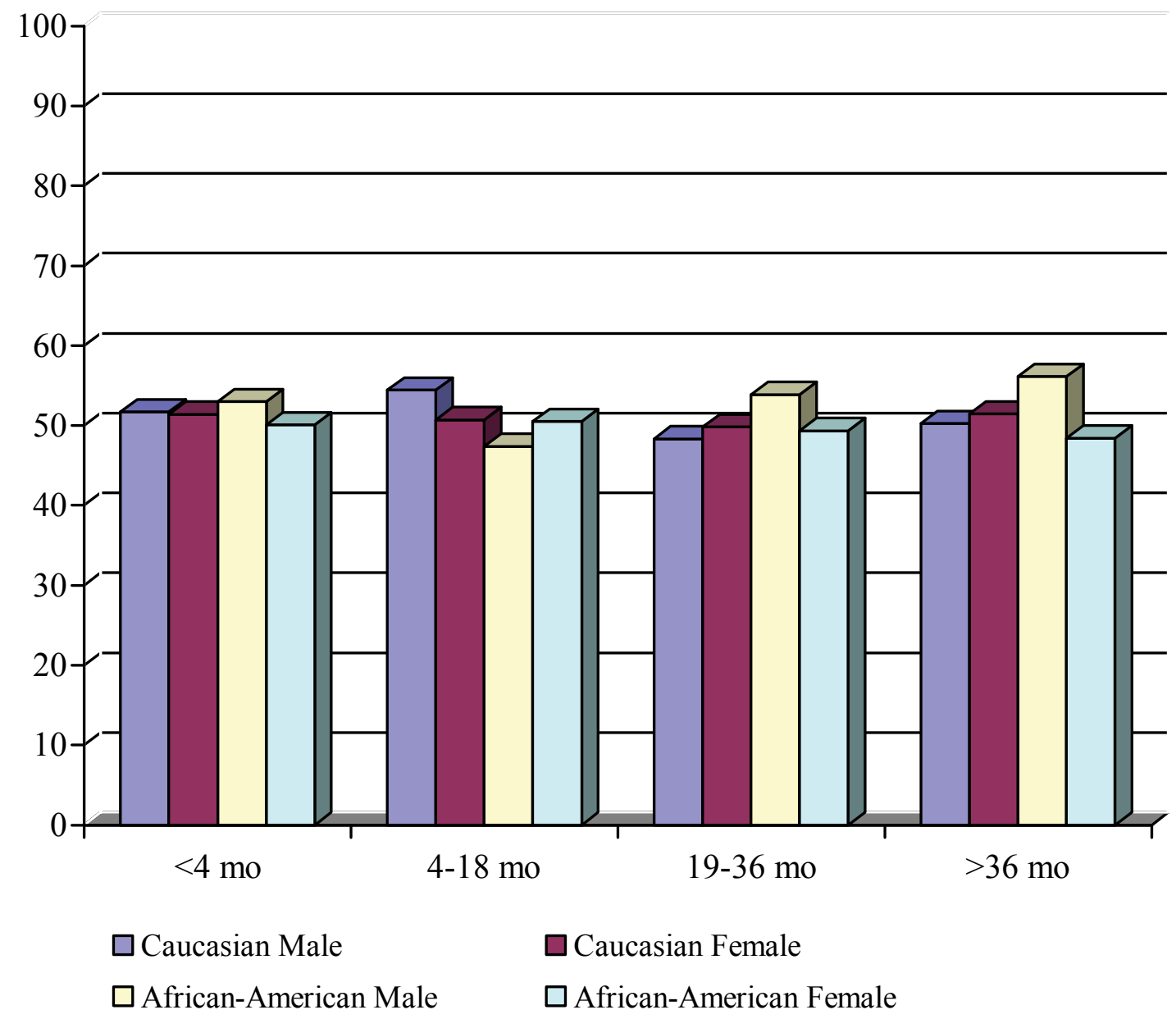

Figure 4.1. Mean MCS Scores for Demographic Groups by Time Since Transplantation. 


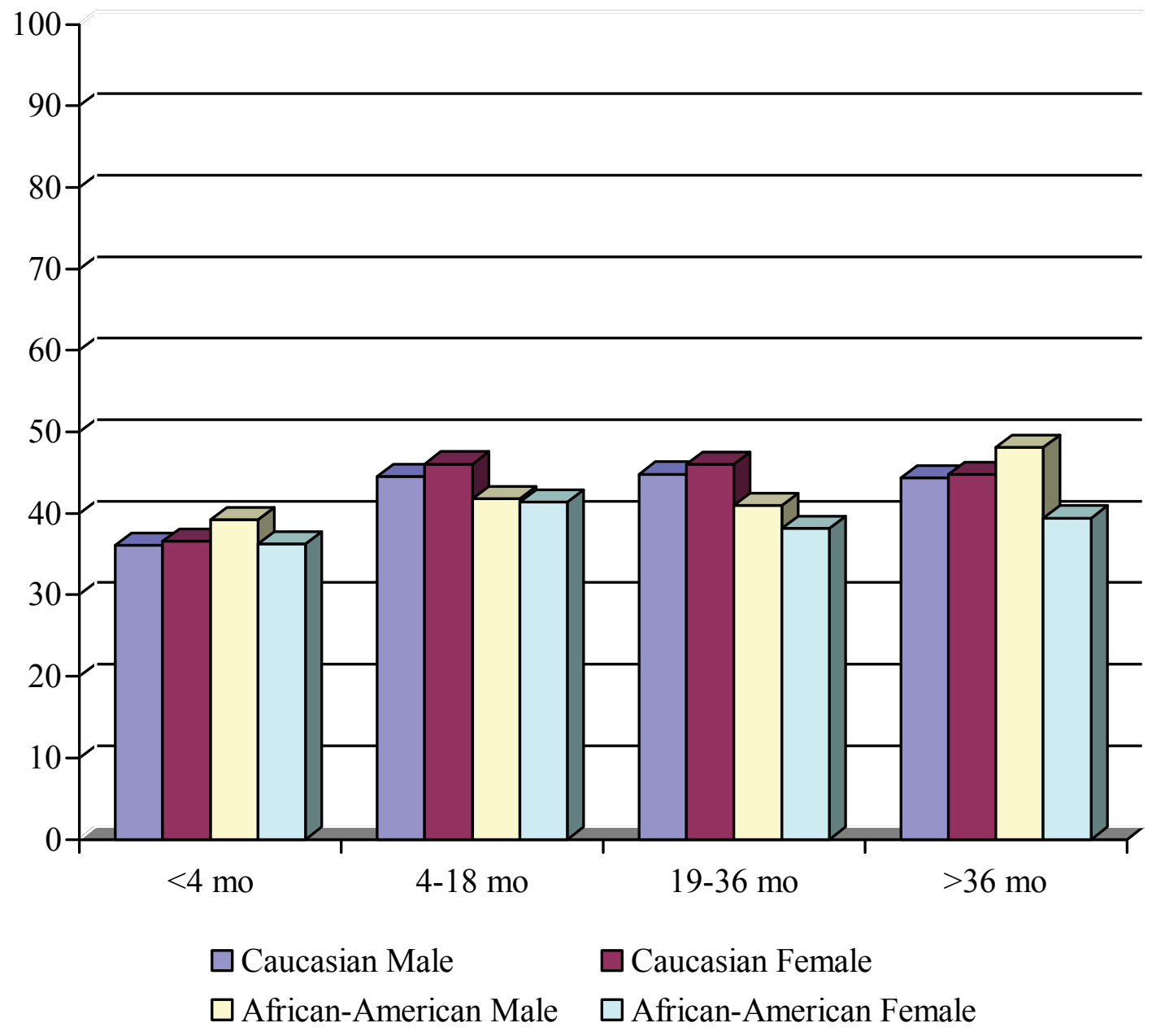

Figure 4.2. Mean PCS Scores for Demographic Groups by Time Since Transplantation. 
Table 4.3. Kruskal-Wallis Ranks and Test Statistics for Differences in Memphis Survey Frequency Scores between Demographic Groups at $<4$ Months, 4-18 Months, 19-36 Months and $>36$ Months Post-Transplantation.

\begin{tabular}{|c|c|c|c|c|c|c|c|c|}
\hline \multirow[b]{2}{*}{$\begin{array}{l}\text { Racial/Gender } \\
\text { Group }\end{array}$} & \multicolumn{2}{|c|}{$<4$ months } & \multicolumn{2}{|c|}{ 4-18 months } & \multicolumn{2}{|c|}{$19-36$ months } & \multicolumn{2}{|c|}{$>36$ months } \\
\hline & $\mathrm{N}$ & $\begin{array}{l}\text { Mean } \\
\text { Rank }\end{array}$ & $\mathrm{N}$ & $\begin{array}{l}\text { Mean } \\
\text { Rank }\end{array}$ & $\mathrm{N}$ & $\begin{array}{l}\text { Mean } \\
\text { Rank }\end{array}$ & $\mathrm{N}$ & $\begin{array}{l}\text { Mean } \\
\text { Rank }\end{array}$ \\
\hline $\begin{array}{l}\text { Caucasian } \\
\text { Male }\end{array}$ & 75 & 89.66 & 78 & 96.26 & 70 & 82.53 & 93 & 104.10 \\
\hline $\begin{array}{l}\text { Caucasian } \\
\text { Female }\end{array}$ & 49 & 107.37 & 65 & 98.40 & 65 & 90.35 & 88 & 113.09 \\
\hline $\begin{array}{l}\text { African } \\
\text { American } \\
\text { Male }\end{array}$ & 27 & 68.85 & 19 & 95.11 & 16 & 83.88 & 15 & 70.73 \\
\hline \multirow{2}{*}{$\begin{array}{l}\text { African } \\
\text { American } \\
\text { Female }\end{array}$} & 34 & 98.84 & 33 & 102.98 & 22 & 93.59 & 16 & 117.75 \\
\hline & \multicolumn{2}{|c|}{$\begin{array}{c}\chi^{2}=9.714 \\
d f=3 \\
p=.021\end{array}$} & \multicolumn{2}{|c|}{$\begin{array}{c}\chi^{2}=.385 \\
d f=3 \\
p=.943\end{array}$} & \multicolumn{2}{|c|}{$\begin{array}{c}\chi^{2}=1.293 \\
\mathrm{df}=3 \\
\mathrm{p}=.731\end{array}$} & \multicolumn{2}{|c|}{$\begin{array}{c}\chi^{2}=6.796 \\
d f=3 \\
p=.079\end{array}$} \\
\hline
\end{tabular}


Table 4.4. Kruskal-Wallis Ranks and Test Statistics for Differences in Memphis Survey Severity Scores between Demographic Groups at $<4$ Months, 4-18 Months, 19-36 Months and $>36$ Months Post-Transplantation.

\begin{tabular}{|c|c|c|c|c|c|c|c|c|}
\hline \multirow[b]{2}{*}{$\begin{array}{l}\text { Racial/Gender } \\
\text { Group }\end{array}$} & \multicolumn{2}{|c|}{$<4$ months } & \multicolumn{2}{|c|}{ 4-18 months } & \multicolumn{2}{|c|}{ 19-36 months } & \multicolumn{2}{|c|}{$>36$ months } \\
\hline & $\mathrm{N}$ & $\begin{array}{l}\text { Mean } \\
\text { Rank }\end{array}$ & $\mathrm{N}$ & $\begin{array}{l}\text { Mean } \\
\text { Rank }\end{array}$ & $\mathrm{N}$ & $\begin{array}{l}\text { Mean } \\
\text { Rank }\end{array}$ & $\mathrm{N}$ & $\begin{array}{l}\text { Mean } \\
\text { Rank }\end{array}$ \\
\hline $\begin{array}{l}\text { Caucasian } \\
\text { Male }\end{array}$ & 71 & 82.68 & 77 & 97.49 & 65 & 79.75 & 90 & 98.82 \\
\hline $\begin{array}{l}\text { Caucasian } \\
\text { Female }\end{array}$ & 46 & 97.78 & 64 & 97.88 & 63 & 86.28 & 88 & 113.65 \\
\hline $\begin{array}{l}\text { African } \\
\text { American } \\
\text { Male }\end{array}$ & 24 & 66.42 & 19 & 83.13 & 16 & 79.00 & 15 & 74.57 \\
\hline \multirow{2}{*}{$\begin{array}{l}\text { African } \\
\text { American } \\
\text { Female }\end{array}$} & 29 & 88.72 & 32 & 99.28 & 20 & 82.35 & 13 & 100.62 \\
\hline & \multicolumn{2}{|c|}{$\begin{array}{c}\chi^{2}=6.831 \\
d f=3 \\
p=.077\end{array}$} & \multicolumn{2}{|c|}{$\begin{array}{c}\chi^{2}=1.244 \\
d f=3 \\
p=.742\end{array}$} & \multicolumn{2}{|c|}{$\begin{array}{c}\chi^{2}=.704 \\
d f=3 \\
p=.872\end{array}$} & \multicolumn{2}{|c|}{$\begin{array}{c}\chi^{2}=6.670 \\
\mathrm{df}=3 \\
\mathrm{p}=.083\end{array}$} \\
\hline
\end{tabular}




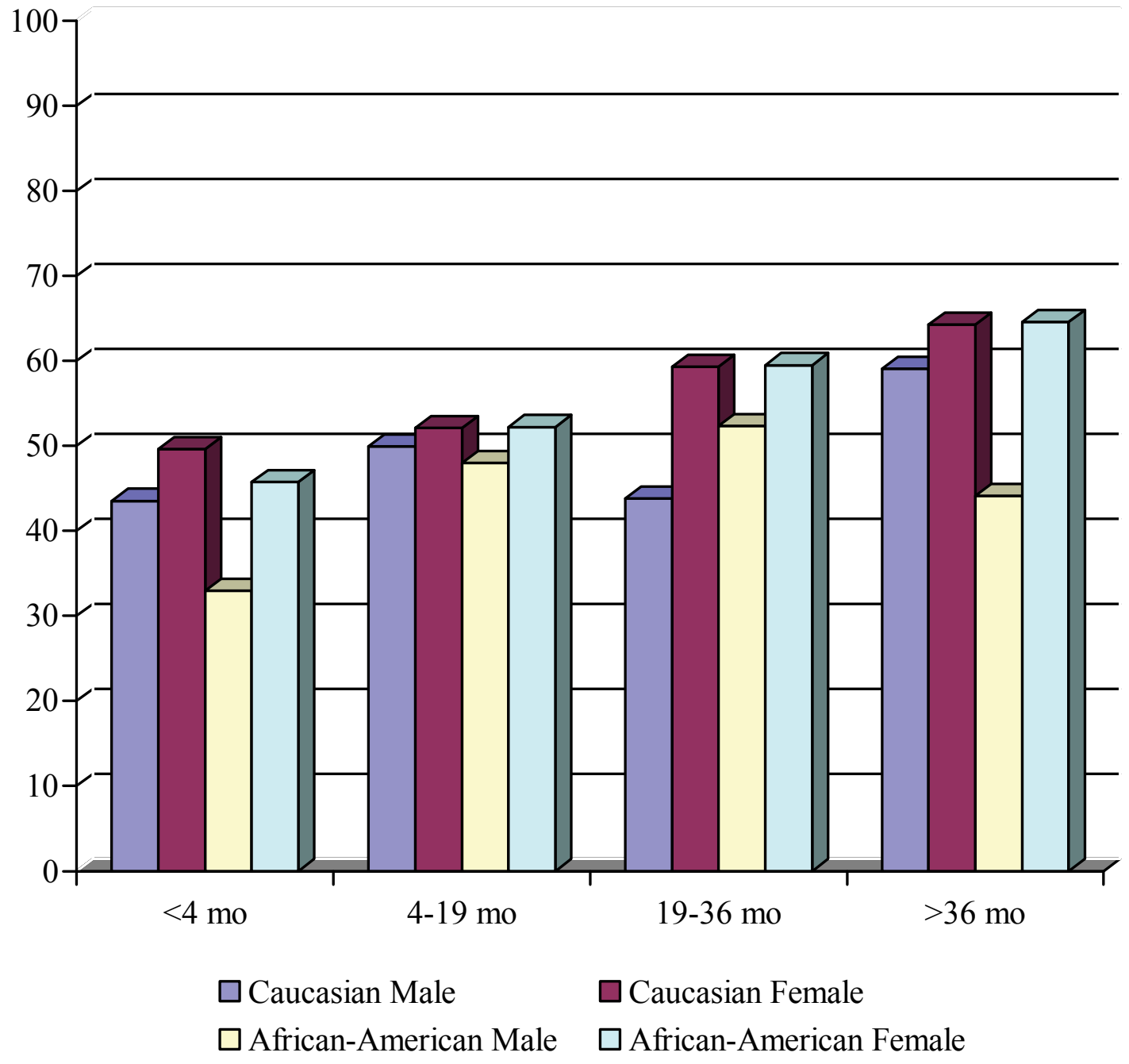

Figure 4.3. Mean Memphis Survey Frequency Scores for Demographic Groups by Time Since Transplantation. 


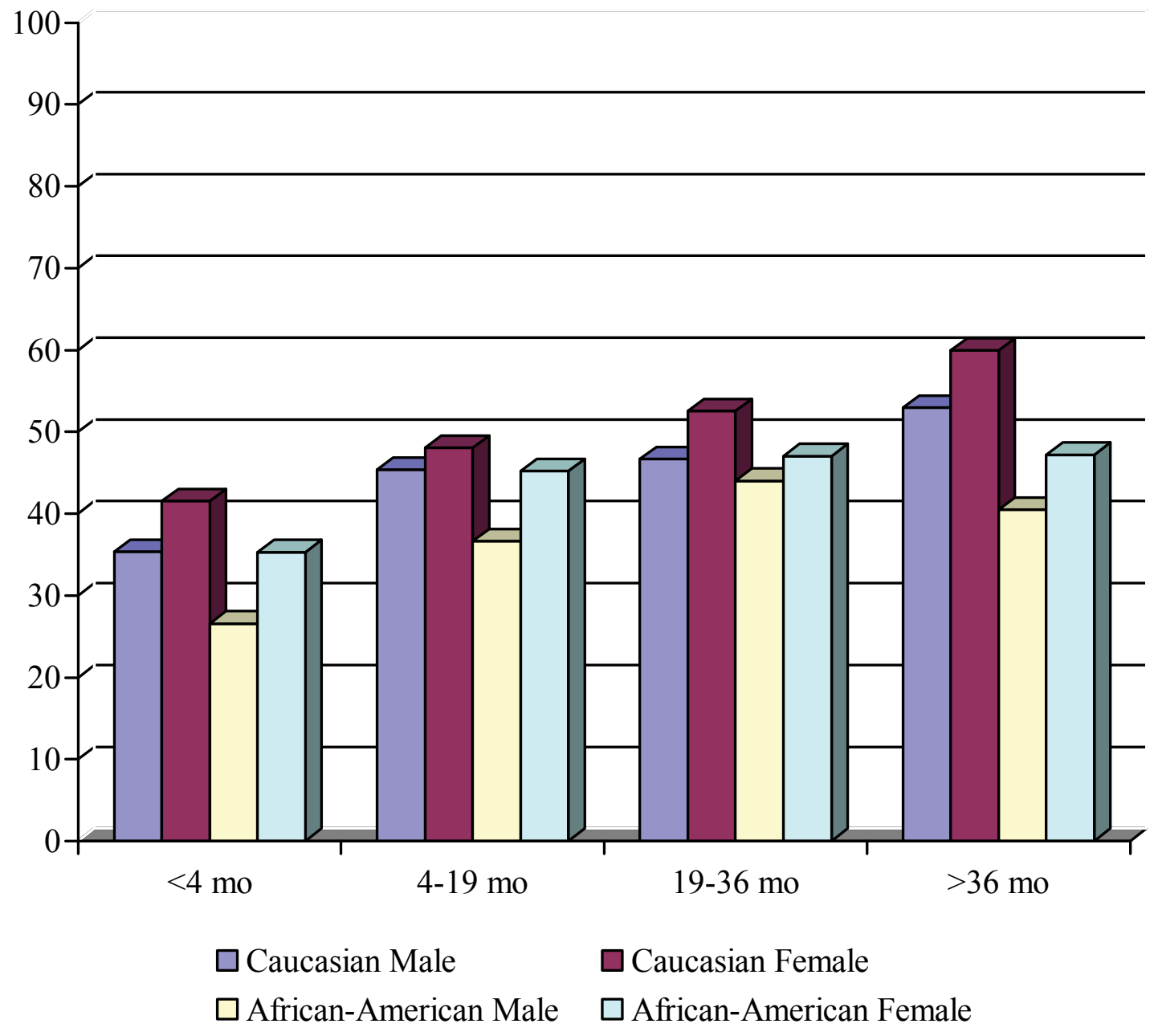

Figure 4.4. Mean Memphis Survey Severity Scores for Demographic Groups by Time Since Transplantation. 


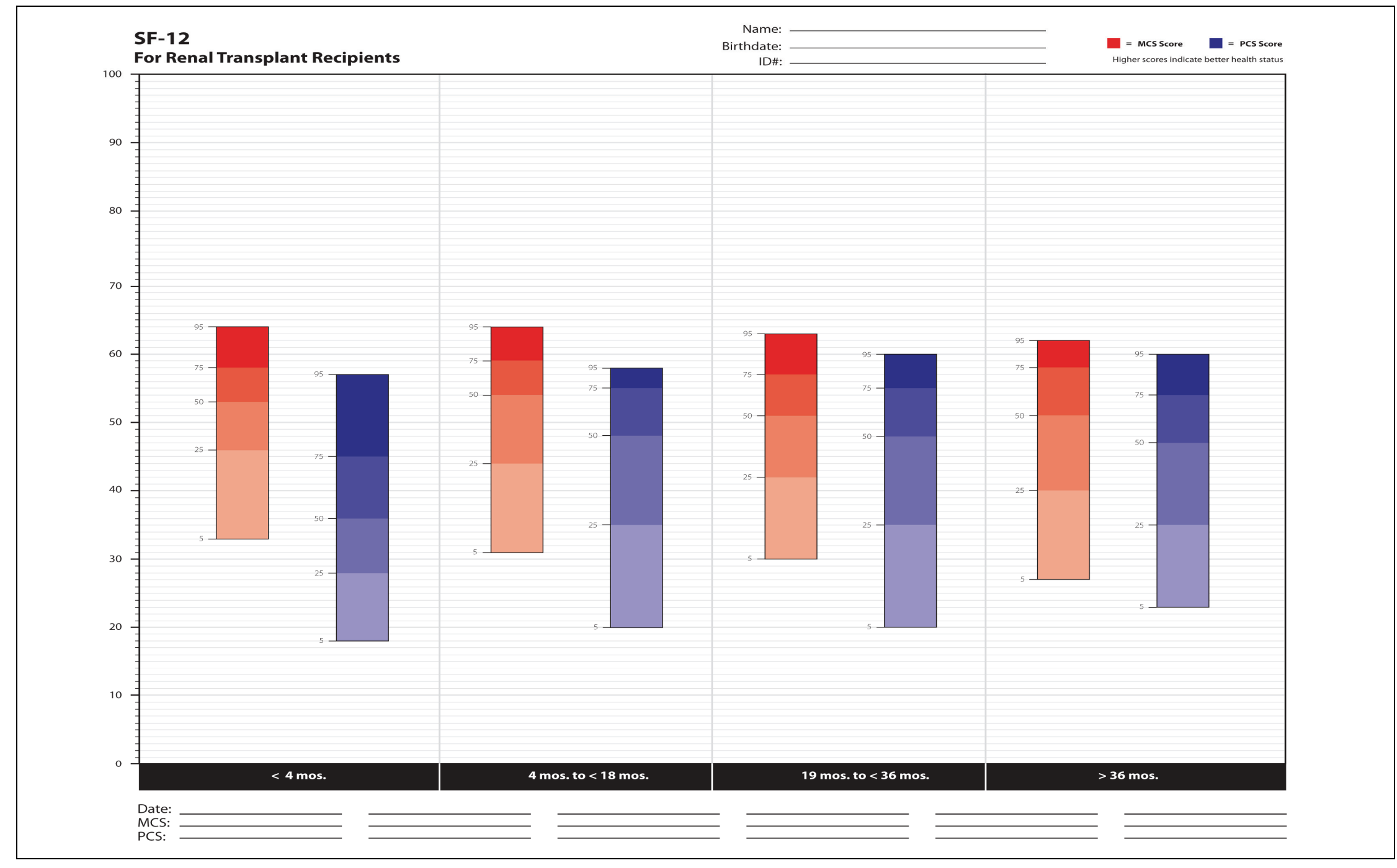

Figure 4.5. Time-Related Centile Range for Kidney Transplantation Recipients: SF-12 Health Survey. 


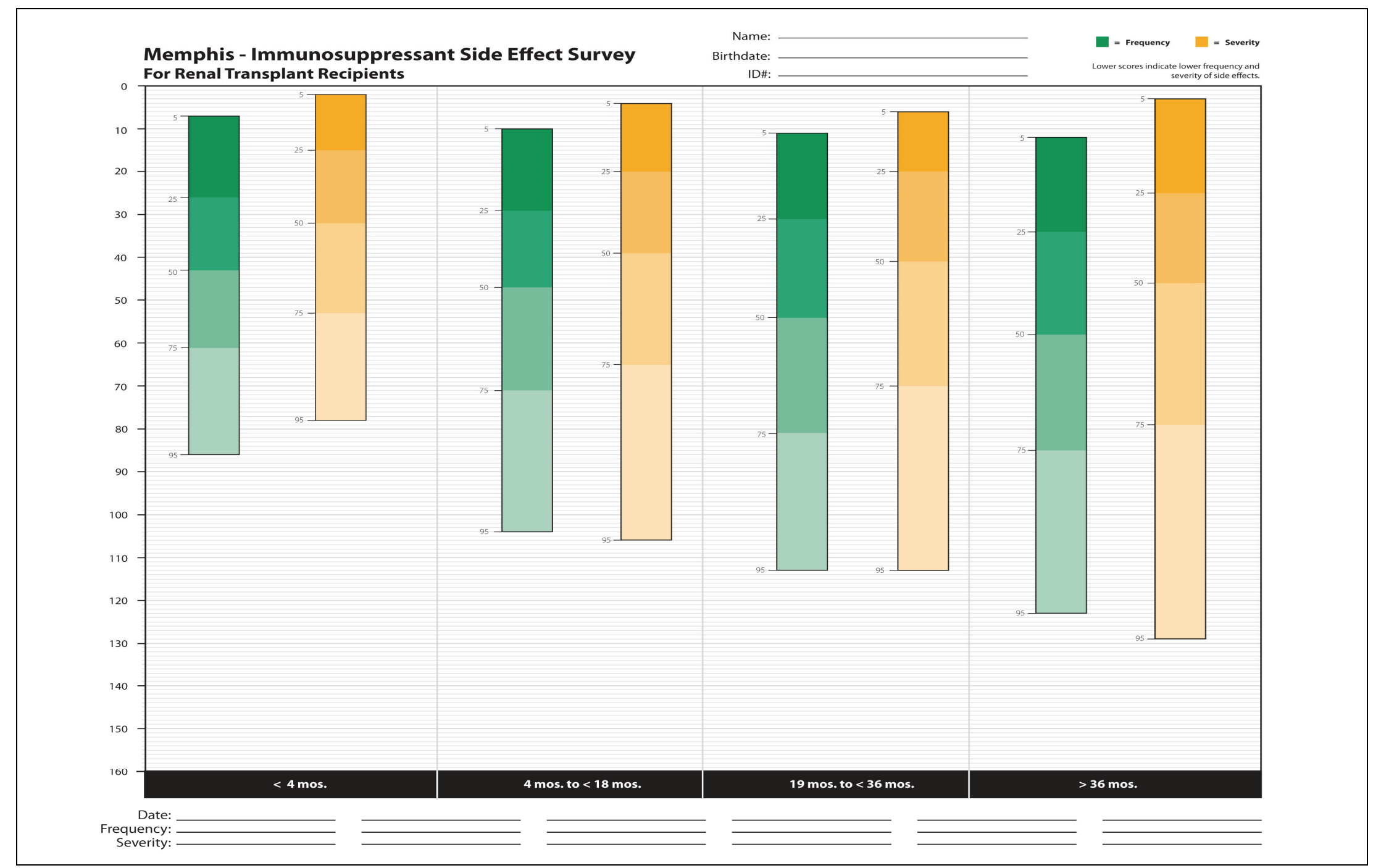

Figure 4.6. Time-Related Centile Range for Kidney Transplantation Recipients: Memphis Survey. 


\section{Discussion}

QoL life measurements such as those provided by the SF-12 and the Memphis Survey are rarely used in the clinical setting to assess individual patients and no studies have reported routine use in the kidney transplantation setting of any QoL outcome measure. A number of reasons have been discussed as to why QoL outcomes are not used in the clinical setting in spite of the importance placed on QoL (Higginson \& Carr, 2001, Greenhalgh, Long, \& Flynn, 2005). Perhaps the most common reason is the perceived time spent completing questionnaires that subsequently provide information that is difficult to interpret and is perceived to offer little insight into an individual patient's status. The SF-12 and Memphis Survey are self-administered questionnaires that most patients can complete without assistance in a short period of time prior to the clinic visit. The time-related centile ranges place the scores in a context that can be easily interpreted for patients as they compare their score with others and monitor their progress over time.

Espallagues, Valderas, and Alonso (2000), examined the influence the use of health status measures had on clinical decision making and improvement in patient outcomes. Although, the assessment of QoL did not have a direct influence on patient outcomes or clinical decision making, this review concluded that using health status or QoL measures modified the process of patient care. Greenhalgh, Long, \& Flynn (2005) support this conclusion suggesting that studies may not be asking the correct question in evaluating the utility of patient outcomes in clinical practice and instead argue for a theory driven approach to evaluation of the use of QoL measurement tools for patient assessment that focuses on the process as well as the effect of QoL measures on decision making or clinical outcomes. For example, QoL assessment has been used in the oncology setting with beneficial results, not in patient outcomes per se but rather in increased communication and heightened provider awareness of the patient's QoL (Detmar et al., 2002). Velikova et al. (2004) likewise found that routine assessment of QoL of oncology patients enhanced patient-provider communication and in addition correlated with improved QoL and emotional functioning. The time-related centile ranges presented in this study for kidney transplant recipients would facilitate interpretation of QoL scores, facilitate routine assessment of QoL outcomes, enhance discussions with patients regarding their Qol outcomes, identify patients who would benefit from interventions designed to improve QoL outcomes, and help or to reassure those patients who are doing well.

The SF-12 has been used to estimate QoL for the general population. Mean scores for the general population reported for the PCS and MCS score respectively are 49.6 and 52.0 (Johnson \& Coons, 1998). Hathaway, et al. (2003b) reported the range of scores for the US general population from 13-69 for the PCS and 10-70 on the MCS. Mean score for this sample for PCS and MCS scores were 42.39 (range 6 to 65) and 50.11 (range 10 to 71) respectively. The mean and range of the MCS scores in this sample are comparable to the general population. However, the PCS scores are were lower when compared to the general population. This is consistent with early data reported from the PORTEL registry and indicates impaired physical QoL following kidney transplantation (Hathaway, et al. 2003b). 
Time-related centile ranges are useful if the sample used for construction of the range is representative of the population for which it is designed. The sample for this study was drawn from a multi-institutional study with participants recruited from different regions of the country. Since the participants were from diverse areas and diverse transplantation centers, the ranges have greater generalizability than a sample drawn from a single site.

The gender and racial distribution in this sample was compared to the distribution reported in the United Network for Organ Sharing (UNOS) data base which represents all transplant recipients. A significant difference was found between the UNOS data and the PORTEL sample $\left(\chi^{2}=25.03, p<.01\right)$. The percentage of Caucasian females in the study sample was slightly higher than that reported in the UNOS database, $35.7 \%$ and $28.52 \%$ respectively. This difference is likely to be of little clinical significance. African American males, however, comprised only $9.5 \%$ of the study sample compared with $16.24 \%$ reported by UNOS. As a result application of the time-related centile ranges in the African-American male population should be done cautiously and the ranges used more as a means to monitor patient progress as opposed to comparison with an established "norm". Even so, the width of the individual centile ranges is such that if the sample of African American males used in this study was different from the larger population of African American male kidney transplant recipients, the impact of this difference on the centile ranges and ultimate clinical use would be minimal.

African American and Causcasians were specifically targeted for this first effort at establishing QoL centile ranges based on available data. Additional QoL data will be required before centile ranges can be constructed or specific recommendations can be made for use in other ethnic groups. Patients who have undergone more than one kidney transplantation are also not represented in these time-related centile ranges. Just as using QoL outcome measure has potential utility for kidney transplant recipients, recipients of other solid organ transplantations may also benefit from QoL benchmarks to interpret QoL outcome scores. The sample size required for development of time-related centile ranges for other solid organ transplantation recipients may make development of the ranges more challenging.

The PORTEL registry recruited participants from a variety of patient and site centric venues. During the first half of the data collection period, participants were recruited from transplantation centers, national transplantation meetings, community events, support groups, and direct mail. This methodology had the potential to select a healthier population that might not be fully representative of QoL following transplantation. During the later data collection period recruitment was limited to referrals from transplantation centers in order to create a more representative sample.

The time-related centile ranges constructed in this study do not account for patient age which has been shown to be a factor in QoL post transplantation (Baiardi et al., 2002; Fujisawa et al., 2000). The current sample includes transplant recipients between the ages of 18 and 65, chosen to represent the working age adult. The decision to include all adults 
in the single time-related centile range was based primarily on the age distribution of the participants in the sample.

\section{Conclusion}

The centile ranges constructed in this study have immediate clinical utility as a tool for educating patients regarding expectations prior to transplantation and for monitoring progress over time post transplantation. They can provide a means for transplant recipients to compare their QoL to a reference range derived from a like population as opposed to the general population and will serve as a catalyst for discussion regarding interventions to enhance QoL.

The outcomes of this project also have application in the research arena as well. QoL and changes in QoL will continue to be a variable of interest to researchers as the kidney transplantation population ages. The outcomes of this study will provide additional baseline data for future QoL research and can provide benchmarks for evaluating interventions designed to improve QoL. 


\section{LIST OF REFERENCES}

Aasebo, W., Midtvedt, K., Hartmann, A., \& Stavem, K. (2005). Predictors of healthrelated quality of life in hypertensive recipients following renal transplantation. Clinical Transplantation, 19, 756-762.

Baars, R. M., van der Pal, S. M., Koopman, H. M., \& Wit, J. M. (2004). Clinicians' perspective on quality of life assessment in paediatric clinical practice. Acta Paediatrica, 93, 1356-1362.

Baiardi, F., Degli Esposti, E., Cocchi, R., Fabbri, A., Sturani, A., Valpiani, G., et al. (2002). Effects of clinical and individual variables on quality of life in chronic renal failure patients. Journal of Nephrology, 15, 61-67.

Baines, L. S., Joseph, J. T., \& Jindal, R. M. (2002). Emotional issues after kidney transplantation: A prospective psychotherapeutic study. Clinical Transplantation, $16,455-460$.

Blake, C., Codd, M. B., Cassidy, A., \& O'Meara, Y. M. (2000). Physical function, employment and quality of life in end-stage renal disease. Journal of Nephrology, $13,142-149$.

Bradford, R. (1991). Children's psychological health status--the impact of liver transplantation: A review. Journal of the Royal Society of Medicine, 84, 550-553.

Brandt, E. N. J., \& Pope, A. M. E. (1997). Enabling America: Assessing the role of rehabilitation science and engineering [executive summary] Institute of Medicine. Washington, DC: National Academy Press.

Bury, M. (1991). The sociology of chronic illness: A review of research and prospects. Sociology of Health \& Illness, 13, 451-468.

Cameron, J. I., Whiteside, C., Katz, J., \& Devins, G. M. (2000). Differences in quality of life across renal replacement therapies: A meta-analytic comparison. American Journal of Kidney Disease, 35, 629-637.

Carr, A. J., Gibson, B., \& Robinson, P. G. (2001). Measuring quality of life: Is quality of life determined by expectations or experience? British Medical Journal, 322, 1240-1243.

Carr, A. J., \& Higginson, I. J. (2001). Are quality of life measures patient centred? British Medical Journal, 322, 1357-1360. 
Cetingok, M., Winsett, R. P., \& Hathaway, D. K. (2004). A comparative study of quality of life among the age groups of kidney transplant recipients. Progress in Transplantation, 14, 33-38.

Cluff, L. E. (1981). Chronic disease, function and the quality of care. Journal of Chronic Disease, 34, 299-304.

Cohen, A., \& Shane, E. (2003). Osteoporosis after solid organ and bone marrow transplantation. Osteoporosis International, 14, 617-630.

Cole, T. J., \& Green, P. J. (1992). Smoothing reference centile curves: The LMS method and penalized likelihood. Statistics in Medicine, 11, 1305-1319.

Corbin, J.M. \& Strauss, A. (1992). A nursing model for chronic illness management based on the trajectory framework. In P. Woog (Ed.), The chronic illness trajectory framework, the Corbin and Strauss nursing model (pp. 9-28). New York: Springer Publishing Company.

Craig, H. M., \& Edwards, J. E. (1983). Adaptation in chronic illness: An eclectic model for nurses. Journal of Advanced Nursing, 8, 397-404.

Crippin, J. S. (2001). Bone disease after liver transplantation. Liver Transplantation, 7 , S27-35.

De Geest, S., \& Moons, P. (2000). The patient's appraisal of side-effects: The blind spot in quality-of-life assessments in transplant recipients. Nephrology, Dialysis, Transplantation, 15, 457-459.

Delate, T., \& Coons, S. J. (2000). The discriminative ability of the 12-Item Short Form Health Survey (SF-12) in a sample of persons infected with HIV. Clinical Therapeutics, 22, 1112-1120.

Detmar, S. B., Aaronson, N. K., Wever, L. D., Muller, M., \& Schornagel, J. H. (2000). How are you feeling? Who wants to know? Patients' and oncologists' preferences for discussing health-related quality-of-life issues. Journal of Clinical Oncology, $18,3295-3301$.

Detmar, S. B., Muller, M. J., Schornagel, J. H., Wever, L. D., \& Aaronson, N. K. (2002). Health-related quality-of-life assessments and patient-physician communication: A randomized controlled trial. Journal of the American Medical Association, 288, 3027-3034.

Dew, M. A., Switzer, G. E., Goycoolea, J. M., Allen, A. S., DiMartini, A., Kormos, R. L., et al. (1997). Does transplantation produce quality of life benefits? A quantitative analysis of the literature. Transplantation, 64, 1261-1273. 
Espallargues, M., Valderas, J. M., \& Alonso, J. (2000). Provision of feedback on perceived health status to health care professionals: A systematic review of its impact. Medical Care, 38, 175-186.

Evans, R. W., Manninen, D. L., Garrison, L. P., Jr., Hart, L. G., Blagg, C. R., Gutman, R. A., et al. (1985). The quality of life of patients with end-stage renal disease. New England Journal of Medicine, 312, 553-559.

Fiebiger, W., Mitterbauer, C., \& Oberbauer, R. (2004). Health-related quality of life outcomes after kidney transplantation. Health and Quality of Life Outcomes, 2(1), 2 .

Fujisawa, M., Ichikawa, Y., Yoshiya, K., Isotani, S., Higuchi, A., Nagano, S., et al. (2000). Assessment of health-related quality of life in renal transplant and hemodialysis patients using the SF-36 Health Survey. Urology, 56, 201-206.

Greenhalgh, J., Long, A. F., \& Flynn, R. (2005). The use of patient reported outcome measures in routine clinical practice: Lack of impact or lack of theory? Social Science and Medicine, 60, 833-843.

Griffiths, J. K., Iles, T. C., Koduah, M., \& Nix, A. B. (2004). Centile charts ii: Alternative nonparametric approach for establishing time-specific reference centiles and assessment of the sample size required. Clinical Chemistry, 50, 907914.

Griva, K., Ziegelmann, J. P., Thompson, D., Jayasena, D., Davenport, A., Harrison, M., et al. (2002). Quality of life and emotional responses in cadaver and living related renal transplant recipients. Nephrology, Dialysis, Transplantation, 17, 2204-2211.

Haas, B. K. (1999). Clarification and integration of similar quality of life concepts. Image-The Journal of Nursing Scholarship, 31, 215-220.

Habwe, V. Q. (2006). Posttransplantation quality of life: More than graft function. American Journal of Kidney Disease, 47, S98-110.

Hathaway, D., Barr, M. L., Ghobrial, R. M., Rodrigue, J., Bogner, S., Prendergast, M. M., et al. (2003a). Assessing quality-of-life outcomes in organ transplant recipients: Progress and priorities. Progress in Transplantation, Supplement, 1-2.

Hathaway, D., Barr, M. L., Ghobrial, R. M., Rodrigue, J., Bogner, S., Prendergast, M. M., et al. (2003b). The PORTEL registry: Overview and selected findings. Progress in Transplantation, Supplement, 3-13.

Hathaway, D. K., Winsett, R. P., Johnson, C., Tolley, E. A., Hartwig, M., Milstead, J., et al. (1998). Post kidney transplant quality of life prediction models. Clinical Transplantation, 12, 168-174. 
Hathaway, D., Winsett, R., Prendergast, M., \& Subaiya, I. (2003). The first report from the patient outcomes registry for transplant effects on life (PORTEL): Differences in side-effects and quality of life by organ type, time since transplant and immunosuppressive regimens. Clinical Transplantation, 17, 183-194.

Holley, J. L. (2007). Palliative care in end-stage renal disease: Illness trajectories, communication, and hospice use. Advances in Chronic Kidney Disease, 14, 402408.

Higginson, I. J., \& Carr, A. J. (2001). Measuring quality of life: Using quality of life measures in the clinical setting. British Medical Journal, 322, 1297-1300.

Ironside, P. M., Scheckel, M., Wessels, C., Bailey, M. E., Powers, S., \& Seeley, D. K. (2003). Experiencing chronic illness: Co-creating new understandings. Qualitative Health Research, 13, 171-183.

Joachim, G., \& Acorn, S. (2000). Living with chronic illness: The interface of stigma and normalization. Canadian Journal of Nursing Research, 32(3), 37-48.

Johnson, J. A., \& Coons, S. J. (1998). Comparison of the EQ-5D and SF-12 in an adult US sample. Quality of Life Research, 7, 155-166.

Khedmat, H., Karami, G. R., Pourfarziani, V., Assari, S., Rezailashkajani, M., \& Naghizadeh, M. M. (2007). A logistic regression model for predicting healthrelated quality of life in kidney transplant recipients. Transplantation Proceedings, 39, 917-922.

Kiely, J. M., Brasel, K. J., Guse, C. E., \& Weigelt, J. A. (2006). Correlation of SF-12 and SF-36 in a trauma population. Journal of Surgical Research, 132, 214-8.

Lazzaretti, C. T., Carvalho, J. G., Mulinari, R. A., \& Rasia, J. M. (2004). Kidney transplantation improves the multidimensional quality of life. Transplantation Proceedings, 36, 872-873.

Leplege, A., \& Hunt, S. (1997). The problem of quality of life in medicine. Journal of the American Medical Association, 278, 47-50.

Levine, M. N., \& Ganz, P. A. (2002). Beyond the development of quality-of-life instruments: Where do we go from here? Journal of Clinical Oncology, 20, 22152216.

Liem, Y. S., Bosch, J. L., Arends, L. R., Heijenbrok-Kal, M. H., \& Hunink, M. G. (2007). Quality of life assessed with the Medical Outcomes Study Short Form 36-item Health Survey of patients on renal replacement therapy: A systematic review and meta-analysis. Value in Health: The Journal of the International Society for Pharmacoeconomics and Outcomes Research, 10,390-397. 
Matas, A. J., Halbert, R. J., Barr, M. L., Helderman, J. H., Hricik, D. E., Pirsch, J. D., et al. (2002). Life satisfaction and adverse effects in renal transplant recipients: A longitudinal analysis. Clinical Transplantation, 16, 113-121.

Matas, A. J., Lawson, W., McHugh, L., Gillingham, K., Payne, W. D., Dunn, D. L., et al. (1996). Employment patterns after successful kidney transplantation.

Transplantation, 61, 729-733.

McGrath, P., Paton, M. A., \& Huff, N. (2005). Beginning treatment for pediatric acute myeloid leukemia: The family connection. Issues in Comprehensive Pediatric Nursing, 28, 97-114.

Meadows, K. A., Rogers, D., \& Greene, T. (1998). Attitudes to the use of health outcome questionnaires in the routine care of patients with diabetes: A survey of general practitioners and practice nurses. The British journal of General Practice, 48, 1555-1559.

Mechanic, D. (1977). Illness behavior, social adaptation, and the management of illness. A comparison of educational and medical models. Journal of Nervous and Mental Disease, 165(2), 79-87.

Meeberg, G. A. (1993). Quality of life: A concept analysis. Journal of Advanced Nursing, $18,32-38$.

Molzahn, A. E. (1991). Quality of life after organ transplantation. Journal of Advanced Nursing, 16, 1042-1047.

Moons, P. (2004). Why call it health-related quality of life when you mean perceived health status? European Journal of Cardiovascular Nursing, 3, 275-277.

Morris, J., Perez, D., \& McNoe, B. (1998). The use of quality of life data in clinical practice. Quality of Life Research, 7, 85-91.

Musschenga, A. W. (1997). The relation between concepts of quality-of-life, health and happiness. Journal of Medicine and Philosophy, 22, 11-28.

Neipp, M., Karavul, B., Jackobs, S., Meyer zu Vilsendorf, A., Richter, N., Becker, T., et al. (2006). Quality of life in adult transplant recipients more than 15 years after kidney transplantation. Transplantation, 81, 1640-1644.

Niu, S. F., \& Li, I. C. (2005). Quality of life of patients having renal replacement therapy. Journal of Advanced Nursing, 51, 15-21. 
Noohi, S., Karami, G. R., Lorgard-Dezfuli-Nejad, M., Najafi, M., \& Saadat, S. H. (2007). Are all domains of quality of life poor among elderly kidney recipients? Transplantation Proceedings, 39, 1079-1081.

Obrecht, J. A., Gallo, A. M., \& Knafl, K. A. (1992). A case illustration of family management style in childhood end stage renal disease. American Nephrology Nurses Association Journal, 19, 255-259; discussion 260.

Ogutmen, B., Yildirim, A., Sever, M. S., Bozfakioglu, S., Ataman, R., Erek, E., et al. (2006). Health-related quality of life after kidney transplantation in comparison intermittent hemodialysis, peritoneal dialysis, and normal controls. Transplantation Proceedings, 38, 419-421.

Ostrowski, M., Wesolowski, T., Makar, D., \& Bohatyrewicz, R. (2000). Changes in patients' quality of life after renal transplantation. Transplantation Proceedings, $32,1371-1374$.

Overbeck, I., Bartels, M., Decker, O., Harms, J., Hauss, J., \& Fangmann, J. (2005). Changes in quality of life after renal transplantation. Transplantation Proceedings, 37, 1618-1621.

Pais-Ribeiro, J. L. (2004). Quality of life is a primary end-point in clinical settings. Clinical Nutrition, 23, 121-130.

Pinson, C. W., Feurer, I. D., Payne, J. L., Wise, P. E., Shockley, S., \& Speroff, T. (2000). Health-related quality of life after different types of solid organ transplantation. Annals of Surgery, 232, 597-607.

Ponton, P., Rupolo, G. P., Marchini, F., Feltrin, A., Perin, N., Mazzoldi, M. A., et al. (2001). Quality-of-life change after kidney transplantation. Transplantation Proceedings, 33, 1887-1889.

Rebollo, P., Ortega, F., Baltar, J. M., Badia, X., Alvarez-Ude, F., Diaz-Corte, C., et al. (2000). Health related quality of life (hrqol) of kidney transplanted patients: Variables that influence it. Clinical Transplantation, 14, 199-207.

Reuben, A. (2001). Long-term management of the liver transplant patient: Diabetes, hyperlipidemia, and obesity. Liver Transplantation, 7, S13-21.

Rosenberger, J., van Dijk, J. P., Nagyova, I., Zezula, I., Geckova, A. M., Roland, R., et al. (2006). Predictors of perceived health status in patients after kidney transplantation. Transplantation, 81, 1306-1310.

Royston, P., \& Wright, E. M. (1998). A method for estimating age-specific reference intervals ('normal ranges') based on fractional polynomials and exponentials transformations. Journal of the Royal Statistical Society. Series A., 161, 79-101. 
Sayin, A., Mutluay, R., \& Sindel, S. (2007). Quality of life in hemodialysis, peritoneal dialysis, and transplantation patients. Transplantation Proceedings, 39, 30473053.

Shah, V. S., Ananth, A., Sohal, G. K., Bertges-Yost, W., Eshelman, A., Parasuraman, R. K., et al. (2006). Quality of life and psychosocial factors in renal transplant recipients. Transplantation Proceedings, 38, 1283-1285.

Singh, A., Gnanalingham, K., Casey, A., \& Crockard, A. (2006). Quality of life assessment using the Short Form-12 (SF-12) questionnaire in patients with cervical spondylotic myelopathy: Comparison with SF-36. Spine, 31, 639-643.

Snethen, J. A., Broome, M. E., Bartels, J., \& Warady, B. A. (2001). Adolescents' perception of living with end stage renal disease. Pediatric Nursing, 27, 159-161, 164-157.

Sullivan, M. (2003). The new subjective medicine: Taking the patient's point of view on health care and health. Social Science and Medicine, 56, 1595-1604.

Testa, M. A., \& Simonson, D. C. (1996). Assesment of quality-of-life outcomes. New England Journal of Medicine, 334, 835-840.

Thorne, S., \& Paterson, B. (1998). Shifting images of chronic illness. Image- Journal of Nursing Scholarship, 30, 173-178.

U.S. Department of Health and Human Services. Office of Disease Prevention and Health Promotion. (n.d.). Healthy People 2010. Retrieved March 31, 2008, from the World Wide Web: http://www.health.gov/healthypeople/

van der Mei, S. F., Groothoff, J. W., van Sonderen, E. L., van den Heuvel, W. J., de Jong, P. E., \& van Son, W. J. (2006). Clinical factors influencing participation in society after successful kidney transplantation. Transplantation, 82, 80-85.

Velikova, G., Booth, L., Smith, A. B., Brown, P. M., Lynch, P., Brown, J. M., et al. (2004). Measuring quality of life in routine oncology practice improves communication and patient well-being: A randomized controlled trial. Journal of Clinical Oncology, 22, 714-724.

Ware, J., Jr., Kosinski, M., \& Keller, S. D. (1996). A 12-item short-form health survey: Construction of scales and preliminary tests of reliability and validity. Medical Care, 34, 220-233.

Winsett, R. P., Arheart, K., Stratta, R. J., Alloway, R., Wicks, M. N., Gaber, A. O., et al. (2004). Evaluation of an immunosuppressant side effect instrument. Progress in Transplantation, 14, 210-216, 240. 
Wright, E. M., \& Royston, P. (1997). A comparison of statistical methods for age-related reference intervals. Journal of the Royal Statistical Society. Series A., 160(Part 1), 47-69.

Yildirim, A. (2006). The importance of patient satisfaction and health-related quality of life after renal transplantation. Transplantation Proceedings, 38, 2831-2834. 
APPENDICES 
Appendix A: Descriptive Statistics for Quality of Life Outcome Measures by Racial and Gender Groups for Time Intervals Following Transplantation

Descriptive statistics, including the mean and median scores, standard deviation, and range of the four QoL outcome variables for the 4 demographic groups (Caucasian male, Caucasian Female, African American Male, and African American Female) at each time interval post transplantation and bar graphs of the $50^{\text {th }}$ percentile scores for each outcome are provided in this appendix. 
Table A.1. Descriptive Statistics for the MCS Scores by Racial and Gender Groups for Time Intervals Following Transplantation.

\begin{tabular}{|c|c|c|c|c|c|}
\hline & $\mathrm{N}$ & Mean & Median & Range & $\begin{array}{c}\text { Standard } \\
\text { Deviation }\end{array}$ \\
\hline \multicolumn{6}{|l|}{ 4-18 months } \\
\hline Caucasian Male & 94 & 51.71 & 53.21 & 52.07 & 10.34 \\
\hline Caucasian Female & 66 & 51.42 & 53.35 & 49.38 & 9.98 \\
\hline $\begin{array}{l}\text { African American } \\
\text { Male }\end{array}$ & 21 & 52.99 & 52.04 & 27.36 & 7.46 \\
\hline $\begin{array}{l}\text { African American } \\
\text { Female }\end{array}$ & 30 & 50.10 & 50.22 & 31.74 & 8.30 \\
\hline \multicolumn{6}{|l|}{ 4-18 months } \\
\hline Caucasian Male & 94 & 54.45 & 54.78 & 52.95 & 11 \\
\hline Caucasian Female & 86 & 50.74 & 54.15 & 50.87 & 10.46 \\
\hline $\begin{array}{l}\text { African American } \\
\text { Male }\end{array}$ & 16 & 47.41 & 44.57 & 30.55 & 10.09 \\
\hline $\begin{array}{l}\text { African American } \\
\text { Female }\end{array}$ & 30 & 50.52 & 51.08 & 33.27 & 9.58 \\
\hline \multicolumn{6}{|l|}{ 19-36 months } \\
\hline Caucasian Male & 89 & 48.33 & 50.04 & 45.88 & 10.78 \\
\hline Caucasian Female & 82 & 49.84 & 51.54 & 54.97 & 10.62 \\
\hline $\begin{array}{l}\text { African American } \\
\text { Male }\end{array}$ & 14 & 50.53 & 53.88 & 34.39 & 10.74 \\
\hline $\begin{array}{l}\text { African American } \\
\text { Female }\end{array}$ & 22 & 49.53 & 49.36 & 25.55 & 8.64 \\
\hline \multicolumn{6}{|l|}{$>36$ months } \\
\hline Caucasian Male & 90 & 48.34 & 50.28 & 58.22 & 11.68 \\
\hline Caucasian Female & 83 & 48.28 & 51.46 & 47.98 & 10.87 \\
\hline $\begin{array}{l}\text { African American } \\
\text { Male }\end{array}$ & 12 & 51.15 & 56.14 & 42.91 & 13.15 \\
\hline $\begin{array}{l}\text { African American } \\
\text { Female }\end{array}$ & 18 & 47.67 & 48.43 & 34.95 & 11.30 \\
\hline
\end{tabular}




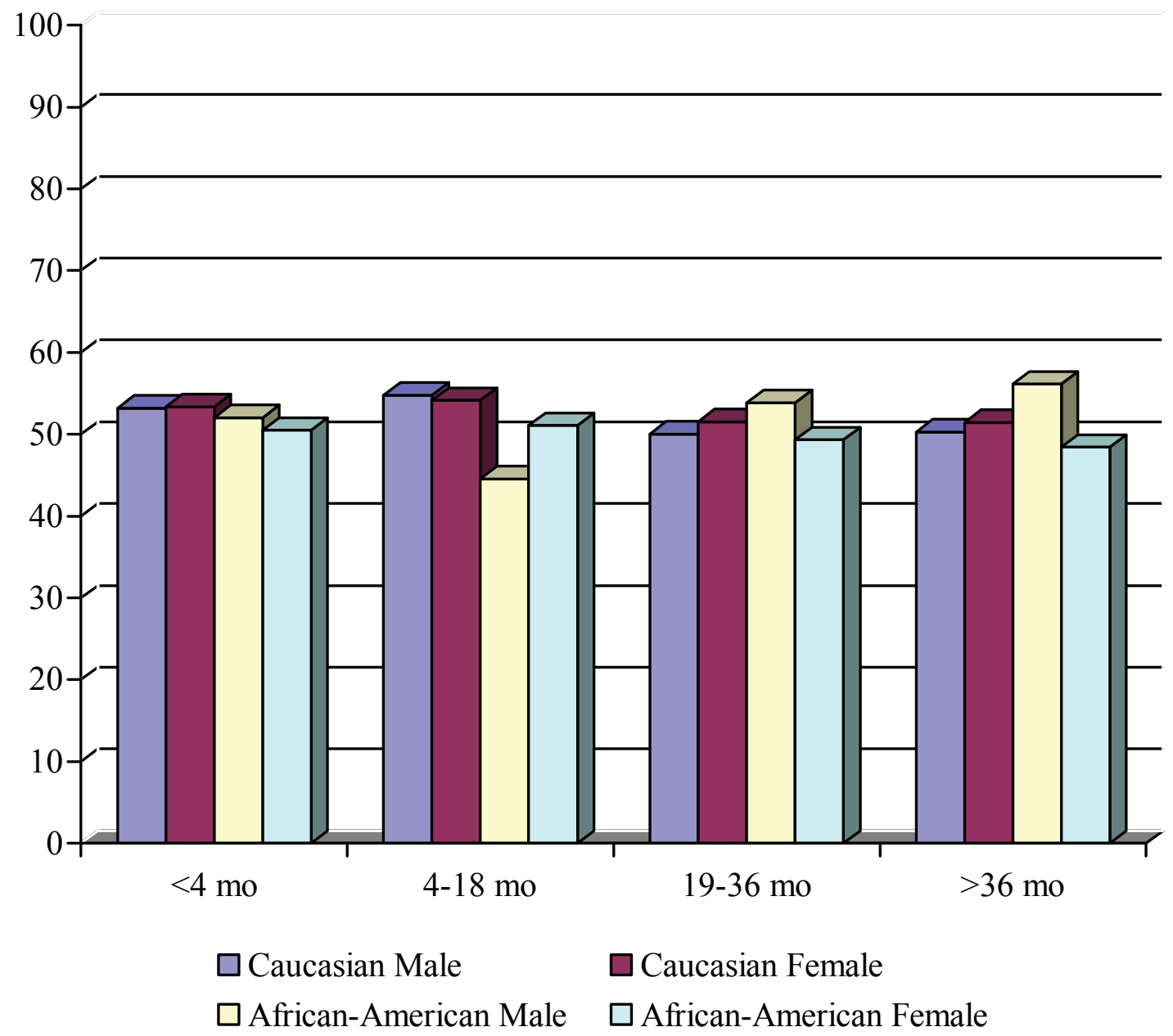

Figure A.1. $50^{\text {th }}$ Percentile, MCS Scores for Demographic Groups by Time Since Transplantation 
Table A.2. Descriptive Statistics for the PCS Scores by Racial and Gender Groups for Time Intervals Following Transplantation.

\begin{tabular}{|c|c|c|c|c|c|}
\hline & $\mathrm{N}$ & Mean & Median & Range & $\begin{array}{c}\text { Standard } \\
\text { Deviation }\end{array}$ \\
\hline \multicolumn{6}{|l|}{$<4$ months } \\
\hline Caucasian Male & 94 & 36.06 & 36.02 & 46.01 & 11.3 \\
\hline Caucasian Female & 66 & 36.59 & 34 & 47.15 & 11.66 \\
\hline $\begin{array}{l}\text { African American } \\
\text { Male }\end{array}$ & 21 & 39.20 & 40.36 & 38.33 & 10.95 \\
\hline $\begin{array}{l}\text { African American } \\
\text { Female }\end{array}$ & 30 & 36.27 & 34.47 & 45.07 & 11.32 \\
\hline \multicolumn{6}{|l|}{ 4-18 months } \\
\hline Caucasian Male & 94 & 44.09 & 45.71 & 59.29 & 12.15 \\
\hline Caucasian Female & 86 & 46.07 & 47.96 & 54.24 & 12.5 \\
\hline $\begin{array}{l}\text { African American } \\
\text { Male }\end{array}$ & 16 & 41.77 & 40.36 & 32.5 & 9.43 \\
\hline $\begin{array}{l}\text { African American } \\
\text { Female }\end{array}$ & 30 & 41.38 & 43.04 & 47.09 & 13.13 \\
\hline \multicolumn{6}{|l|}{ 19-36 months } \\
\hline Caucasian Male & 89 & 44.83 & 47.98 & 51.62 & 13.05 \\
\hline Caucasian Female & 82 & 45.99 & 50.15 & 52.34 & 12.7 \\
\hline $\begin{array}{l}\text { African American } \\
\text { Male }\end{array}$ & 14 & 40.94 & 41.13 & 42.9 & 13.48 \\
\hline $\begin{array}{l}\text { African American } \\
\text { Female }\end{array}$ & 22 & 38.15 & 38.42 & 44.96 & 13.1 \\
\hline \multicolumn{6}{|l|}{$>36$ months } \\
\hline Caucasian Male & 90 & 44.36 & 48.46 & 45.23 & 12.34 \\
\hline Caucasian Female & 83 & 44.79 & 47.9 & 52.98 & 12.15 \\
\hline $\begin{array}{l}\text { African American } \\
\text { Male }\end{array}$ & 12 & 48.08 & 48.32 & 38.29 & 11 \\
\hline $\begin{array}{l}\text { African American } \\
\text { Female }\end{array}$ & 18 & 39.43 & 39.72 & 36.45 & 9.47 \\
\hline
\end{tabular}




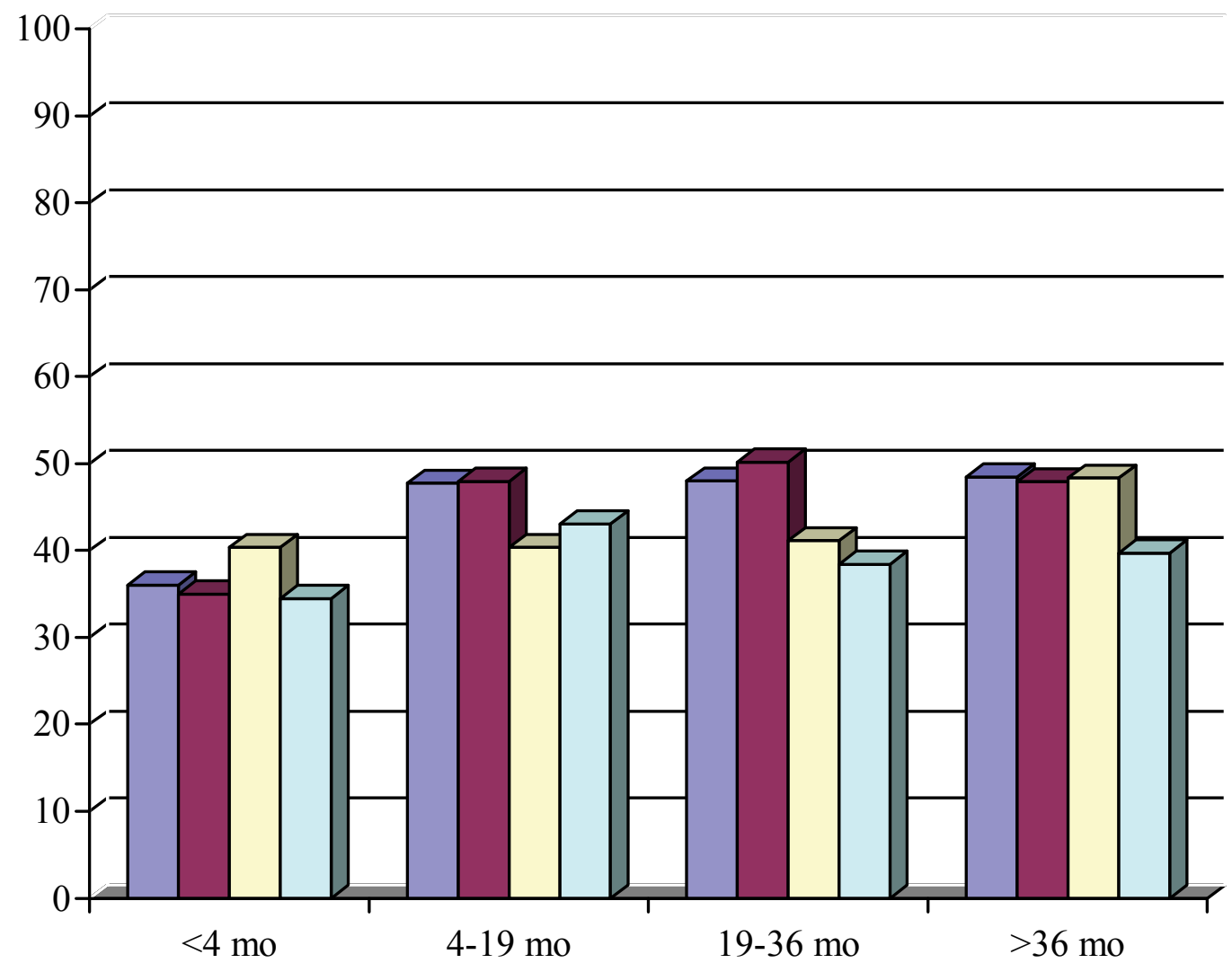

$\square$ Caucasian Male

$\square$ Caucasian Female

$\square$ African-American Male $\quad \square$ African-American Female

Figure A.2. $50^{\text {th }}$ Percentile, PCS Scores for Demographic Groups by Time Since Transplantation. 
Table A.3. Descriptive Statistics for the Memphis Survey Frequency Scores by Racial and Gender Groups for Time Intervals Following Transplantation.

\begin{tabular}{|c|c|c|c|c|c|}
\hline & $\mathrm{N}$ & Mean & Median & Range & $\begin{array}{c}\text { Standard } \\
\text { Deviation } \\
\end{array}$ \\
\hline \multicolumn{6}{|l|}{$<4$ months } \\
\hline Caucasian Male & 75 & 43.52 & 40.93 & 111.97 & 25.91 \\
\hline Caucasian Female & 49 & 49.63 & 50.5 & 96.96 & 22.92 \\
\hline $\begin{array}{l}\text { African American } \\
\text { Male }\end{array}$ & 27 & 32.98 & 27.58 & 85.84 & 23.2 \\
\hline $\begin{array}{l}\text { African American } \\
\text { Female }\end{array}$ & 34 & 45.75 & 43.92 & 70.16 & 20 \\
\hline \multicolumn{6}{|l|}{ 4-18 months } \\
\hline Caucasian Male & 78 & 49.93 & 45.13 & 131.36 & 29.64 \\
\hline Caucasian Female & 65 & 52.1 & 46.61 & 132.62 & 31.86 \\
\hline $\begin{array}{l}\text { African American } \\
\text { Male }\end{array}$ & 19 & 48 & 42.38 & 80.60 & 21.15 \\
\hline $\begin{array}{l}\text { African American } \\
\text { Female }\end{array}$ & 33 & 52.2 & 50 & 92.00 & 23.21 \\
\hline \multicolumn{6}{|l|}{$19-36$ months } \\
\hline Caucasian Male & 70 & 53.81 & 45.67 & 133.46 & 33.47 \\
\hline Caucasian Female & 65 & 59.29 & 57.97 & 142.14 & 35.04 \\
\hline $\begin{array}{l}\text { African American } \\
\text { Male }\end{array}$ & 16 & 52.31 & 43. & 82.84 & 23 \\
\hline $\begin{array}{l}\text { African American } \\
\text { Female }\end{array}$ & 22 & 59.5 & 60.15 & 100.14 & 27.87 \\
\hline \multicolumn{6}{|l|}{$>36$ months } \\
\hline Caucasian Male & 93 & 59.08 & 57.36 & 167.73 & 35.82 \\
\hline Caucasian Female & 88 & 64.28 & 59.1 & 168.51 & 34.33 \\
\hline $\begin{array}{l}\text { African American } \\
\text { Male }\end{array}$ & 15 & 44.09 & 36.33 & 147.86 & 40.73 \\
\hline $\begin{array}{l}\text { African American } \\
\text { Female }\end{array}$ & 16 & 64.56 & 67.24 & 88.51 & 27.82 \\
\hline
\end{tabular}




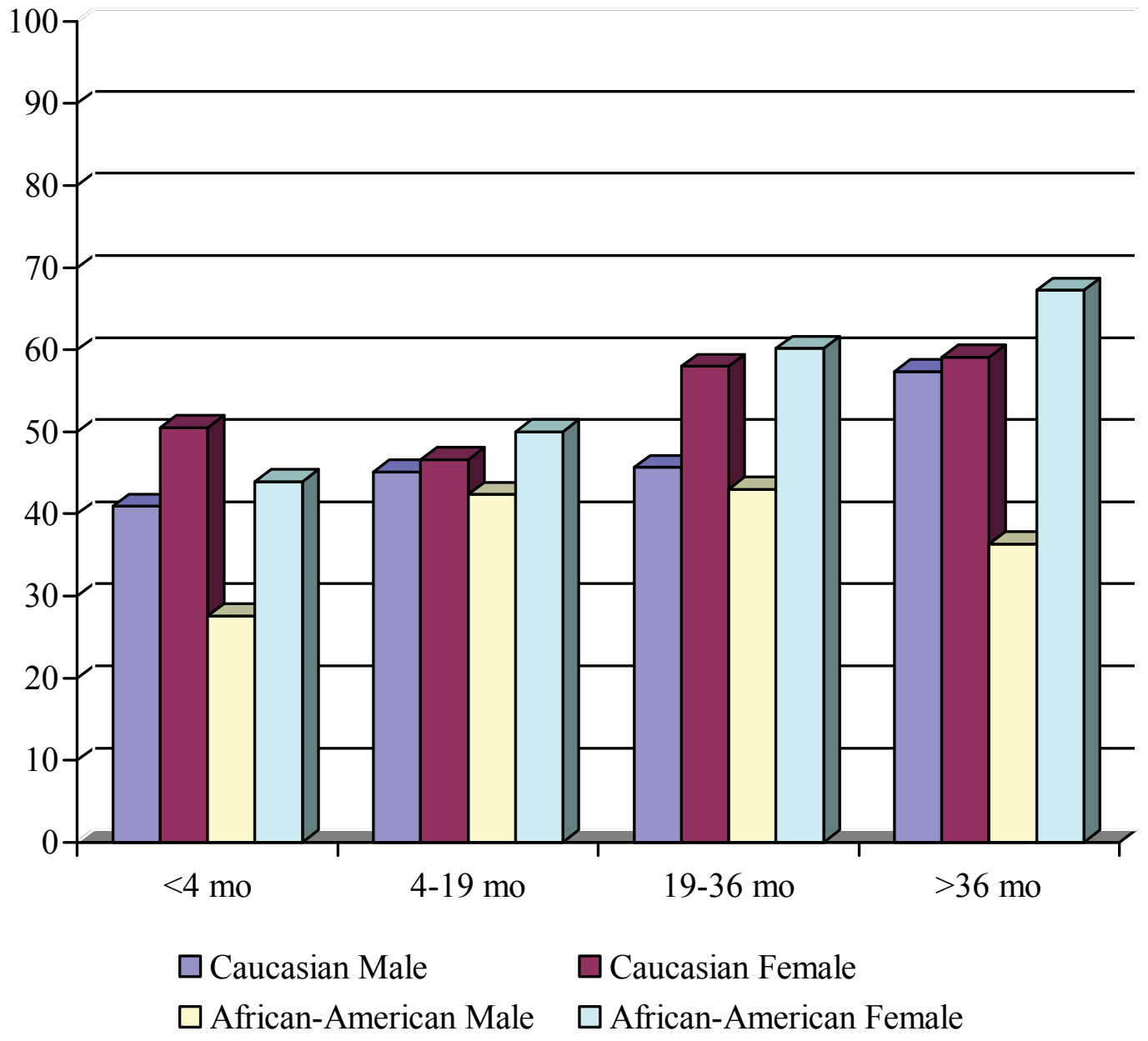

Figure A.3. $50^{\text {th }}$ Percentile, Memphis Survey Frequency Scores for Demographic Groups by Time Since Transplantation. 
Table A.4. Descriptive Statistics for the Memphis Survey Severity Scores by Racial and Gender Groups for Time Intervals Following Transplantation.

\begin{tabular}{|c|c|c|c|c|c|}
\hline & $\mathrm{N}$ & Mean & Median & Range & $\begin{array}{c}\text { Standard } \\
\text { Deviation }\end{array}$ \\
\hline \multicolumn{6}{|l|}{$<4$ months } \\
\hline Caucasian Male & 71 & 35.32 & 29.83 & 29.83 & 27.6 \\
\hline Caucasian Female & 46 & 41.53 & 42.73 & 106.75 & 25.23 \\
\hline $\begin{array}{l}\text { African American } \\
\text { Male }\end{array}$ & 24 & 26.59 & 15.42 & 83.12 & 24.38 \\
\hline $\begin{array}{l}\text { African American } \\
\text { Female }\end{array}$ & 29 & 35.28 & 32.94 & 69.18 & 19.28 \\
\hline \multicolumn{6}{|l|}{ 4-18 months } \\
\hline Caucasian Male & 77 & 45.37 & 41.38 & 133.18 & 30.91 \\
\hline Caucasian Female & 64 & 48.03 & 38 & 135.17 & 36.33 \\
\hline $\begin{array}{l}\text { African American } \\
\text { Male }\end{array}$ & 19 & 36.66 & 34.55 & 98.57 & 25.41 \\
\hline $\begin{array}{l}\text { African American } \\
\text { Female }\end{array}$ & 32 & 45.18 & 38.73 & 109.33 & 26.74 \\
\hline \multicolumn{6}{|l|}{$19-36$ months } \\
\hline Caucasian Male & 65 & 46.67 & 40.3 & 113.28 & 33.68 \\
\hline Caucasian Female & 63 & 52.53 & 49.46 & 132.21 & 37.15 \\
\hline $\begin{array}{l}\text { African American } \\
\text { Male }\end{array}$ & 16 & 44 & 32.55 & 82.90 & 25.54 \\
\hline $\begin{array}{l}\text { African American } \\
\text { Female }\end{array}$ & 20 & 47.03 & 40.95 & 116.75 & 31.83 \\
\hline \multicolumn{6}{|l|}{$>36$ months } \\
\hline Caucasian Male & 90 & 52.92 & 43.31 & 183.64 & 41.7 \\
\hline Caucasian Female & 88 & 59.95 & 53.64 & 172.14 & 37.15 \\
\hline $\begin{array}{l}\text { African American } \\
\text { Male }\end{array}$ & 15 & 40.46 & 27.81 & 149.68 & 43.54 \\
\hline $\begin{array}{l}\text { African American } \\
\text { Female }\end{array}$ & 13 & 47.21 & 58.25 & 68.61 & 23.27 \\
\hline
\end{tabular}




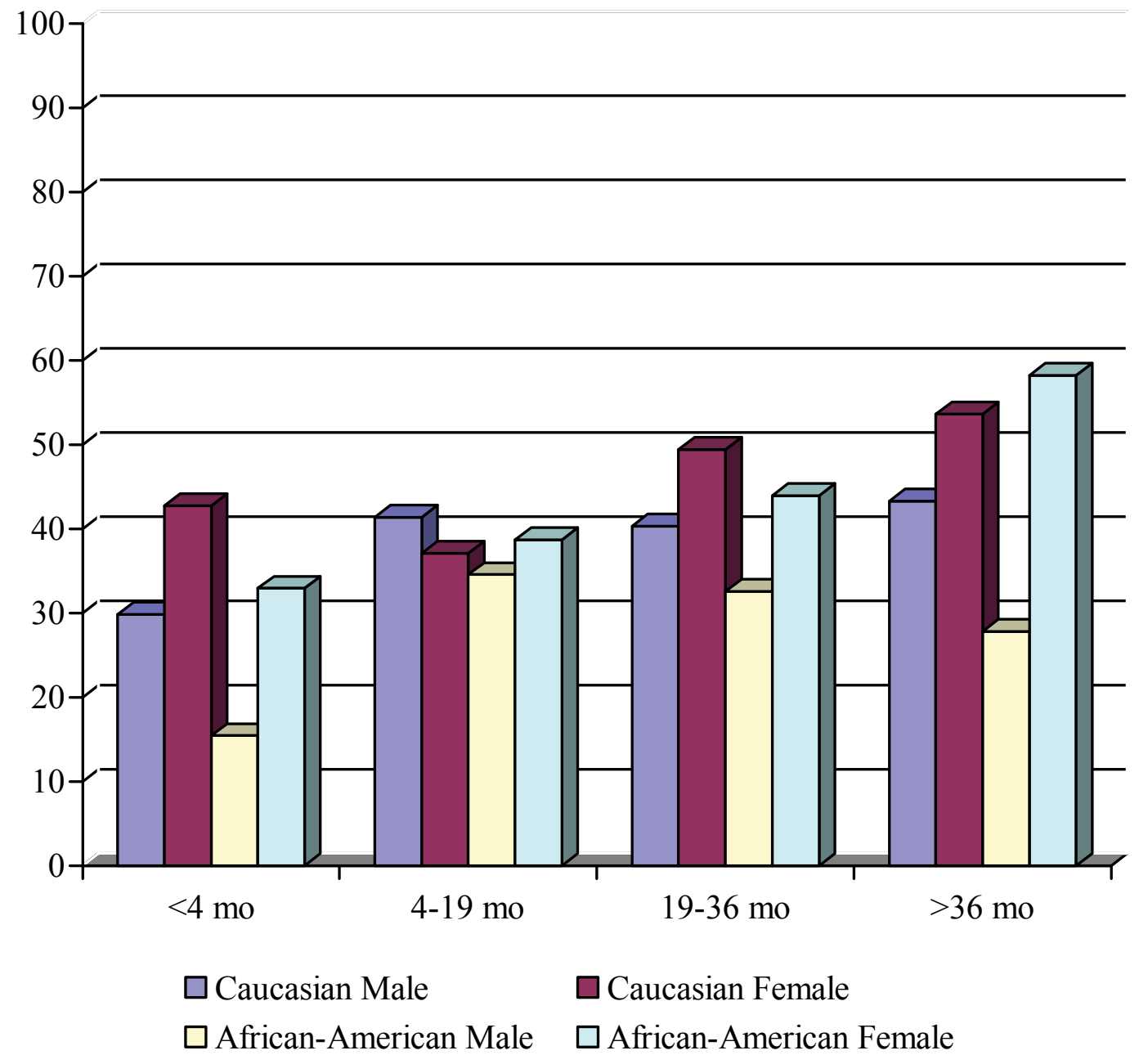

Figure A.4. $50^{\text {th }}$ Percentile, Memphis Survey Severity Scores for Demographic Groups by Time Since Transplantation. 


\section{Appendix B: Memphis Survey Subscales}

The Memphis Survey was developed at the University of Tennessee Health Science to assess frequency and severity of side effect from immunosuppressant medications. The survey consists of 5 subscales to evaluate the areas that have been reported to be most problematic for transplant recipients. The subscale scores are totaled to provide a cumulative score for frequency and severity of side effects of immunosuppressant therapy. Descriptive statistics for the subscales were reviewed for the sample as a whole with all time groups combined by the racial and gender specific demographic groups, Caucasian men, Caucasian women, African-American men and African-American women. The means and ranges for the subscale scores were similar (Tables B.1 and B.2) and were represented in the total frequency and severity scores. The study aim was to design time-related centile ranges that would be useful in clinical practice. Separate ranges for the 5 subscales which would be very similar to each other and to the range for the total scores would be more unwieldy to implement in practice and contribute little additional information. As a result the decision was made include only the cumulative Memphis Survey frequency and severity scores in the analysis for this study. 
Table B.1. Descriptive Statistics for the Memphis Survey Frequency Subscale Scores.

\begin{tabular}{|c|c|c|c|c|c|c|}
\hline Subscale & $\begin{array}{l}\text { Racial-Gender } \\
\text { Group }\end{array}$ & $\mathrm{N}$ & Mean & $\begin{array}{c}\text { Standard } \\
\text { Deviation }\end{array}$ & Min & Max \\
\hline \multirow{5}{*}{$\begin{array}{l}\text { Emotional } \\
\text { Burden }\end{array}$} & Caucasian Male & 395 & 10.38 & 8.50 & 0.00 & 40.00 \\
\hline & Caucasian Female & 336 & 10.66 & 8.34 & 0.00 & 39.09 \\
\hline & $\begin{array}{l}\text { African-American } \\
\text { Male }\end{array}$ & 78 & 7.45 & 6.19 & 0.00 & 28.18 \\
\hline & $\begin{array}{l}\text { African-American } \\
\text { Female }\end{array}$ & 108 & 10.33 & 6.82 & 0.00 & 25.45 \\
\hline & Total & 917 & 10.23 & 8.12 & 0.00 & 40.00 \\
\hline \multirow{5}{*}{$\begin{array}{l}\text { Life/Role } \\
\text { Responsibility }\end{array}$} & Caucasian Male & 388 & 9.49 & 9.08 & 0.00 & 39.09 \\
\hline & Caucasian Female & 335 & 9.45 & 9.47 & 0.00 & 40.00 \\
\hline & & 78 & 8.1 & 9.19 & 0.00 & 36.36 \\
\hline & $\begin{array}{l}\text { African-American } \\
\text { Female }\end{array}$ & 106 & 9.95 & 8.45 & 0.00 & 34.55 \\
\hline & Total & 907 & 9.41 & 9.16 & 0.00 & 40.00 \\
\hline \multirow[t]{5}{*}{ GI distress } & Caucasian Male & 394 & 7.15 & 6.67 & 0.00 & 28.33 \\
\hline & Caucasian Female & 338 & 9.21 & 7.27 & 0.00 & 35.00 \\
\hline & $\begin{array}{l}\text { African-American } \\
\text { Male }\end{array}$ & 77 & 7.03 & 6.06 & 0.00 & 28.33 \\
\hline & $\begin{array}{l}\text { African-American } \\
\text { Female }\end{array}$ & 109 & 8.36 & 6.18 & 0.00 & 26.27 \\
\hline & Total & 918 & 8.04 & 6.86 & 0.00 & 35.00 \\
\hline \multirow{5}{*}{ Mobility } & Caucasian Male & 327 & 12.94 & 6.83 & 0.00 & 37.27 \\
\hline & Caucasian Female & 270 & 14.50 & 6.97 & 0.00 & 32.73 \\
\hline & $\begin{array}{l}\text { African-American } \\
\text { Male }\end{array}$ & 78 & 10.16 & 6.02 & 0.00 & 25.45 \\
\hline & $\begin{array}{l}\text { African-American } \\
\text { Female }\end{array}$ & 110 & 11.67 & 5.58 & 0.00 & 25.45 \\
\hline & Total & 785 & 13.02 & 6.77 & 0.00 & 37.27 \\
\hline \multirow[t]{5}{*}{ Miscellaneous } & Caucasian Male & 393 & 11.86 & 9.89 & 0.00 & 40.00 \\
\hline & Caucasian Female & 338 & 13.13 & 10.59 & 0.00 & 40.00 \\
\hline & $\begin{array}{l}\text { African-American } \\
\text { Male }\end{array}$ & 78 & 9.87 & 8.64 & 0.00 & 40.00 \\
\hline & $\begin{array}{l}\text { African-American } \\
\text { Female }\end{array}$ & 109 & 13.25 & 8.96 & 0.00 & 38.57 \\
\hline & Total & 918 & 12.33 & 9.98 & 0.00 & 40.00 \\
\hline
\end{tabular}


Table B.2. Descriptive Statistics for the Memphis Survey Severity Subscale Scores.

\begin{tabular}{|c|c|c|c|c|c|c|}
\hline Subscale & $\begin{array}{l}\text { Racial-Gender } \\
\text { Group }\end{array}$ & $\mathrm{N}$ & Mean & $\begin{array}{c}\text { Standard } \\
\text { Deviation }\end{array}$ & Min & Max \\
\hline \multirow{5}{*}{$\begin{array}{l}\text { Emotional } \\
\text { Burden }\end{array}$} & \multirow{5}{*}{$\begin{array}{l}\text { Caucasian Male } \\
\text { Caucasian Female } \\
\text { African-American } \\
\text { Male } \\
\text { African-American } \\
\text { Female } \\
\text { Total }\end{array}$} & 390 & 9.33 & 9.14 & 0.00 & 40.00 \\
\hline & & 335 & 9.74 & 9.05 & 0.00 & 40.00 \\
\hline & & 77 & 5.75 & 6.55 & 0.00 & 28.18 \\
\hline & & 103 & 7.73 & 7.11 & 0.00 & 32.73 \\
\hline & & 905 & 9.00 & 8.76 & 0.00 & 40.00 \\
\hline \multirow{5}{*}{$\begin{array}{l}\text { Life/Role } \\
\text { Responsibility }\end{array}$} & \multirow{5}{*}{$\begin{array}{l}\text { Caucasian Male } \\
\text { Caucasian Female } \\
\text { African-American } \\
\text { Male } \\
\text { African-American } \\
\text { Female } \\
\text { Total } \\
\end{array}$} & 382 & 8.08 & 8.71 & 0.00 & 40.00 \\
\hline & & 332 & 8.51 & 9.38 & 0.00 & 40.00 \\
\hline & & 77 & 6.59 & 9.05 & 0.00 & 36.36 \\
\hline & & 101 & 7.06 & 7.44 & 0.00 & 28.18 \\
\hline & & 892 & 8.00 & 8.87 & 0.00 & 40.00 \\
\hline \multirow[t]{5}{*}{ GI distress } & \multirow{5}{*}{$\begin{array}{l}\text { Caucasian Male } \\
\text { Caucasian Female } \\
\text { African-American } \\
\text { Male } \\
\text { African-American } \\
\text { Female } \\
\text { Total } \\
\end{array}$} & 389 & 6.31 & 7.24 & 0.00 & 30.00 \\
\hline & & 333 & 8.18 & 7.73 & 0.00 & 35.00 \\
\hline & & 76 & 6.05 & 6.19 & 0.00 & 28.33 \\
\hline & & 105 & 6.49 & 5.74 & 0.00 & 21.67 \\
\hline & & 903 & 7.00 & 7.24 & 0.00 & 35.00 \\
\hline \multirow[t]{5}{*}{ Mobility } & \multirow{5}{*}{$\begin{array}{l}\text { Caucasian Male } \\
\text { Caucasian Female } \\
\text { African-American } \\
\text { Male } \\
\text { African-American } \\
\text { Female } \\
\text { Total }\end{array}$} & 388 & 11.16 & 10.31 & 0.00 & 40.00 \\
\hline & & 334 & 12.63 & 11.25 & 0.00 & 40.00 \\
\hline & & 77 & 90.5 & 8.91 & 0.00 & 40.00 \\
\hline & & 101 & 11.71 & 9.63 & 0.00 & 38.57 \\
\hline & & 900 & 11.59 & 10.52 & 0.00 & 40.00 \\
\hline \multirow{5}{*}{ Miscellaneous } & \multirow{5}{*}{$\begin{array}{l}\text { Caucasian Male } \\
\text { Caucasian Female } \\
\text { African-American } \\
\text { Male } \\
\text { African-American } \\
\text { Female } \\
\text { Total }\end{array}$} & 318 & 10.36 & 7.21 & 0.00 & 36.36 \\
\hline & & 268 & 12.37 & 7.61 & 0.00 & 32.73 \\
\hline & & 77 & 7.49 & 6.16 & 0.00 & 27.27 \\
\hline & & 105 & 8.95 & 6.45 & 0.00 & 32.73 \\
\hline & & 768 & 10.58 & 7.32 & 0.00 & 36.36 \\
\hline
\end{tabular}




\section{VITA}

Katy Garth graduated from East Prairie High School in East Prairie, MO. She received her BSN from Murray State University in Murray, Kentucky in 1980 and MSN from Vanderbilt University in Nashville, TN in 1983 with a clinical focus in the FNP option and a functional minor in nursing education. She has practiced as a Family Nurse Practitioner in both adult and child health. She taught at Arkansas State Unversity in Jonesboro, AR for two years before coming to Murray State University in August 1993 where she has taught at both the undergraduate and graduate levels. She began doctoral studies at the University of Tennessee Health Science Center-Memphis in 2005. Her research advisor was Dr. Donna Hathaway, who provided invaluable guidance and support. Date of birth 2/16/1958. 